Printed August 1983

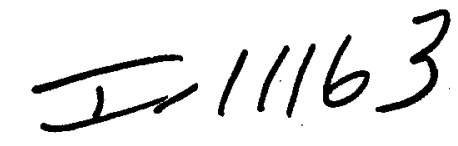

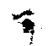 \\ Development of a Geothermal Acoustic Borehole Televiewer
}

SAND--83-0681

DE83 017935

Fred E. Heard, Tom J. Bauman

Prepared by

Sandia National Laboratories

Albuquerque, New Mexico 87185 and Livermore, California 94550

for the United States Department of Energy

under Contract DE-AC04-76DPOO789

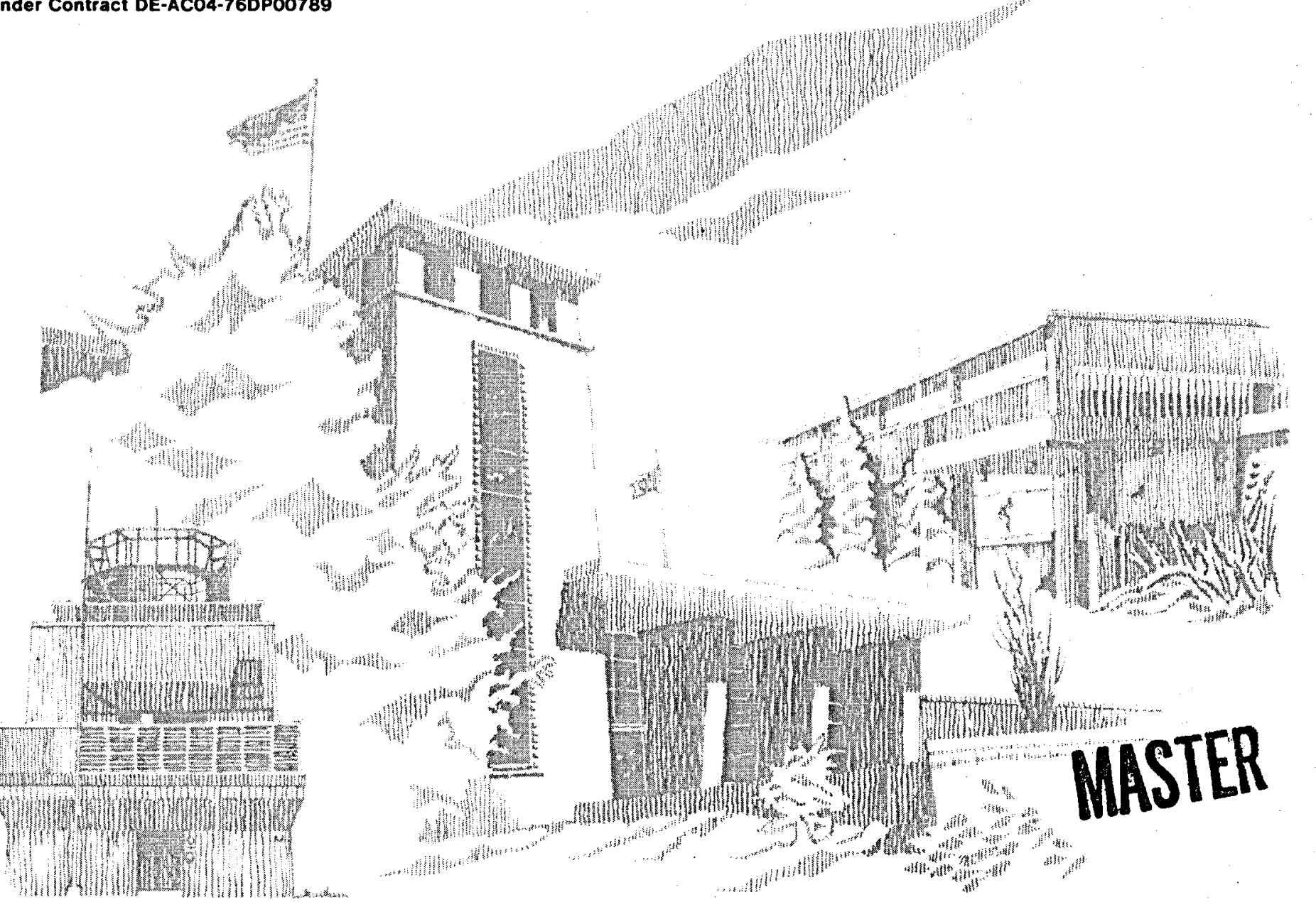

$\frac{1}{1}$ 


\section{DISCLAIMER}

This report was prepared as an account of work sponsored by an agency of the United States Government. Neither the United States Government nor any agency Thereof, nor any of their employees, makes any warranty, express or implied, or assumes any legal liability or responsibility for the accuracy, completeness, or usefulness of any information, apparatus, product, or process disclosed, or represents that its use would not infringe privately owned rights. Reference herein to any specific commercial product, process, or service by trade name, trademark, manufacturer, or otherwise does not necessarily constitute or imply its endorsement, recommendation, or favoring by the United States Government or any agency thereof. The views and opinions of authors expressed herein do not necessarily state or reflect those of the United States Government or any agency thereof. 


\section{DISCLAIMER}

Portions of this document may be illegible in electronic image products. Images are produced from the best available original document. 
Isaued by Sandia National Laboratories, operated for the United States Department of Energy by Sandia Corporation.

NOTICE: This report was prepared as an account of work sponsored by an arency of the United States Government. Neither the United States Govern ment nor any agency thereof, nor any of their employees, nor any of their contractors, vubcontractors, or their employees, makes any warranty, express or implied, or assumes any legal liability or responsibility for the accuracy, completeres or usefulness of any information apparatus, product, or process discer

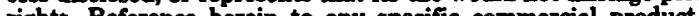
rights. Reference herein to any specific commercial product, process, or service by trade name, trademar, manufacturer, or otherwise, does not necessarily constitute or imply its endorsement, recommendation, or favoring by the United States Government, any agency thereof or any of their contractors or subcontractors. The views and opinions expressed herein do not necessarily state or reflect those of the United States Government, any agency thereof or any of their contractors or subcontractors.

Printed in the United States of America Available from

National Technical Information Service

U.S. Department of Commerce

5285 Port Royal Road

Springfield, VA 22161

NTIS price codes

Printed copy: A05

Microfiche copy: A01

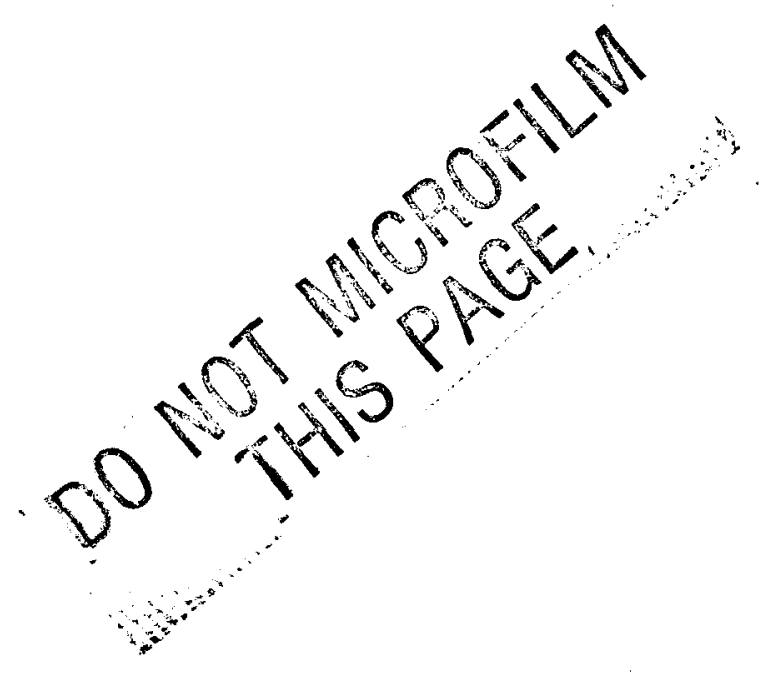




\title{
DEVELOPMENT OF A GEOTHERMAL ACOUSTIC BOREHOLE TELEVIEWER
}

\section{SAND83-0681}

\author{
Fred E. Heard, \\ Sensor Systems Division 0322 \\ Tom J. Bauman, \\ Geotherma1 Technology \\ Development Division 6241 \\ Sandia National Laboratories \\ Albuquerque, NM 87185
}

\begin{abstract}
Most geotinermal wells are arilled in hard rock formations where fluid flow is through systems of open fractures. Productivity of these wells is usually determined by the extent of intersection of the wellbore with the tracture system. A need exists for fracture-mapping metnods and tools winich can operate in a geotinermal environment. In less-hostile environments, the acoustic borenole televiewer has been shown to be a useful tool for determining location, orientation, and characterization of fractures as they intersect the borehole and for general wellbore and casing inspection. This report describes the development conducted at Sandia National Laboratories to adapt an acoustic borehole televiewer for operation in a geothermal environment. The modified instrument has been successfully tested at temperatures as nigh as $280^{\circ} \mathrm{C}$ and pressures up to $5000 \mathrm{ps} i$, and used successfully to map tractures and casing damage in geothermal wells.
\end{abstract}




\section{DISCLAIMER}

This report was prepared as an account of work sponsored by an agency of the United States Government. Neither the United States Government nor any agency thereof, nor any of their employees, makes any warranty, express or implied, or assumes any legal liability or responsibility for the accuracy, completeness, or usefulness of any information, apparatus, product, or process disclosed, or represents that its use would not infringe privately owned rights. Reference herein to any specific commercial product, process, or service by trade name, trademark, manufacturer, or otherwise does not necessarily constitute or imply its endorsement, recommendation, or favoring by the United States Government or any agency thereof. The views and opinions of authors expressed herein do not necessarily state or reflect those of the United States Government or any agency thereof. 


\section{CONTENTS}

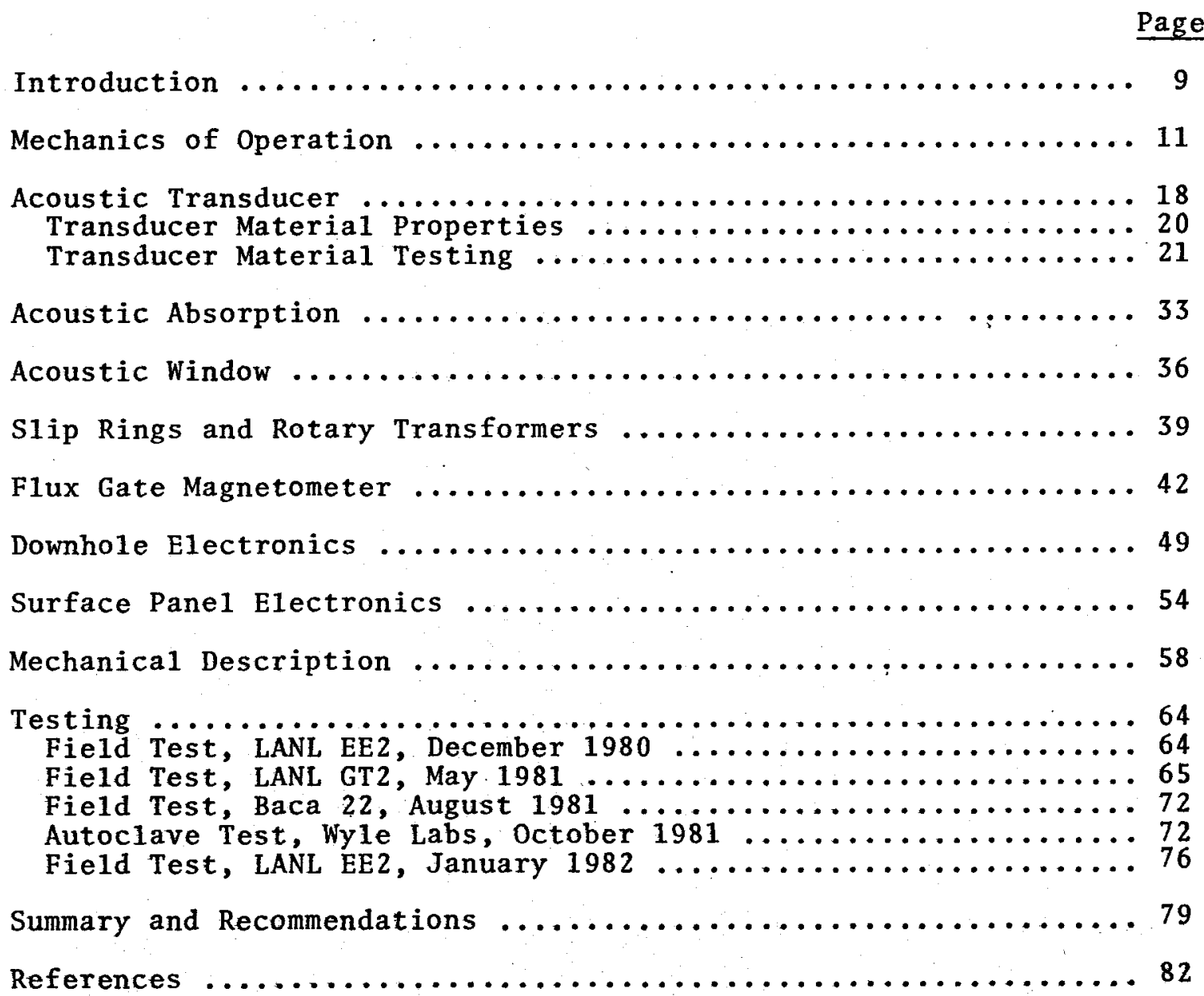




\section{FIGURES}

$\underline{\text { Page }}$

1. Block Diagram of Borehole Televiewer .............. 12

2. Measured Beam Pattern of Piezoelectric Transducer ...... 13

3. (a) Standard Reflectivity Log .................. 15

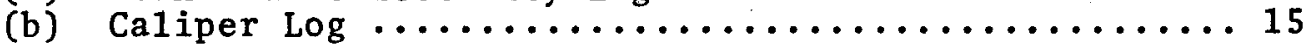

4. Transducer Pulsing and Receiving Circuit ........... 19

5. Transducer Electrical Pulsing Waveform ............. 19

6. Dielectric Capacitance as a Function of Temperature .... 23 and Transducer Material

7. Dielectric Resistance as a Function of Temperature ..... 24 and Transducer Material

8. Transducer Test $\operatorname{Setup} \ldots \ldots \ldots \ldots \ldots \ldots \ldots \ldots \ldots \ldots \ldots$

9. Lead Metaniobate Samp1e ......................... 27

10. Sodium Bismuth Titanate Sample $\ldots \ldots \ldots \ldots \ldots \ldots \ldots \ldots . \ldots 28$

11. Modified Lead Titanate Sample $\ldots \ldots \ldots \ldots \ldots \ldots \ldots \ldots \ldots$

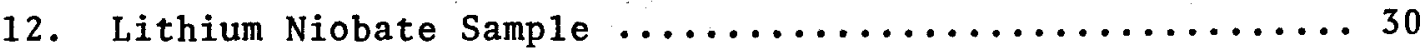

13. Results of Acoustic Absorber Autoclave Tests ......... 34

14. Transducer Pulsing Waveform ................. 35

15. Envex 1000 Window Before and After Exposure to ....... 37 Synthetic Brine

16. Vespe1 Window Before and After Exposure to .......... 37 Synthetic Brine

17. Tefion Window Before and After Exposure to ......... 37 Synthetic Brine

18. Acoustic Window Configuration ................ 38

19. Rotating Transformer ..................... 40

20. Rotating Transformer Assembly ................. 41

21. F1ux Lines Due to Earth's Field ................ 43 
FIGURES cont.

$\underline{\text { Page }}$

22. (a) Winding Configuration Due to Drive Current ...... 45

(b) F1ux Lines with Core Saturated .............. 45

(c) Flux Lines with Core Unsaturated ............. 45

23. Magnetometer Configuration ................. 46

24. B-H Curves of Deltamax $\ldots \ldots \ldots \ldots \ldots \ldots \ldots \ldots \ldots \ldots$

25. Block Diagram of Downhole Electronics ............. 50

26. BHTV P.C. Boards ...................... 51

27. Block Diagram of Surface Panel Electronics .......... 55

28. Sandia High-Temperature Borehole Televiewer ......... 59

29. Alberox Bulkhead Feed-Throughs ................ 63

30. BHTV Log - LANL GT2 Open Hole ................ 68-69

31. GT-2 Vertical Spinner Survey ................ 71

32. High Temperature/High Pressure Autoclave ........... 73

33. Wyle Autoclave Target ..................... 74

34. Reflected Amp1itude Waveform for One Complete Rotation 75

35. BHTV Log - LANL EE2 Casing ............... 77

36. BHTV Log - LANL EE2 Casing $\ldots \ldots \ldots \ldots \ldots \ldots \ldots \ldots \ldots$ 
Development of the earth's geothermal resources as a significant alternative source of energy requires well logging to obtain borehole measurements of physical characteristics required for geothermal reservoir evaluation and production. Methods for obtaining borehole measurements are at the present limited to logging tools developed for the $0 i 1$ and gas industry, which rarely require operation at temperatures higher than about $150^{\circ} \mathrm{C}$. These logging tools often fail when used in higher-temperature geothermal wells. The Geothermal Technology Development Program, managed by Sandia for the Department of Energy, addresses the needs of the geothermal producers by developing instrumentation capable of surviving the hostile geothermal environments.

In most oil and gas wells, production is determined by fluid flow through intergranular-dominated, permeable zones of sedimentary rock. Most of the geothermal reservoirs in the western U.S., however, are low permeability igneous rock. Water and steam, necessary for heat transfer, are only able to move through systems of open fractures. The success of a well is usually determined by the extent of penetration of the fracture system by the borehole. For this reason, the development of fracture mapping techniques for geothermal reservoir assessment is of high priority.

Data is needed to characterize the fracture system as it intersects the borehole and there are a number of methods which may be used to gather this data. One obvious metiod is the extraction of cores during the drilling process. However, the inconvenience and expense of coring limits its use to shallow exploratory holes. Sonic logs may be used to observe the changes in the velocity and amplitude of acoustic signals propagating in the formation near the borehole which may be affected by the fracture density of the rock. Resistivity logs can detect changes in bulk resistivity of the rock, which is related to many things, including fracture density. Gamma-gamma density can sometimes be correlated with the presence of fractures. Measuring họle diameter with a caliper tool can 
locate large open fractures and washed out enlarged zones that may have been caused by rock weakened by fractures. Changes in temperature and flow meter measurements along the wellbore may give information relating to the hydraulic properties of fractures. All of these fracture finding methods provide indirect evidence of fractures and give no information about the geometry or orientation of fractures. The tool discussed in this report, the acoustic borehole televiewer, makes a picture of the surface of the borehole wall using ultrasonic imaging techniques and provides information for determining location, orientation, and characterization of fractures.

The televievier was introduced in $1968^{l}$ by Mobil Research. Its main application was to detect and evaluate the degree of fracturing within a wellbore. It was licensed by several $0 i 1$ and gas service companies and the service was commercially available for about five years. Due to the variability in the data quality, insufficient applications, and a limited interest in fractured reservoirs, extensive use of the televiewer was abandoned by industry. In spite of this decreased interest in the televiewer, a number of pioneering efforts were carried out by people wino saw in the televiewer capabilities worth developing. The manufacturer, Simplec Manufacturing Company of Dallas, Texas, mindful of the potential of this tool, continued to make improvements and satisfy the limited demand for borenole televiewers. Researchers at Amoco R\&D in Tulsa, Oklanoma greatly improved televiewer display methods by applying video image enhancement tecinniques to the televiewer data ${ }^{2,3}$ and extending the televiewer principle another step to a tinree-dimensional. scan of the rock beyond the wellbore surface. ${ }^{4}$ Researchers at the water Resources Division of the U.S.G.S. in Denver, Colorado continued to use the televiewer as a data gathering tool, making significant contributions to the field of reservoir assessment ${ }^{5,6}$, as well as initiating the incorporation of a number of improvements that extended the televiewer operating temperature range. In 1979, at the suggestion of industry personnel reviewing the Sandia Program, a borehole televiewer, built under the Mobil patents, was purchased from Simplec Manufacturing Company to determine the feasibility of adapting it for operation in the geothermal environment. An upgrade effort was initiated with 
performance goals of operation at temperatures up to $275^{\circ} \mathrm{C}$ and pressures up to 5000 psi.

The approach taken by Sandia was first to identify the problems of operating the televiewer at elevated temperatures. Most helpful were discussions with the manufacturer and with the USGS, Water Resources Division of Denver, Colorado, who, with much effort, have had some limited success in operating the televiewer in geothermal wells. Individual components, both mechanical and electronic, were evaluated in lab tests. As required, components and subassemblies of the tool were redesigned and retested until successful elevated temperature operation could be verified. For verification, the composite tool was tested in an operating mode viewing a target inside of a large autoclave at a temperature of $280^{\circ} \mathrm{C}$ and pressure of $4500 \mathrm{psi}$. In addition, several field tests have been run to evaluate the fieldability of the new televiewer in actual geothermal wells. This report describes the specific steps taken in this development project, including the results of both laboratory and field tests.

\section{MECHANICS OF OPERATION}

The acoustic borehole televiewer is a logging tool capable of forming an oriented ultrasonic image of the borehole wall. The fundamental parts of the televiewer are shown in the block diagram of Figure 1. The downhole portion of the instrument is approximately 16 feet long with a $3-1 / 2$ inch 00 and is connected to eitner a 4 or 7 conductor electric wireline. The transducer is a $1 / 2$ inch diameter disc of piezoelectric material thickness resonant at $1.3 \mathrm{MHz}$ which acts as both a transmitter and receiver of acoustic energy. The transducer beam width has been measured at about 3 degrees ( $3 \mathrm{~dB}$, two way) in the farfield (greater than 1-1/2" from transducer) as shown in figure 2. It is pulsed by a short burst of 1.3 $\mathrm{MHz}$ electrical energy at a rate of $1800 \mathrm{pulses} / \mathrm{sec}$, generating a pressure

pulse that travels to the wall and is then reflected. If the tool is properly centered in the hole by the centralizers on top and bottom so that the direction of transmission is normal to the wall, the energy will be reflected back in the 
direction of the transducer. This reflected pulse is received by the transducer and generates an electrical signal whose amplitude is a function of the amount of energy reflected by the illuminated spot on the wall. The time of arrival is a function of the round-trip acoustic travel time of the pulse, hence distance to the wall.

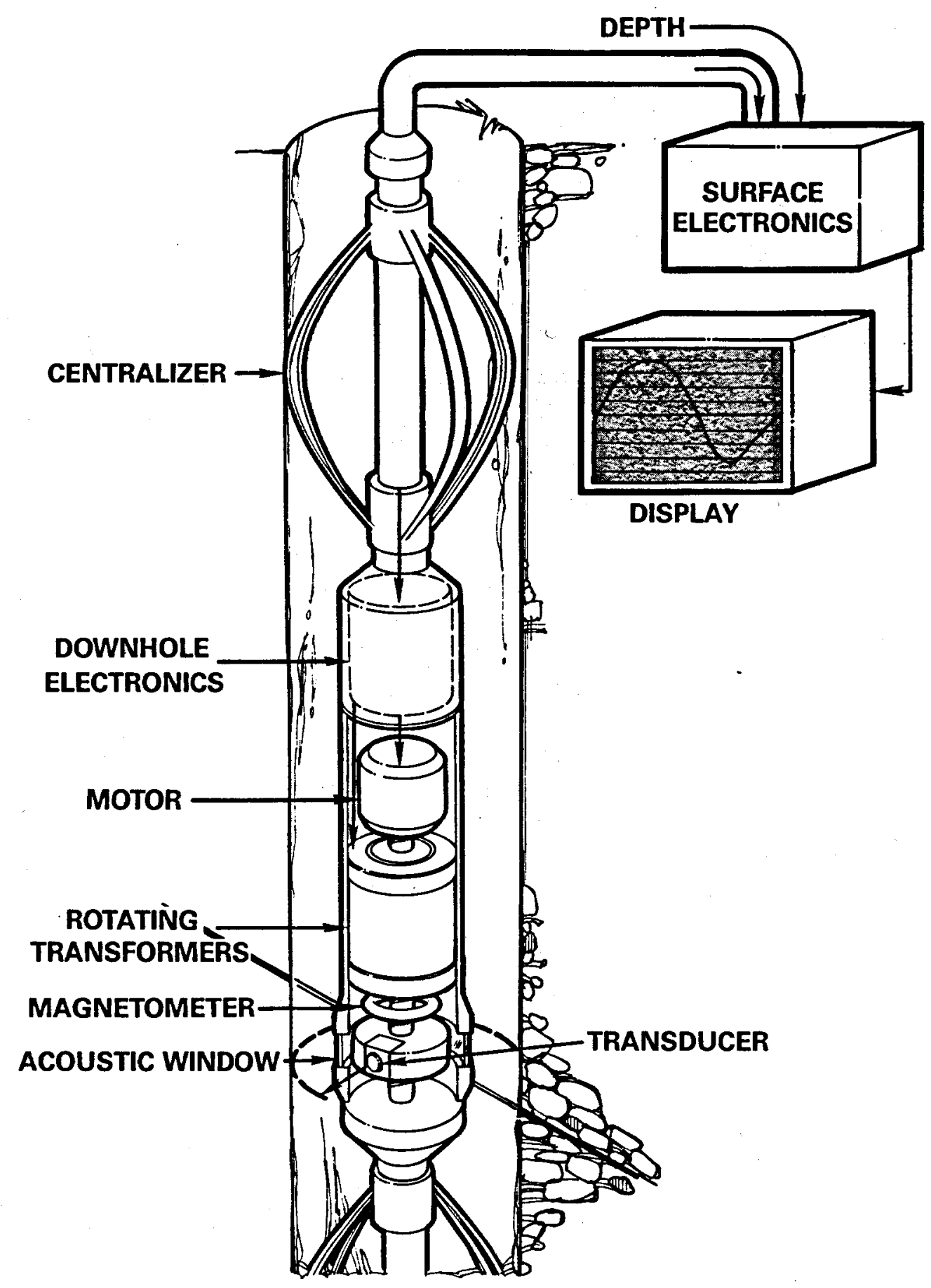

Figure 1. Block Diagram of Borehole Televiewer 


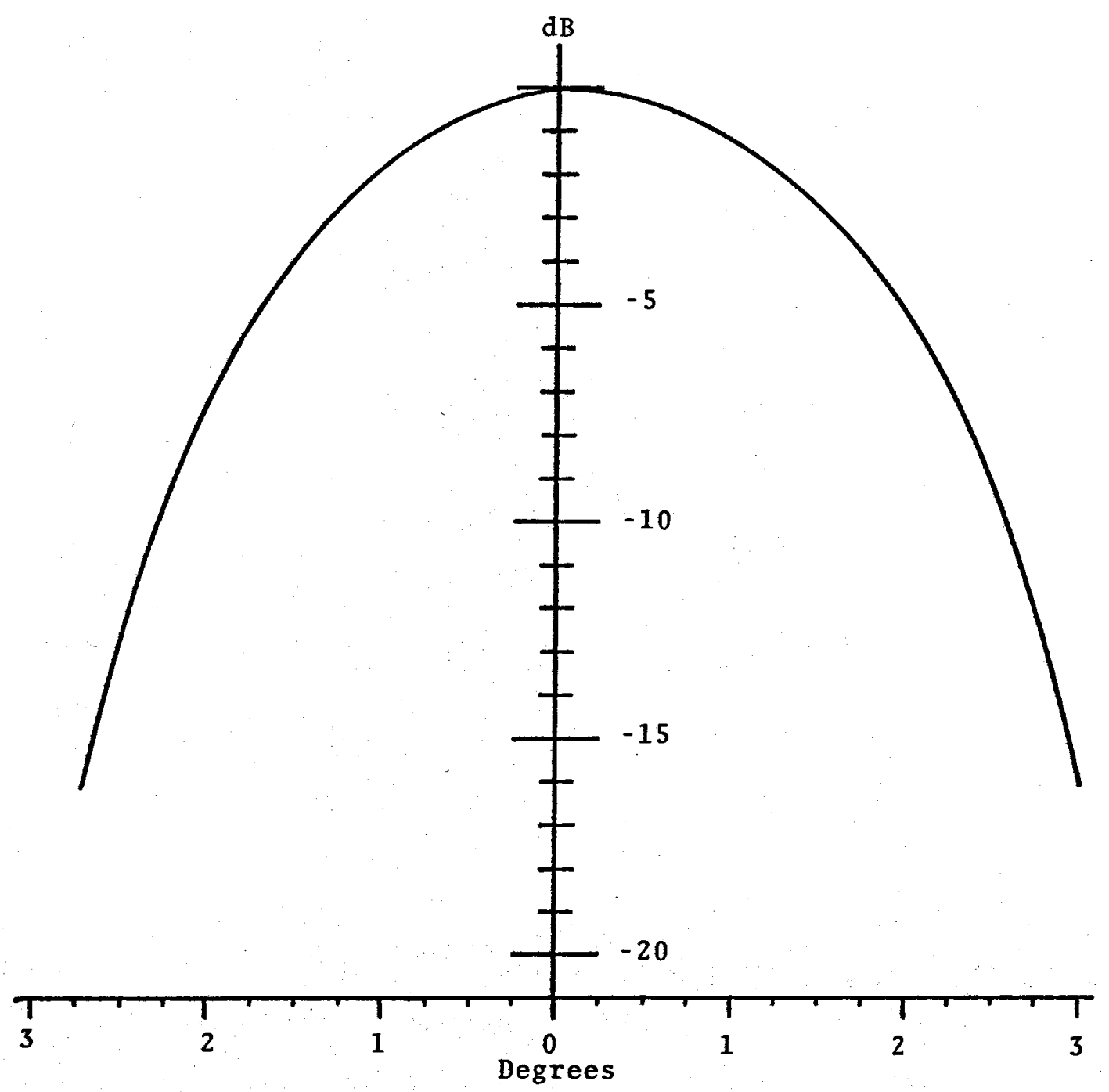

Figure 2. Measured Beam Pattern of Piezoelectric Transducer 
For good televiewer operation using the $1.3 \mathrm{MHz}$ transducer, the borehole must be water-filled. Heavy drilling mud will attenuate the acoustic signal and limit the maximum allowable hole size. In clear water, acoustic propagation is very good and nole size tends to only be limited by the centralizer span (about 18" for the Sandia tool). For very large hole sizes (greater than 20") it may be necessary to lower the pulse rate to eliminate range ambiguity problems.

The transducer is rotated by a synchronous motor at a rate of 3 revolutions per second. At the pulse rate of $1800 \mathrm{~Hz}$, there will be about 600 illuminations of the wall per revolution, or 1 pulse every 0.6 degree, allowing considerable pulse-to-pulse overlap of the 3 degree beam. The tool is pulled up at a rate of 5 $\mathrm{ft} / \mathrm{min}(1 \mathrm{in} / \mathrm{sec}$ ) so that a spiral strip is illuminated.

A flux gate magnetometer is rotated with the transducer to sense the orientation of the earth's magnetic field with respect to the transducer. The magnetometer circuitry generates a pulse each time the transducer rotates through magnetic nortin; however, when the televiewer is operated in casing or in the vicinity of ore deposits which locally disturb the earth's field vector, the magnetometer output is erratic. In these cases, the televiewer must be switched to the mark mode winich generates a reference pulse for aligning the beginning and end of each sweep or rotation. This is done by synchronizing to the output of a stationary magnetic pickup as a permanent magnet on a disc mounted on the motor drive shaft is rotated by it.

The electronics package, shown in the block diagram of Figure 1, contains circuitry for pulsing the transducer, detecting and amplifying received signals, processing the magnetometer output, and driving the signals to the surface via the cable. In the logging truck at the surface, additional circuitry is used to process and generate signals for use by a catnode ray tube (CRT) to form the log. The Sandia televiewer is normally used in two modes: 1) the standard reflectivity mode; and 2) the caliper mode. Figure 3 shows two different representations of the same 10 feet of nole. 


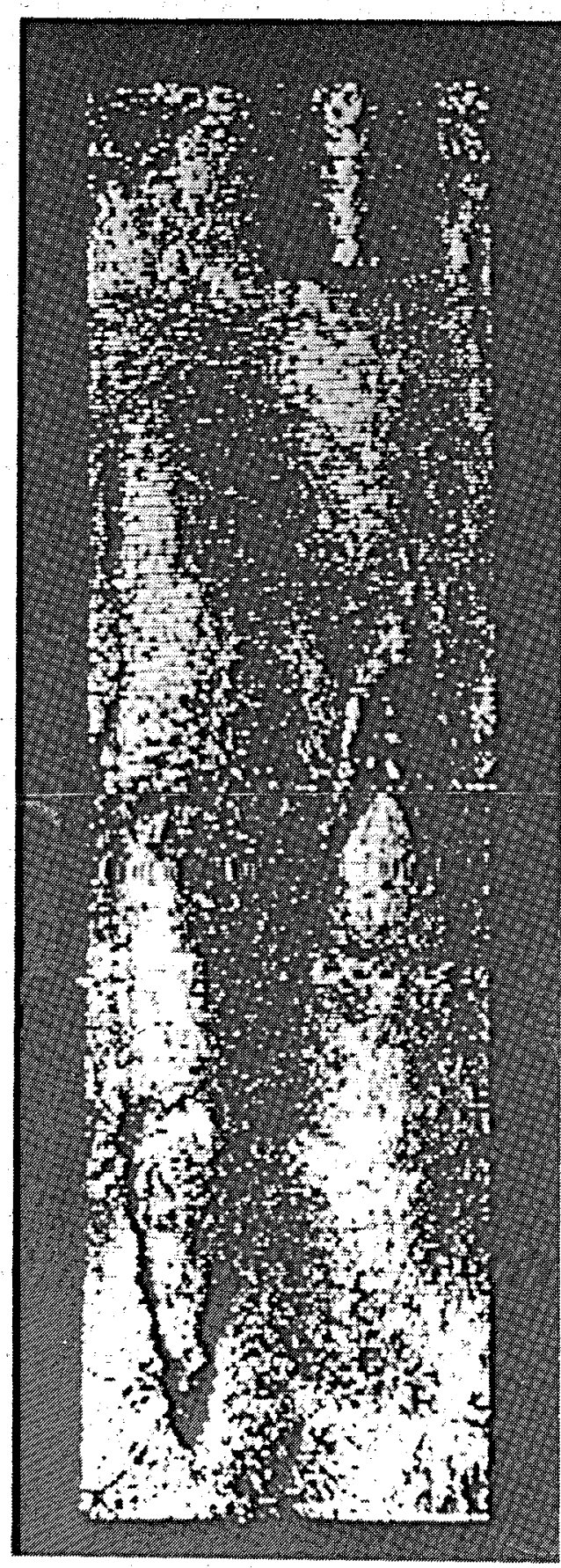

$\mathbf{N} \boldsymbol{W} \quad \boldsymbol{S} \quad \boldsymbol{E} \quad \boldsymbol{N}$

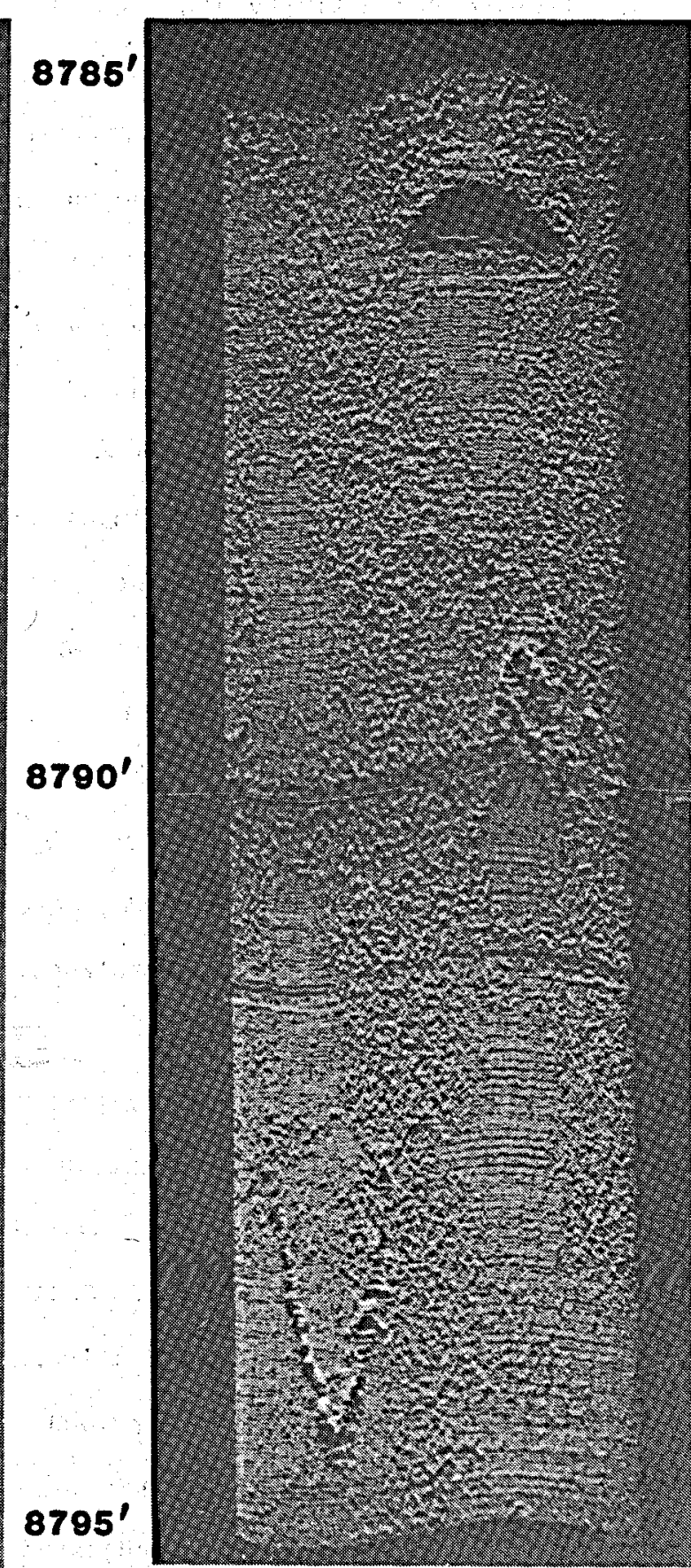

N W S E N

(a)

(b)

Figure 3. (a) Standard Reflectivity Log (b) Caliper Log 
The standard reflectivity log uses the amplitude variation of the reflected signal as the wall is scanned to vary the intensity or brightness of the CRT beam. The beam is swept in the horizontal direction by a ramping voltage such that a sweep is ended and another is begun on receiving the pulse generated by the magnetometer when the transducer rotates through magnetic north. The vertical sweep voltage moves the beam in the vertical direction as the tool is pulled up, using information derived from an optical encoder on a pulley wheel over which the cable rides. The resulting $l 0 g$, when recorded on film or light sensitive paper, is an acoustically generated visual image of the surface of the borehole wall as if split open along the north axis and laid flat. Since the tool is centered in the hole, as smooth portions of the wall are scanned, the amplitude of the reflected signal will be a maximum and produce uniform high intensity traces on the face of the CRT. As discontinuities are scanned, the amplitude of the signal will drop due to the scattering of energy by surfaces not normal to the direction of propagation, producing areas of decreased intensity on the CRT face. These discontinuities may be fractures, scratches, chips, washed out areas, or simply rough spots on the borenole surface.

Figure $3 a$ is a section of a log representing 10 feet of a borehole. The beam is swept from right to left, representing a transducer rotation of north, west, south, east, to north. Areas of the wall which reflect a lot of energy in the direction of the transducer are winite. Areas which reflect very little energy are black. In this log, a fracture plane intersecting the borehole can be seen with a characteristic sine wave shape dipping toward the west.

The caliper mode display makes use of the travel time of the acoustic pulse to form the log. The CRT beam is adjusted for uniform brightness witn no intensity modulation. The horizontal and vertical sweeps are generated in the same way as for the standard reflectivity log. However, a voltage of amplitude corresponding to the acoustic travel time is added to the vertical sweep, giving rise to a psuedo three dimensional display as shown in Figure $3 b$. 
The sensitivity and resolution of the televiewer are functions of acoustic velocity, beam width, frequency, pulse repetition rate, rotation rate, and vertical velocity. With these parameters fixed, the sensitivity and resolution will be different for different hole sizes, rock reflectivity, sound transmission properties of the borehole fluid, and rock rugosity. To determine the sensitivity and resolution which might be expected under ideal conditions, measurements were made in the lab using an aluminum bore with machined vertical slots. The circumferential sensitivity, or the smallest target (scatterer), which can be detected was found to be about 0.030 inch in an 8 inch wellbore. The lateral resolution, or in this case, the circumferential resolution is defined as the ability to resolve objects separated by a minimum distance. This minimum distance was experimentally found to be in the range of 0.124 inch to 0.188 inch in an 8 inch wellbore. The circumferential resolution which can be achieved by a scanning system depends mainly on the width of the ultrasonic beam. With a two-way beam width of 3 degrees the apparent spot diameter on the wall of an 8 inch wellbore is calculated to be 0.170 inch, which agrees with resolution measurements.

As mentioned above, a measure of distance from the transducer to a reflector on the wall is available from the acoustic travel time data. Accuracy is limited by how precisely the acoustic velocity in the fluid, which varies with temperature, pressure, and dissolved solids, can be determined. But resolution of 0.050 incin can easily be achieved.

For fracture mapping, the televiewer's unique capability is that, in addition to locating fractures, it allows one to determine orientation of the fractures. Dip angle is determined by measuring the height, $h$, of the intersection of the fracture with the wellbore (peak-to-peak amplitude of the sinusoid) and combining it with the diameter, $d$, of the wellbore.

$$
\text { dip angle }=\tan ^{-1} \mathrm{~h} / \mathrm{d}
$$

Dip azimuth is simply the direction of the minimum of the sinusoid. The strike or direction of the fracture is normal to the dip azimuth. Assuming a vertical hole, the fracture shown in Figure 3 dips to the west at an angle of 81 degrees and runs approximately nortin-soutin. Since fractures in a given field tend to run parallel, 
knowledge of the orientation of the fracture system can be applied to the determination of locations for future wells in the same field and how they should be deviated to obtain maximum penetration of the fracture system.

The televiewer has a number of other applications in addition to fracture mapping. The televiewer, being sensitive to the changes of acoustic reflectivity of different types of rock, can also be used to detect changes in lithology. This allows the determination of bed thickness as well as angle and azimuth of formation dip. It can also be used as a tool to determine the nature and geometry of zones where expensive drilling fluid is lost into the formation and give clues on methods for restoring circulation. The televiewer is a powerfur toot for use in casing inspection; it easily locates and determines the extent of casing damage such as splitting, corrosion, ovalling, and scratches caused by drilling and fishing. In the words of the inventor, "At one time or another, almost everyone who has worked with oil production problems has longed to be able to take a look and see what the conditions were downinole. The borehole televiewer is a significant step toward filling this need." 1

\section{ACOUSTIC TRANSDUCER}

As mentioned previously, the acoustic transducer is a $1 / 2^{\prime \prime}$ disc of piezoelectric material thickness resonant at $1.3 \mathrm{MHz}$ with a two way beam width of about 3 degrees. A method for calculating beam width, as well as nearfield-farfield boundary considerations, are detailed in the literature ${ }^{7}$ and will not be discussed here.

The Sandia borehole televiewer originally used a ceramic lead metaniobate piezoelectric transducer, which at the time was thought to be the state of the art in high temperature transducer materials. Some initial testing, however, indicated that the dielectric properties of the material changed significantly with temperature, making the design of efficient pulsing and receiving circuitry impossible.

Figure 4 is a scinematic of the pulsing circuit. The circuitry shown in the box is the electrical equivalent circuit of a piezoelectric transducer operating near a fundamental resonance. The elements $L_{m}, C_{m}$ and $R_{m}$ are mass, elastic 
compliance, and mechanical damping transformed into electrical parameters by the piezoelectric effect. $C_{D}$ and $R_{D}$ are electrical properties of the transducer die lectric.

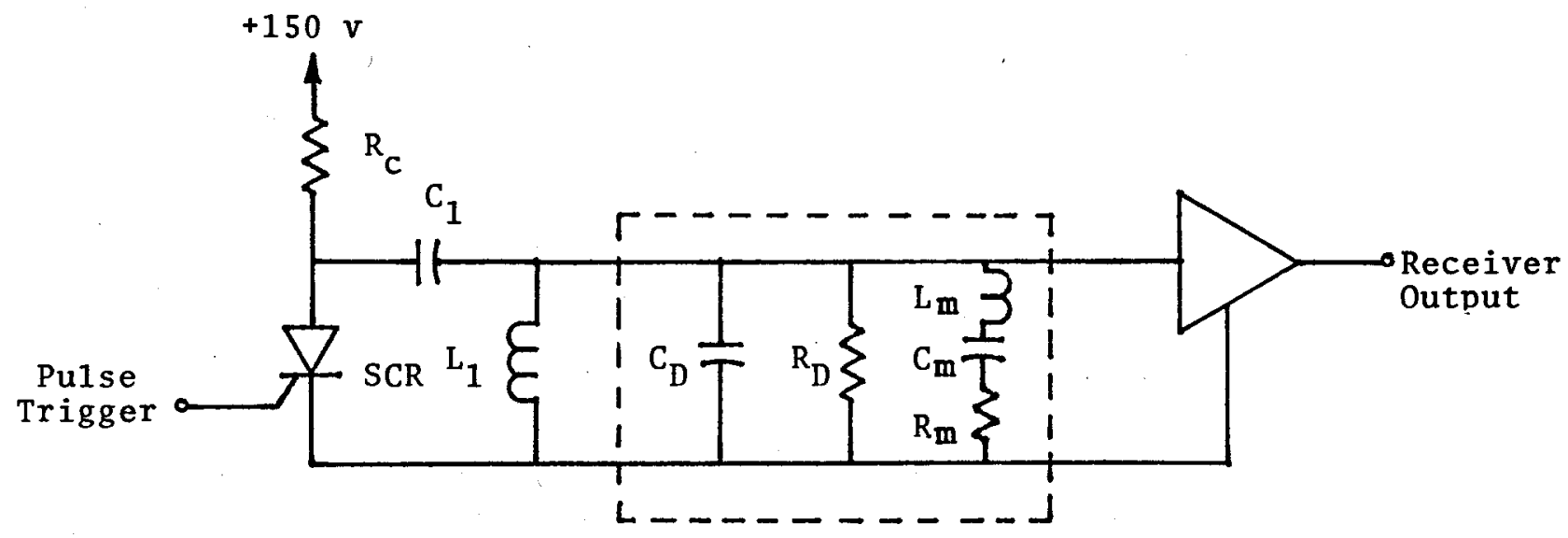

Figure 4. Transducer Pulsing and Receiving Circuit

In order to resolve targets separated by small distances along the axis of acoustic propagation, the transducer must be energized by a very short rise time pulse. An SCR (silicon controlled rectifier) with a fast turn on time can be used, as shown in Figure 4, to provide this pulse. The energy stored by capacitor $C_{1}$ is dumped through the transducer to generate a very fast, hign voltage pulse when the SCR is triggered. Resistor $R_{C}$ is used to slow charge the capacitor $C_{1}$ when the SCR is in the off mode between pulses and must be large so that it does not affect the circuit operation during the pulsing mode or the reception mode. The inductor $L_{1}$ is used to resonate the capacitance $C_{D}$ and $C_{1}$ at the mechanical resonant frequency of the transducer. This tends to produce a fast rising pulse of energy as shown in Figure 5.

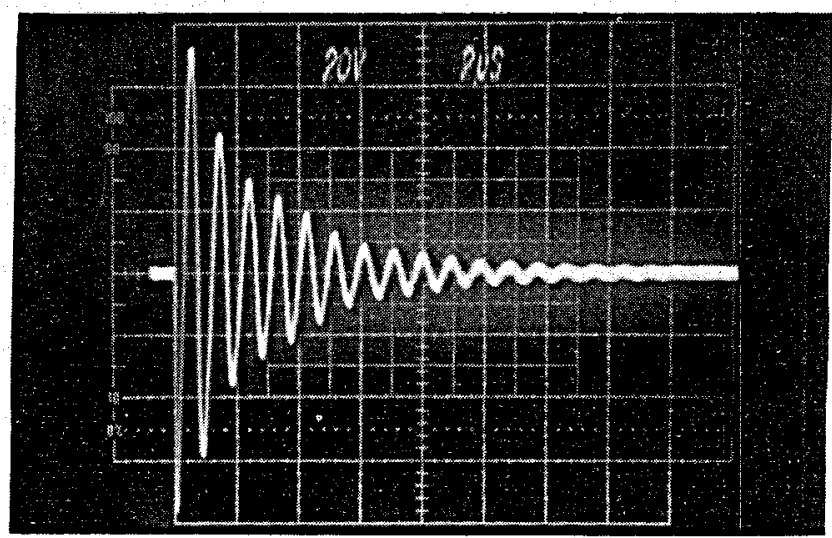

Figure 5. Transducer Electrical Pulsing Waveform 
On reception of the reflected signal, the leg of the circuit composed of $L_{m}, C_{m}$, and $R_{m}$ can be thought of as a voltage source of internal impedance $R_{m}$. With $L_{1}$ present to resonate $C_{D}$ the pulse rise time will not be degraded. Maximum voltage output from the transducer results when the input impedance of the receiver and the dielectric resistance $R_{D}$ are large with respect to $R_{m}$.

Lead metaniobate exhibits piezoelectric properties at temperatures above $275^{\circ} \mathrm{C}$; but, the dielectric permitivity (nence $C_{D}$ ) increases by over an order of magnitude as the temperature is increased from room temperature to $275^{\circ} \mathrm{C}$. The dielectric leakage resistance $R_{D}$ decreases by more than 5 orders of magnitude over the same temperature range. It is apparent that with such large variations in $C_{D}$ an inductor $L_{1}$ cannot be chosen to resonate out its effect on pulse rise time. Likewise, with small values of $R_{D}$, much of the transformed mechanical energy will be lost as heat in the dielectric. For the televiewer system to operate at $275^{\circ} \mathrm{C}$, a piezoelectric material must be found that does not suffer this dielectric degradation.

The literature 8 indicates that for all piezoelectric materials, this type of dielectric degradation occurs as the Curie temperature of the material is approacined (the Curie temperature of a piezoelectric material is the temperature above which the material loses all of its piezoelectric properties.) A material with a higher Curie temperature should exhibit less of this effect over a given temperature range below the Curie temperature.

Transducer Material Properties

There are trio basic types of piezoelectric materials in use today: 1) single crystalline materials, and 2) poled ceramic materials. For piezoelectric interaction to exist it is necessary that certain axes of the medium intrinsically possess a one-wayness, or polarity. This polarity is inherent in the symmetry of piezoelectric single-crystalline materials. This polarity is imparted to the ceramic materials by laboratory processes. Piezoelectric ceramics are made by the solid state interaction of several oxides or carbonates, followed by hightemperature firing involving crystal grain growth and the electric poling pro- 
cess. In the poling process, a polarity is given to the material by raising the temperature above the Curie temperature, applying a high-voltage $D C$ electric field, and allowing the material to cool.

The ceramic materials offer a wide range of desirable properties which can many times be custom tailored for a specific application. The most obvious advantage of the ceramics is their ability to be cast or pressed into a variety of odd shapes before polarization, allowing modes of excitation which can't be realized with single-crystalline materials. A single-crystalline material usually will have a much higher mechanical Q than a ceramic material. The mechanical $Q$ of a material is related to its ability to sustain mechanical oscillations. A material with a high mechanical $Q$, once shocked, will oscillate longer than one with a lower $Q$. In the televiewer application, a material with a low $Q$ is desirable to minimize the interference of the pulsing signal with the received signal, allowing inspection of close targets. The most significant advantage ceramics have over the single-crystalline materials in acoustic applications is their ability to achieve much nigher electromechanical coupling factors, resulting in more efficient operation. Since the advent of ceramic piezoelectrics, they have been much preferred over single-crystalline materials for acoustic devices. However, if one is concerned with operation at elevated temperatures, the single-crystalline materials must be considered for their higher Curie temperatures.

Transducer Material Testing

A search was conducted for a piezoelectric material capable of better operation at $275^{\circ} \mathrm{C}$ than ceramic lead metaniobate, which was thought to be the state of the art for high-temperature acoustic transducers. A ceramic sodium bismuth titanate was selected for testing because its Curie temperature $\left(600^{\circ} \mathrm{C}\right)$ was higher than that of lead metaniobate $\left(400^{\circ} \mathrm{C}\right)$. An unmarketed experimental formulation of lead titanate (Curie temperature, $500^{\circ} \mathrm{C}$ ) developed for high-temperature use by Keramos Inc. of Lizton, Indiana, was chosen for testing. Single-crystalline lithium niobate was also chosen because of its extremely high Curie temperature $\left(1250^{\circ} \mathrm{C}\right)$, and because it was discovered in the literature ${ }^{9}$ that when cut at a specific orientation ( 36 degrees rotated $Y$ cut) an electromechanical coupling co- 
efficient can be realized that is much larger than that of other single crystalline materials. While its coupling coefficient is not as large as that of lead metaniobate, the problem of reduced efficiency was overcome by the use of higher pulsing voltages and a low noise-high gain receiver. The parallel plate resonator geometry of the televiewer transducer is a simple one which can be realized with any single-crystalline material. The higher mechanical Q results in a longer time for the transmitted pulses to decay, but this problem was resolved by using mechanical loading to reduce the $Q$.

Electroded, 1.3 MHz, 1/2-inch discs were made using each of the three candidates for comparison to the lead metaniobate. Figures 6 and 7 compare their dielectric properties over the temperature range. These tests were performed in an open air oven with unmounted transducers.

In Figure 6 the capacitance of the three ceramic materials all show variation with temperature. As expected, the lithium niobate exhibits very little change over the range. In Figure 7 an onmeter with $20 \mathrm{M} \Omega$ maximum measurement capability was used to measure leakage resistance (an out of range reading $>20 M \Omega$ is simply plotted at $20 \mathrm{M} \Omega$ ). All materials tested were better than the lead metaniobate. The leakage resistance of the lithium niobate transducer remained above $20 \mathrm{M} \Omega$ throughout the temperature range.

A test setup (Figure 8 ) was devised to compare the high temperature operation of the candidate transducers in a working mode similar to actual televiewer use. The transducer was placed in a fixture inside an autoclave capable of pressurization to $3000 \mathrm{psi}$ and heating to $275^{\circ} \mathrm{C}$. The transducer was mounted on a block of tungsten alumina cement which is held by a fixture so that emitted energy is directed toward the autoclave bottom, 4 inches away, reflected with normal incidence and received by the same transducer. Wires were attached to the electrodes on the faces of the transducer and connected to the pulsing circuit (outside the autoclave) tinrough high-pressure, electrical "feedthroughs" fitted into the top of the autoclave. The autoclave is filled with high-temperature Mobil Jet 0il II as the acoustic transmission medium. A circuit similar to the circuit of Figure 4 was used to pulse the transducer with a 150 volt charge on capacitor $C_{1}$. 


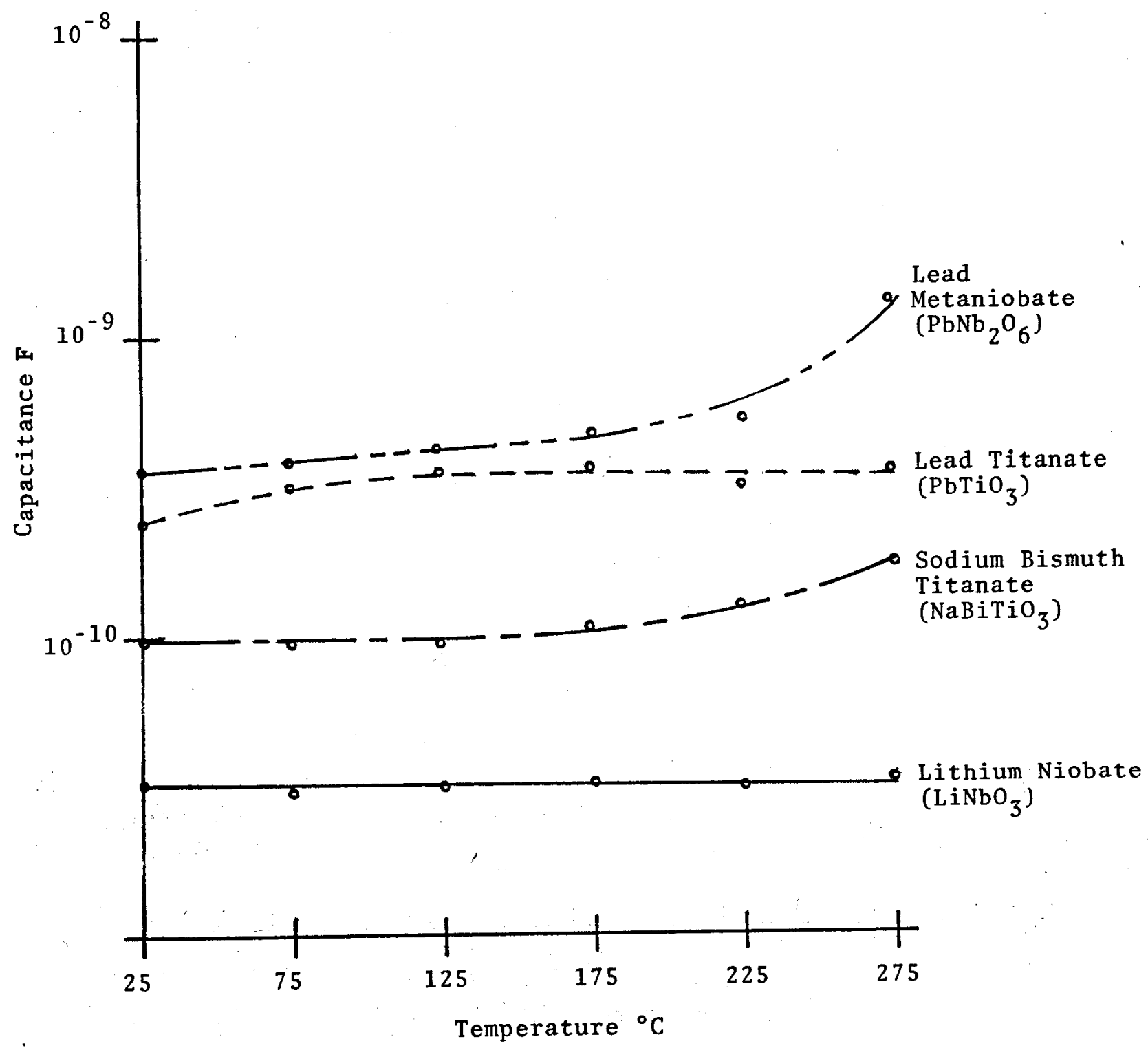

Figure 6. Dielectric Capacitance as a Function of Temperature and Transducer Material 


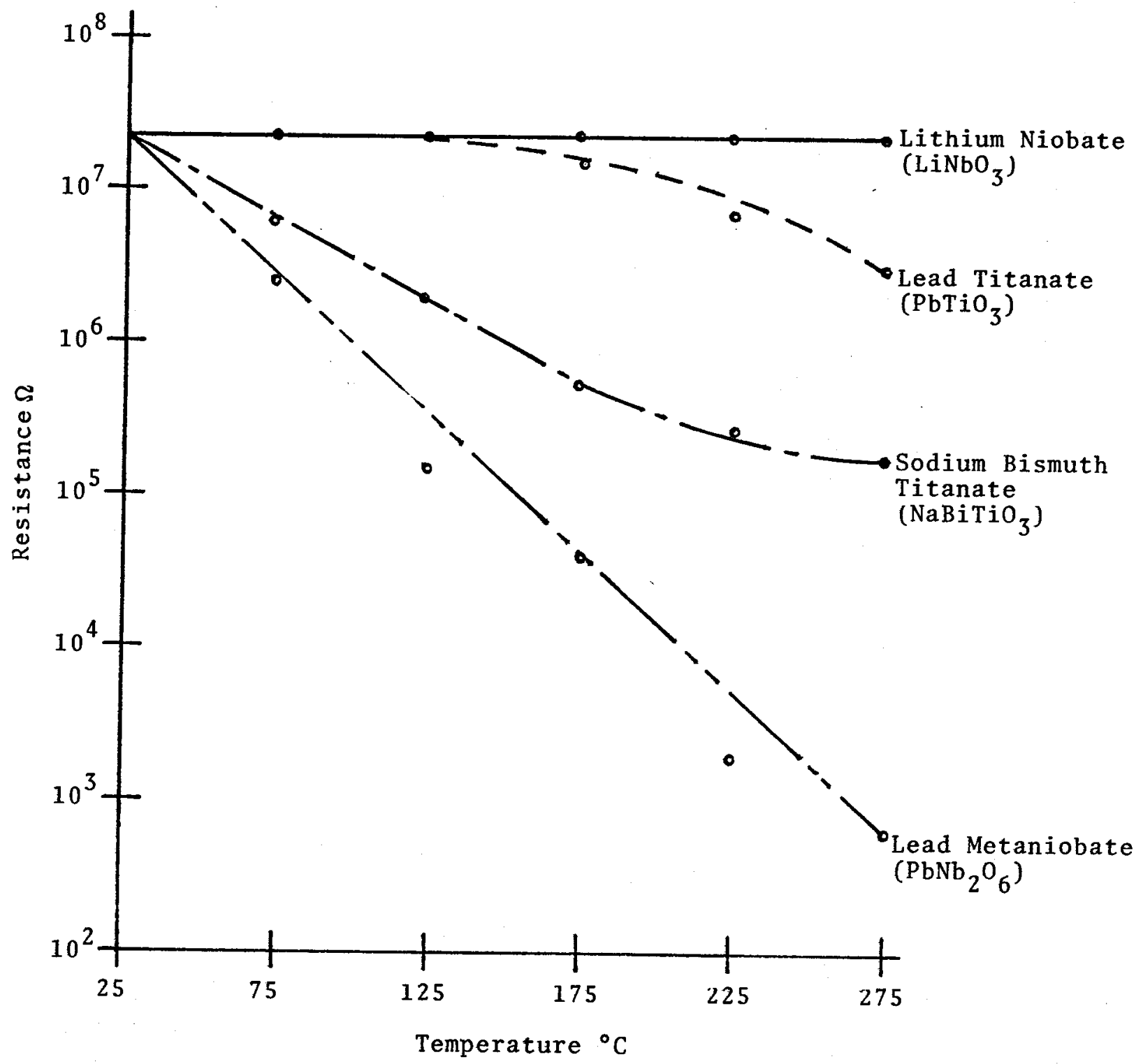

Figure 7. Dielectric Resistance as a Function of Temperature and Transducer Material 


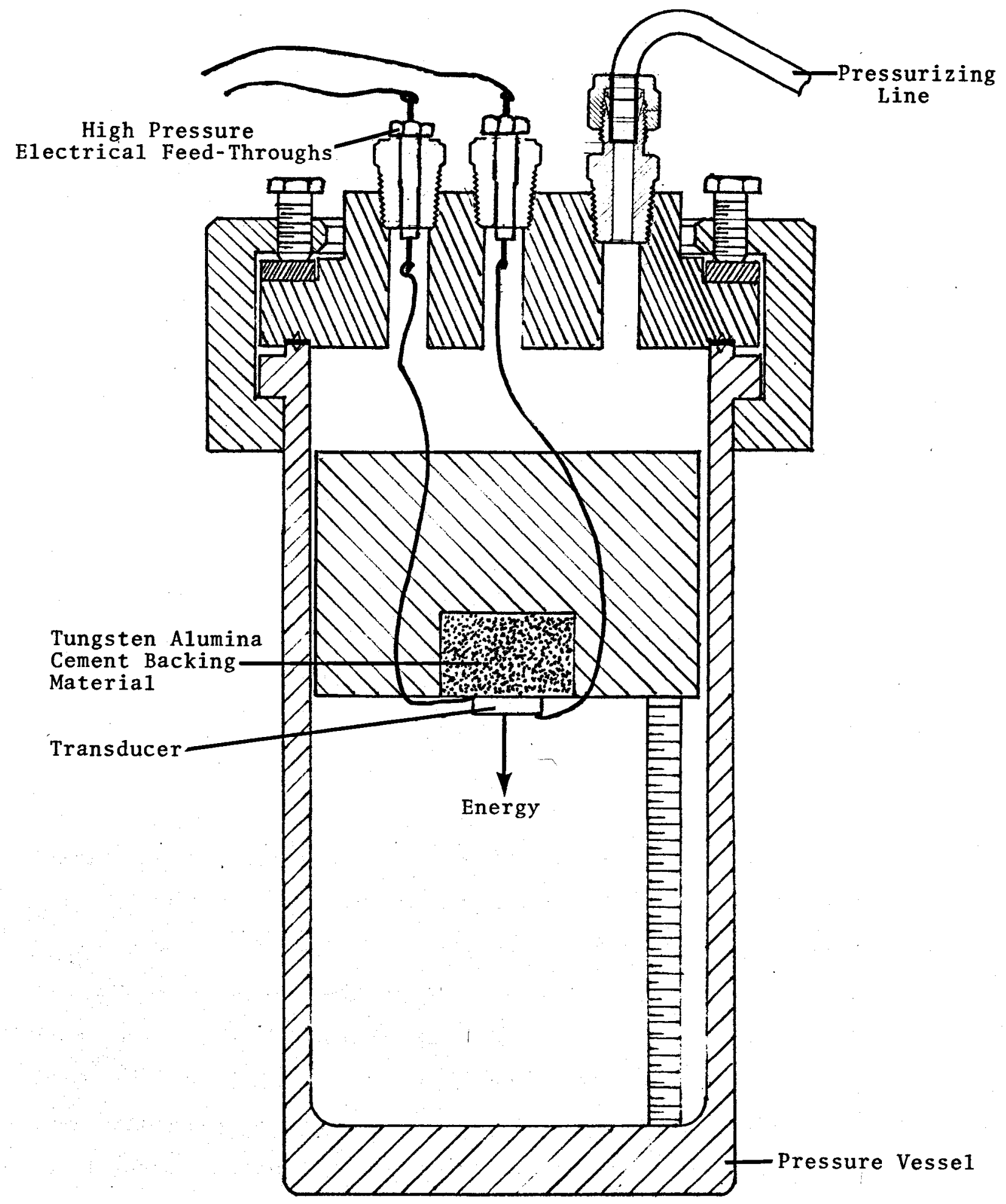

Figure 8. Transducer Test Setup 
At the beginning of each test the transducer under test is mounted, the autoclave is sealed, and a tuning procedure is performed to maximize the energy coupling efficiency at room temperature and pressure. This tuning procedure is performed using a spectrum analyzer to view the pulsing waveform spectrum relative to the mechanical resonance of the transducer. The values of components $c_{1}$ and $L_{1}$ (Figure 4 ) are adjusted until the peak of the pulsing waveform spectrum, caused by the parallel resonance of $C_{1}, C_{D}$, and $L_{1}$, overlaps a dip in the spectrum caused by the series resonance of $L_{m}$ and $C_{m}$.

Data was recorded before the temperature was raised, after the temperature had stabilized for $20 \mathrm{hrs}$ at $275^{\circ} \mathrm{C}$, and again after the autoclave had cooled overnight. These data consisted of measurements of dielectric leakage resistance $R_{D}$, measurements of capacitance $C_{D}$, oscilloscope pictures of the pulse waveform, pictures of the pulse spectrum, and pictures of the received reflected signal waveform. All measurements were made directly across the transducer.

Figures 9 through 12 show some of the oscilloscope pictures recorded in this series of testing. In each of the figures picture "a" shows the frequency spectrum of the pulsing waveform measured across the transducer at $25^{\circ} \mathrm{C}$. To avoid saturating the spectrum analyzer, a resistive attenuator was used to decrease the amplitude. The white dot above the spectrum is a marker set at $1.32 \mathrm{MHz}$, the desired mechanical resonance of the transducer. The dip in the spectrum near the midpoint of the waveform is caused by the mechanical resonance of the transducer (series resonance of $L_{m}$ and $C_{m}$ ). The position of this dip with respect to the 1.32 MHz marker varies from transducer to transducer due to the tolerances maintained in machining the transducer discs. The horizontal scale is $200 \mathrm{KHz}$ per division and the vertical scale is $2 \mathrm{~dB}$ per division measured in a $1 \mathrm{KHz}$ bandwidth. Picture "b" shows the reflected pulse measured across the transducer at $25^{\circ}$ C. The upper trace is a $50 \mu \mathrm{sec}$ per division sweep beginning after the transducer is pulsed. The lower sweep snows the same reflected pulse expanded in time by a delayed sweep of $1 \mu \mathrm{sec}$ per division. Oscilloscope gain setting (volts/division) is indicated by the number on the left at the bottom of the picture. Pictures "c" and "d" are similar to "a" and "b" except these measurements were made at a temperature of $275^{\circ} \mathrm{C}$. 


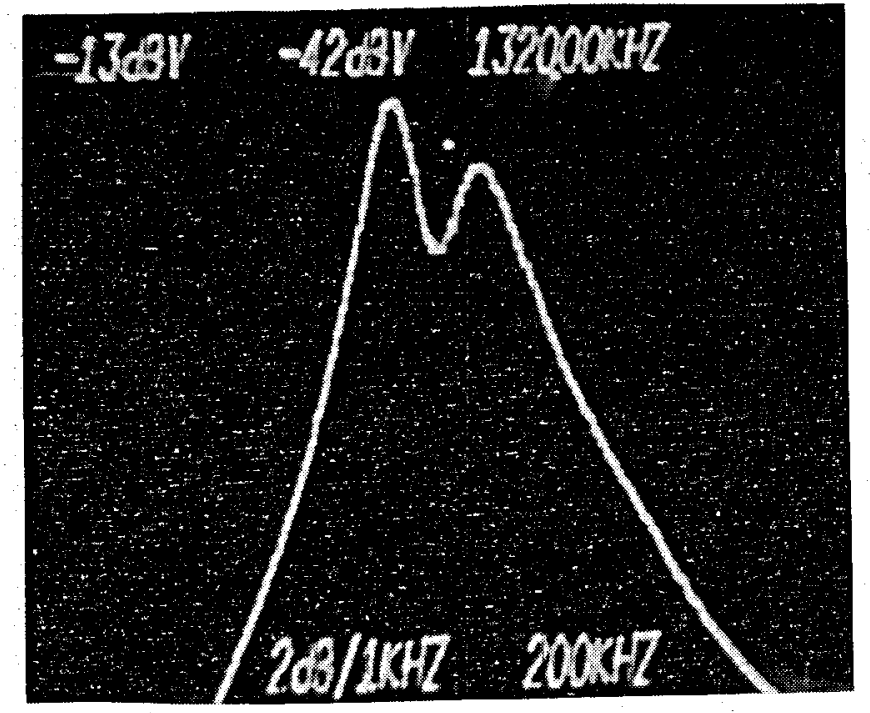

a) Pu1se Spectrum at $25^{\circ} \mathrm{C}$

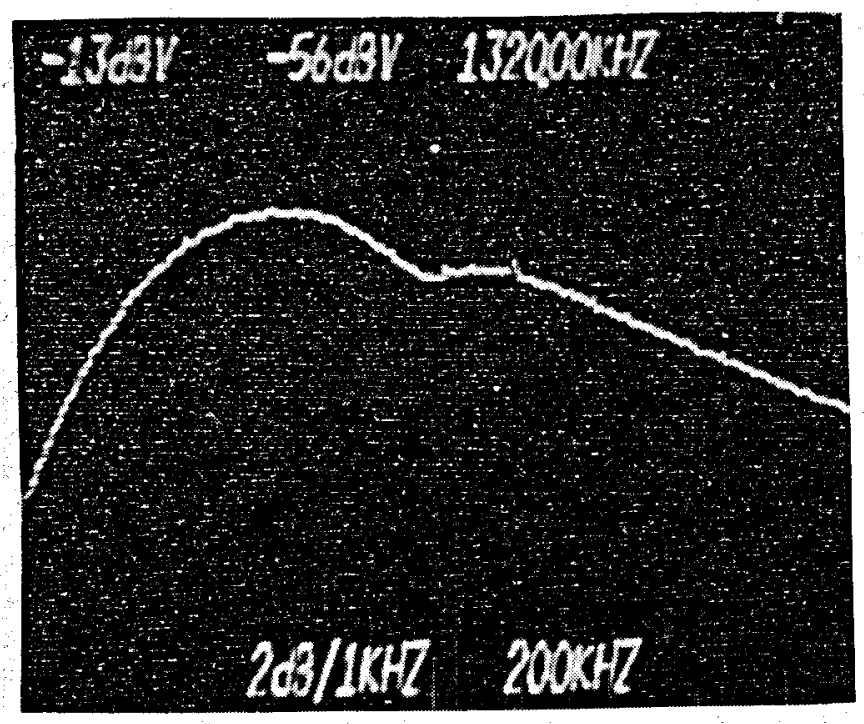

c) Pu1se Spectrum at $275^{\circ} \mathrm{C}$

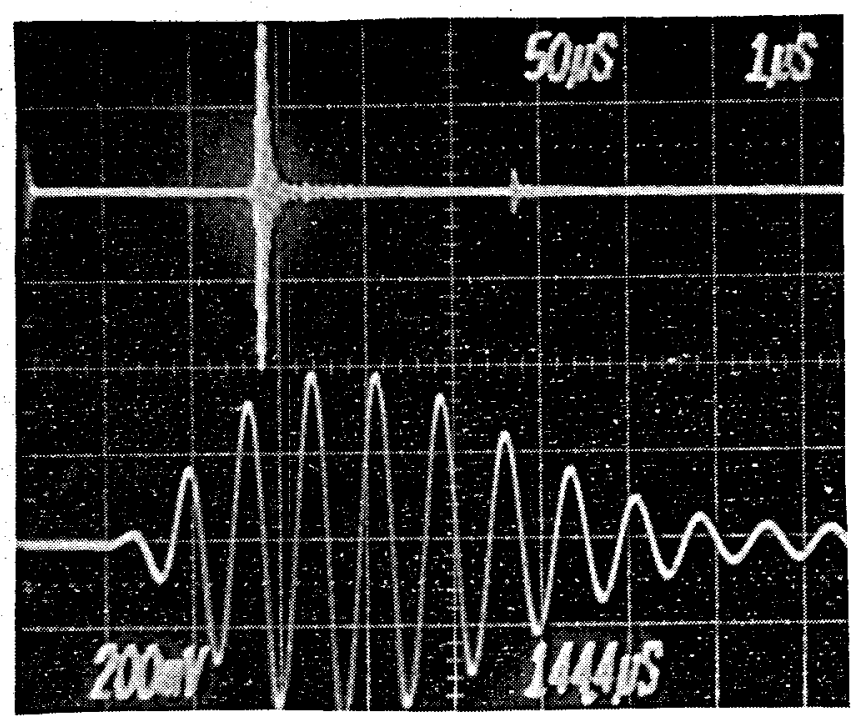

b) Reflected Waveform at $25^{\circ} \mathrm{C}$

Figure 9. Lead Metaniobate Sample 


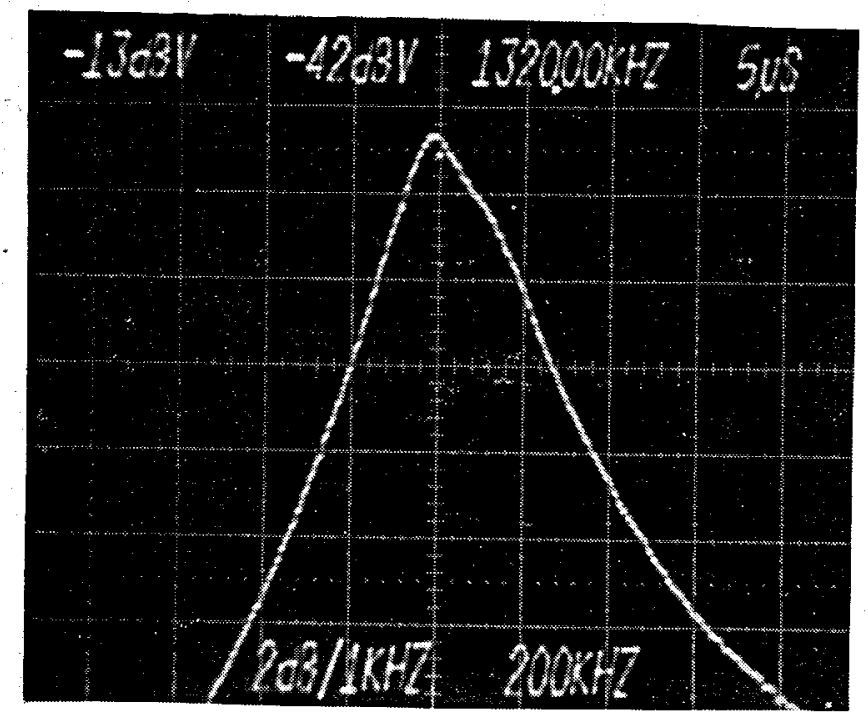

a) Pulse Spectrum at $25^{\circ} \mathrm{C}$

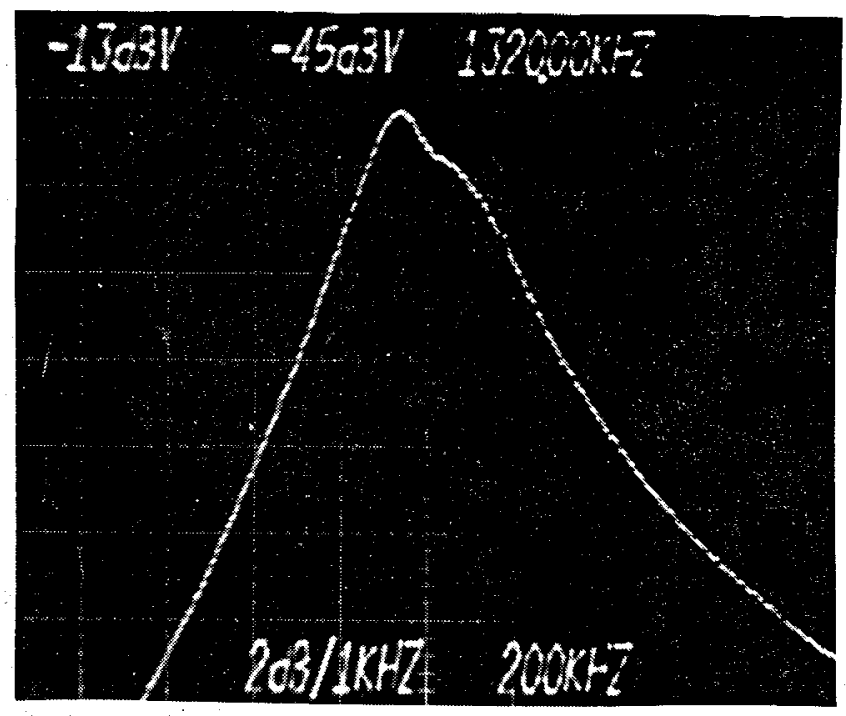

c) Pulse Spectrum at $275^{\circ} \mathrm{C}$

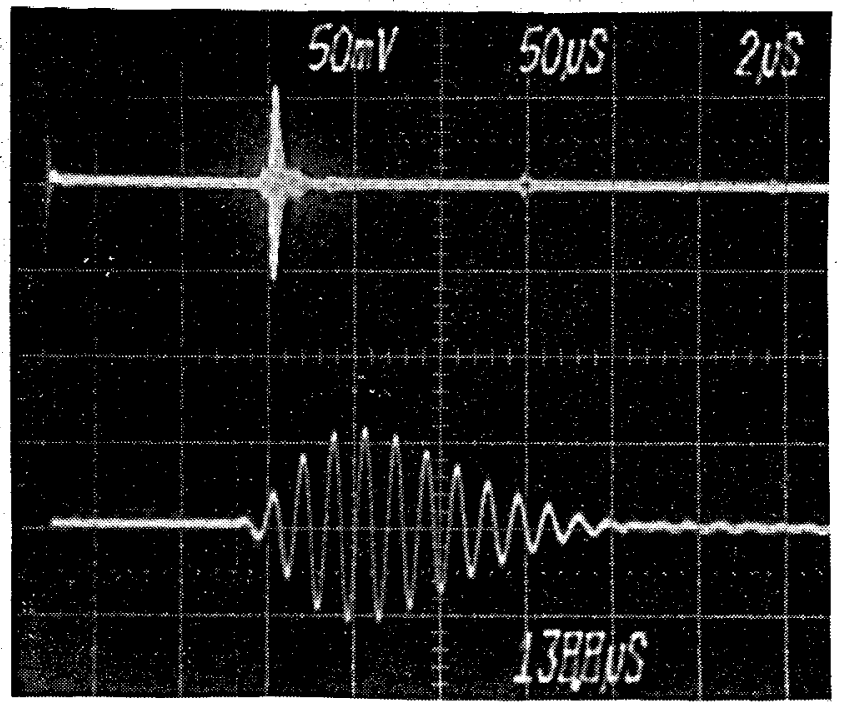

b) Reflected Waveform at $25^{\circ} \mathrm{C}$

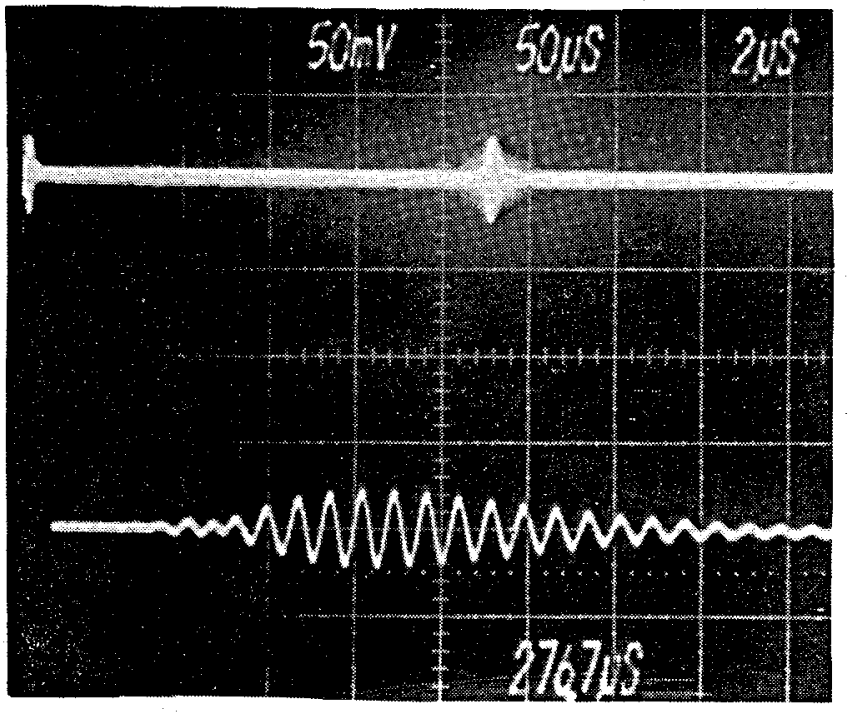

d) Reflected Waveform at $275^{\circ} \mathrm{C}$

Figure 10. Sodium Bismuth Titanate Sample 


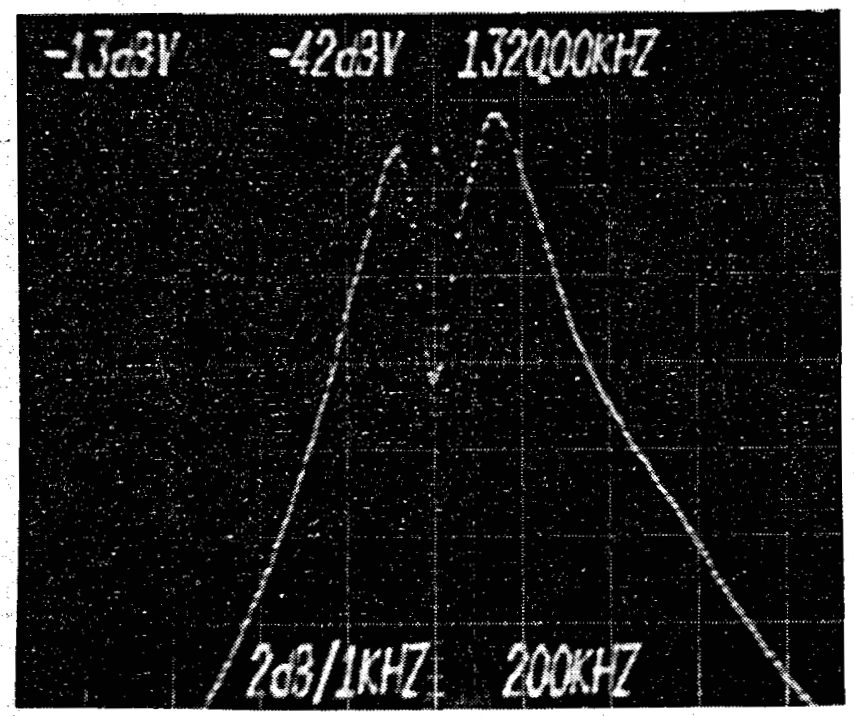

a) Pulse Spectrum at $25^{\circ} \mathrm{C}$

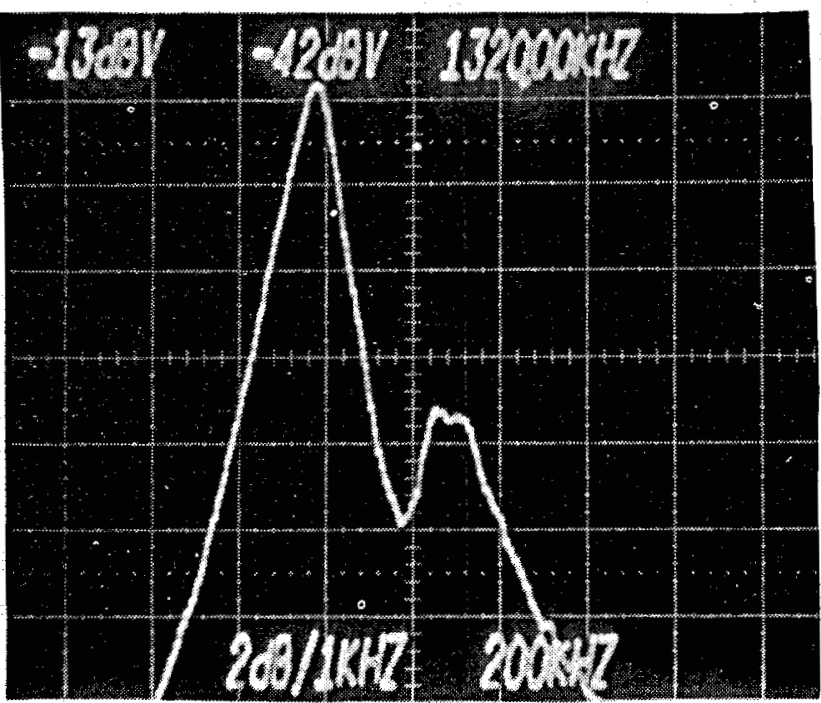

c) Pulse Spectrum at $275^{\circ} \mathrm{C}$

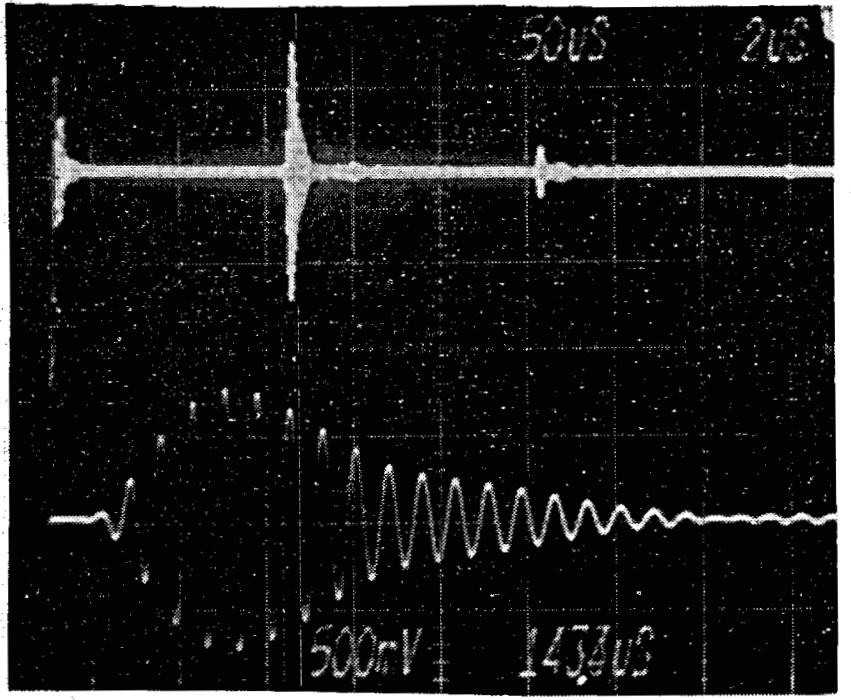

b) Reflected Waveform at $25^{\circ} \mathrm{C}$

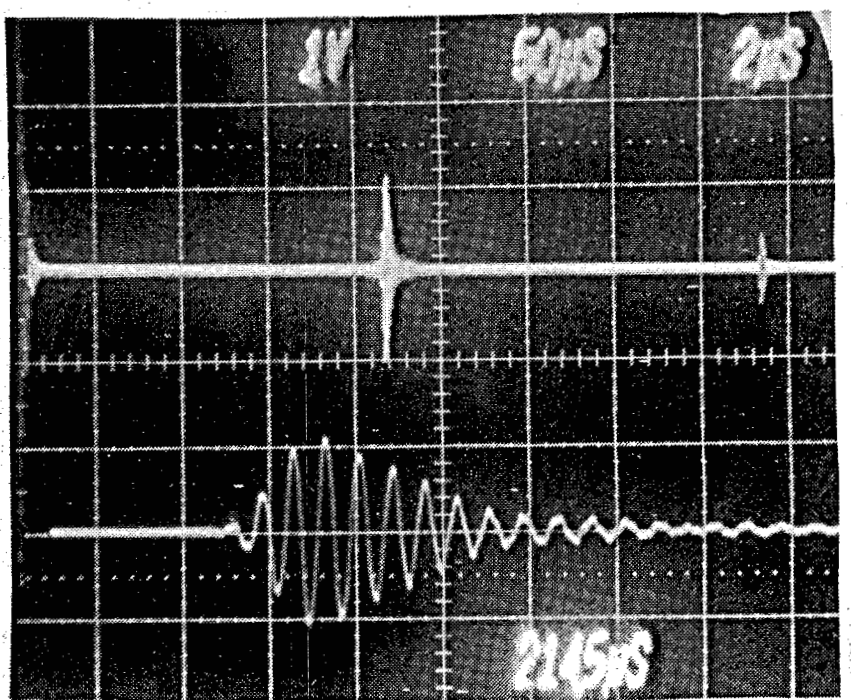

d) Reflected Waveform at $275^{\circ} \mathrm{C}$

Figure 11. Modified Lead Titanate Sample 


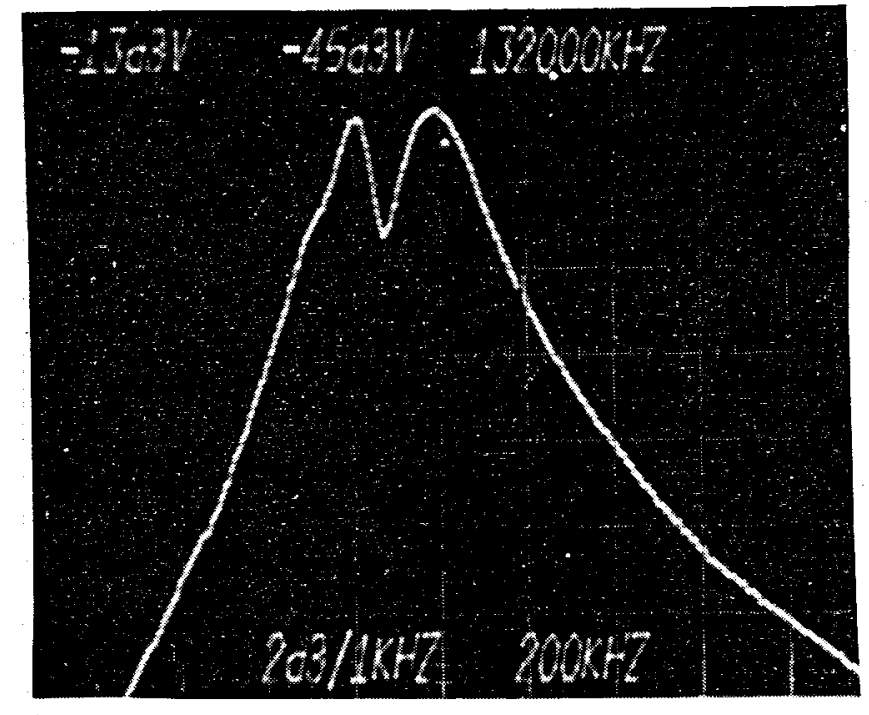

a) Pulse Spectrum at $25^{\circ} \mathrm{C}$

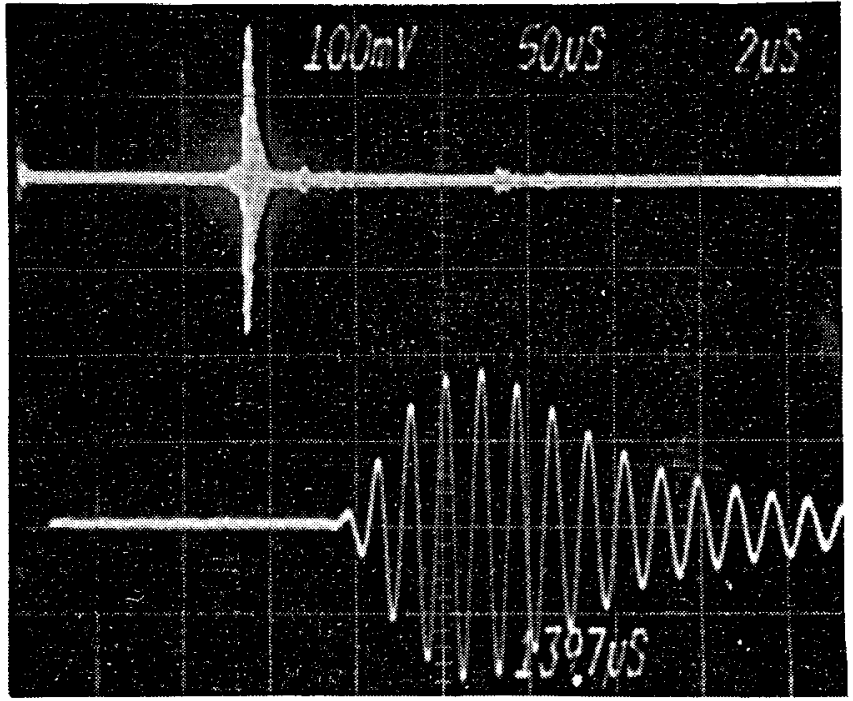

b) Reflected Waveform at $25^{\circ} \mathrm{C}$

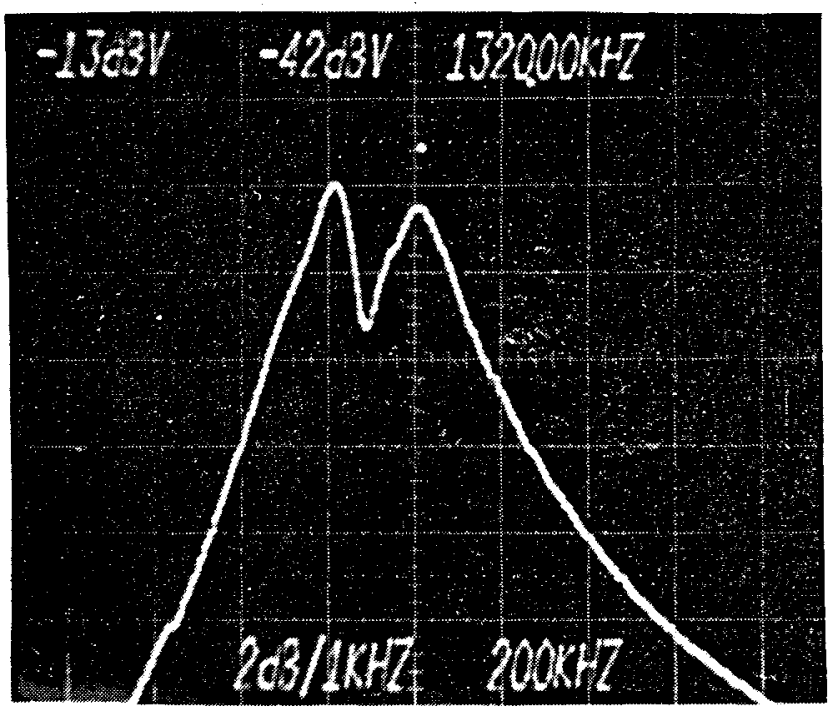

c) Pulse Spectrum at $275^{\circ} \mathrm{C}$

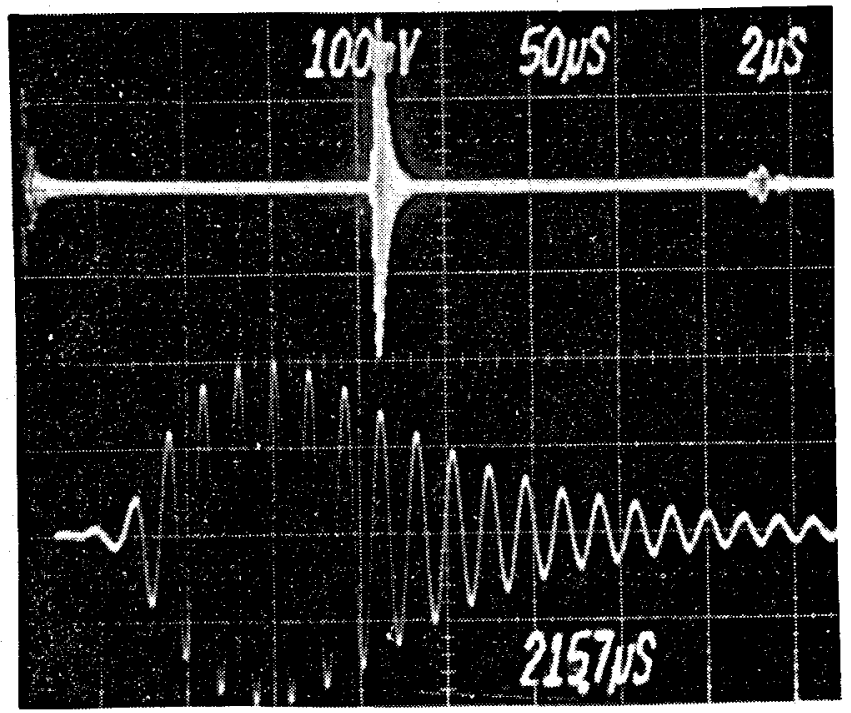

d) Reflected Waveform at $275^{\circ} \mathrm{C}$

Figure 12. Lithium Niobate Sample 
The pictures of Figure 9 for lead metaniobate show that the pulse spectrum broadens significantly when the temperature is raised. This is caused by the increase in dielectric leakage which tends to damp the pulsing waveform. There is also a shift in the frequency of the peak of the pulsing spectrum due to the change in dielectric capacitance, along with a reduction in the reflected signal amplitude from about $400 \mathrm{mV}$ at $25^{\circ} \mathrm{C}$ to $30 \mathrm{mV}$ at $275^{\circ} \mathrm{C}$. The pictures of Figure 10 for sodium bismuth titanate show similar, although less dramatic, behavior. The modified lead titanate sample (Figure 11) exhibits an increase in reflected signal amplitude with the temperature increase. This increase is not understood but could be due to a tuning shift which compensates for poor initial tuning of the pulsing circuit. The lithium niobate sample (Figure 12) exhibits very little change in signal amplitude over the temperature range.

Table 1 summarizes the results of the transducer autoclave testing. Two materials, modified lead titanate and lithium niobate, warrant consideration for use as a high-temperature transducer. The modified lead titanate showed excellent amplitude characteristics, but the dielectric leakage resistance is down to $38 \mathrm{k} \Omega$ at $275^{\circ} \mathrm{C}$ and a smal1, increase in temperature will likely bring it down to a level below the mechanical impedance $\left(R_{m}\right)$ and reduce the signal amplitude with its loading effect. Among the ceramic materials tested the modified lead titanate was the best for high temperature use.

The dielectric leakage resistance of the lithium niobate sample remained beyond the measurement capability $(20 \mathrm{M} \Omega)$ of the meter, the capacitance changed very little, and the signal amplitude was stable. Because of these excellent characteristics, lithium niobate was chosen as the material to use for the high temperature transducer. 
Table 1. Results of Transducer Autoclave Tests

\begin{tabular}{|c|c|c|c|}
\hline $\begin{array}{l}\text { Lead } \\
\text { Metaniobate }\end{array}$ & $\begin{array}{c}\text { Modified } \\
\text { Lead } \\
\text { Titanate }\end{array}$ & $\begin{array}{l}\text { Sodium } \\
\text { Bismuth } \\
\text { Titanate }\end{array}$ & $\begin{array}{l}\text { Lithium } \\
\text { Niobate }\end{array}$ \\
\hline
\end{tabular}

\section{Capacitance}

$\begin{array}{rrrrr}25^{\circ} \mathrm{C} & 300 & 250 & 130 & 60 \\ 275^{\circ} \mathrm{C} & 2000 & 620 & 1000 & 75\end{array}$

Resistance

\section{$25^{\circ} \mathrm{C}$}

$275^{\circ} \mathrm{C}$

Reflected Amplitude

$25^{\circ} \mathrm{C}$

$275^{\circ} \mathrm{C}$
$>20 \mathrm{M} \Omega$

$165 \Omega$

$400 \mathrm{mV}$

$30 \mathrm{mV}$
$>20 \mathrm{M} \Omega$

$38 \mathrm{~K} \Omega$

$800 \mathrm{mV}$

$1000 \mathrm{mV}$
$>20 \mathrm{M} \Omega>20 \mathrm{M} \Omega$

$4.5 \mathrm{~K} \Omega>20 \mathrm{M} \Omega$

$80 \mathrm{mV} \quad 200 \mathrm{mV}$

$20 \mathrm{mV} \quad 200 \mathrm{mV}$ 


\section{ACOUSTIC ABSORPTION}

A flat plate piezoelectric transducer will radiate acoustic energy in two directions normal to the faces of the transducer (forward and reverse). The desired energy transmission is directed out of the tool through the acoustic window, but an equal amount of energy is directed in the reverse direction toward the tool interior. If this energy is not absorbed in some way, it can bounce around inside the tool and interfere with the signal return from the borehole wall.

In the original televiewer design the transducer was epoxied to a brass plate (for mechanical strength) over a round cutout slightly smaller than the transducer diameter so that only the edge of the transducer actually touched the brass. A rubber absorbing material was placed behind this brass plate. Since brass is not a good absorber, a pattern of small holes was drilled in the plate to attenuate the energy coupled into and propagating through the brass.

When this rubber absorbing material was exposed to high temperature in the presence of the coupling fluid (Mobil Jet $0 i 1$ II) used in the acoustic sensor housing, it completely disintegrated. In the search for a better acoustic absorber, three materials were tried: 1) a high temperature rubber used for chemical stoppers, 2) a sand-filled nigh temperature RTV (room temperature vulcanizing) rubber suggested by experimentalists at the USGS, and 3) a tungsten-loaded alumina cement suggested by researchers at westinghouse. ${ }^{10}$ Samples of each of these materials were prepared, placed in autoclaves filled with Mobil Jet 0il II and subjected to a temperature of $275^{\circ} \mathrm{C}$ for 18 hours. Figure 13 is a picture of tine samples after these autoclave tests. Only the tungsten-loaded alumina cement could mechanically survive these conditions. This was the material selected for use in the extended temperature range transducer assemb ly. 


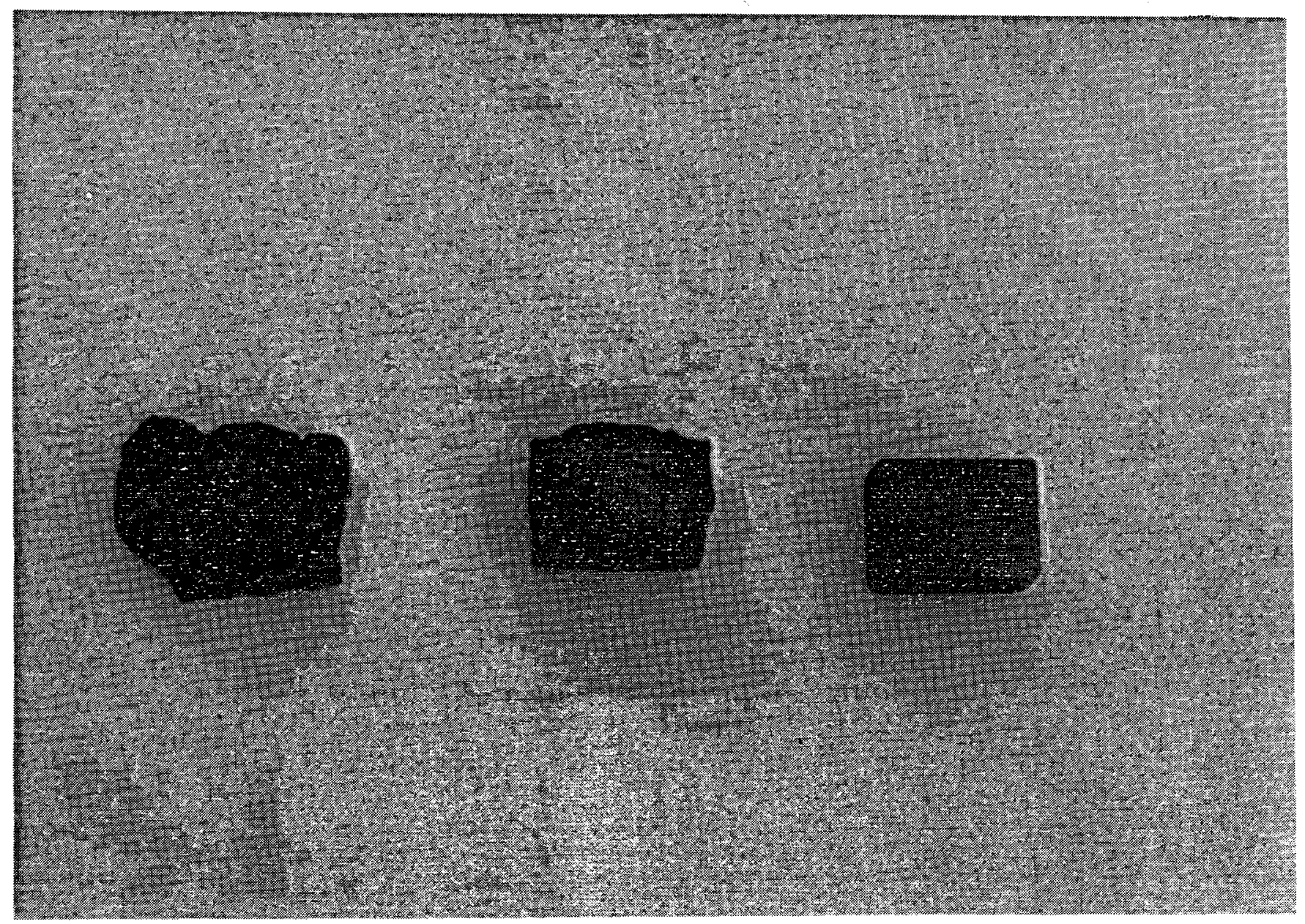
High-Temperature Rubber
Sand-Loaded RTV

Tungsten
Cement

Figure 13. Results of Acoustic Absorber Autoclave Tests 
The tungsten-loaded alumina cement, unlike the other absorbers, is a hard rigid material with a high acoustic impedence. The good mechanical strength of this material allows the direct mounting of the transducer to the absorber using silver epoxy, eliminating the brass plate. With this absorber bonded to the transducer its high acoustic impedence mechanically loads the transducer and reduces the $Q$ and, hence, the ring-down time of the mechanical oscillations. Figure 14 illustrates the differing decay rates of the lithium niobate transducer pulsing waveforms with the rubber absorber and the tungsten alumina cement absorber. When the transducer is in the receiving mode the reduced amplitude of this decaying oscillation interferes less with the reflected return signal, allowing detection of much smaller signals. Without the benefit of the loading effects of the tungsten alumina cement, the high Q lithium niobate transducer material would have been difficult to use.

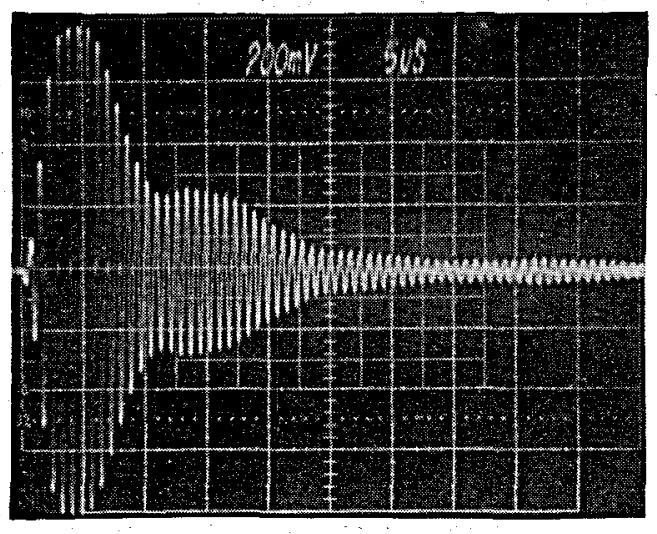

a) Rubber Absorber

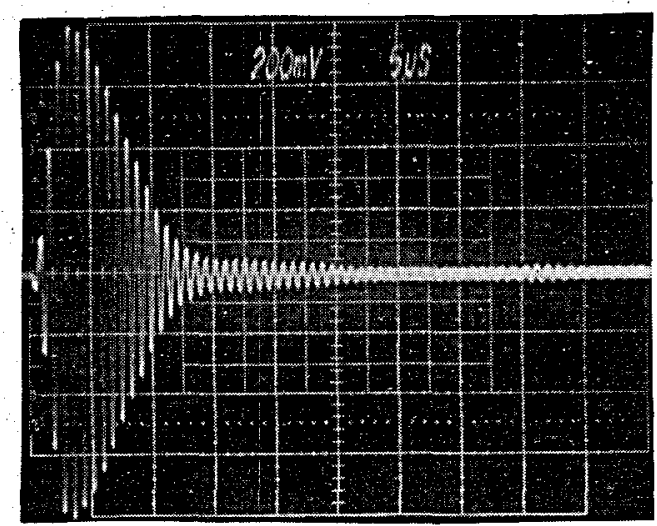

b) Tungsten Alumina Cement Absorber

Figure 14. Transducer Pu1sing Waveform 


\section{ACOUSTIC WINDOW}

The acoustic window is the medium through which the acoustic energy must enter and exit the acoustic sensor housing. It must be capable of excluding the borehole fluid from the tool interior and containing the coupling fluid in the acoustic sensor housing. It must also be acoustically transparent. This means that it must have an acoustic impedence very near the acoustic impedence of the coupling fluid inside the acoustic sensor housing and the borehole fluid outside the window. Polymeric materials come closest to satisfying this criteria while still maintaining some mechanical strength.

Very early televiewers used a neoprene rubber for this purpose, but because of the limited thermochemical stability of neoprene, the manufacturer (Simplec) replaced it with Vespel, a polymide plastic with excellent thermal stability. Failures in the field reported by the USGS ${ }^{17}$ in nigh temperature corrosive geothermal environments led to a search for a better window material. In prior work $^{10}$, researchers at westinginouse concluded that polymeric materials could not operate for extended life periods in a geothermal environment. They demonstrated, however, that a very thin (0.002 inch) metal window may be used. This approach was not pursued at Sandia due to concern of the frágility of such a thin window.

Tests were conducted at Sandia by $C$. A. Arnold ${ }^{12}$ on a number of polymeric window materials to determine their survivability to the combined effects of high temperature, pressure, and corrosive brine. Figures 15, 16, and 17 graphically indicate the results of the static aging tests of three candidate materials: Envex, Vespel, and Tefion. Test results indicate that Teflon (TFE) has very good thermochemical stability, but because of its tendency to creep under stress at elevated temperatures a different sealing configuration had to be devised.

The Vespel window design relied on an 0-ring seal betwieen the tubular window and the tool housing. Because of the tendency of Teflon to creep or relax it is not likely that a seal could be maintained. 
Figure 15.

Envex 1000 Window Before and After Exposure to Synthetic Brine at $260^{\circ} \mathrm{C} / 24 \mathrm{Hrs} .1$ $3000 \mathrm{psi}$

Figure 16. Vespe1 Window Before and After Exposure to Synthetic Brine at $260^{\circ} \mathrm{C} / 24 \mathrm{Hrs} . /$ $3000 \mathrm{psi}$

Figure 17.

Tefion Window Before and After Exposure to Synthetic Brine at $260^{\circ} \mathrm{C} / 24 \mathrm{Hrs} .1$ $3000 \mathrm{psi}$
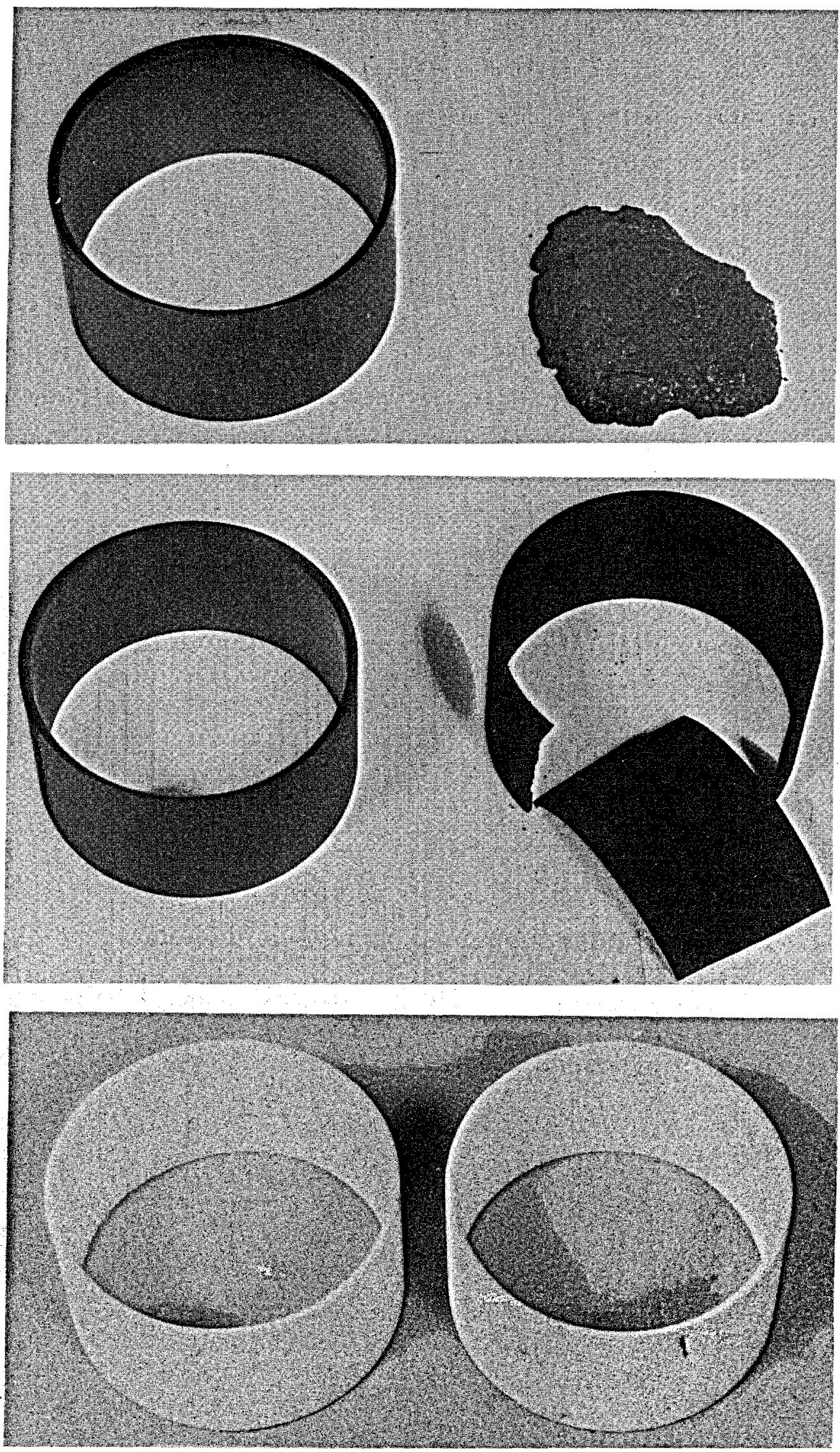
The Teflon window material has been incorporated into the televiewer through the use of the sealing configuration shown in Figure 18. The Teflon window is machined with a flange or lip on top and bottom. These flanges serve as sealing gaskets which are squeezed down between flanges on the housing and split ring assemblies by screws. Spring washers are used to hold tension on the flange should the Teflon yield in such a way as to relieve the tension applied during assembly. There is also a notch in the housing flange that cuts into the Teflon to inhibit any creeping action. A pressure-equalizing bellows insures that no differential pressure can be sustained across the window which would tend to collapse it. This window design has worked well without failure in numerous tests in the field and in the lab.

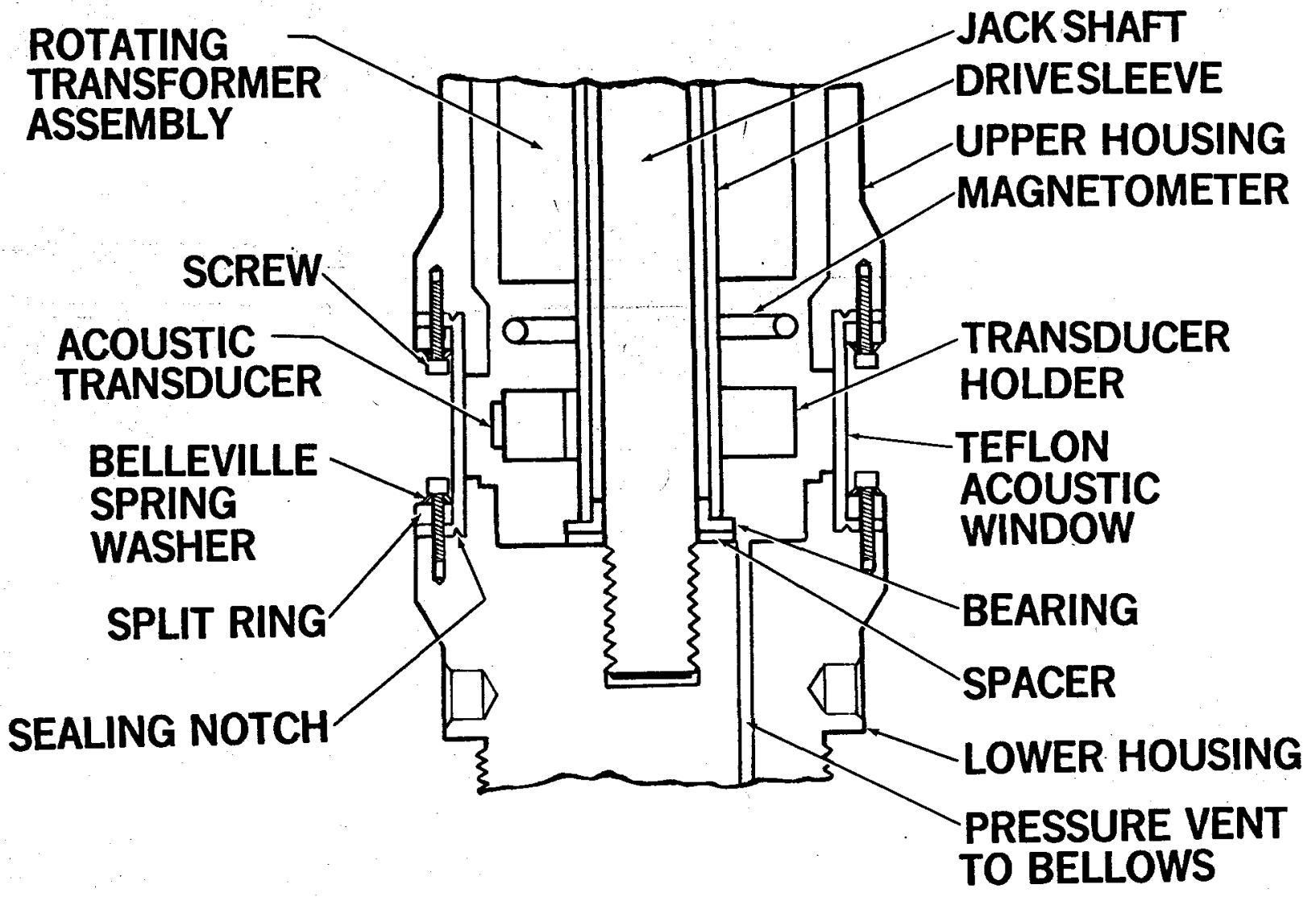

Figure 18. Acoustic Window Configuration 


\section{SLIP RINGS AND ROTARY TRANSFORMERS}

As discussed in the mechanics of operation section of this report, the magnetometer and transducer are rotated inside the stationary housing by the motor. The electronics package must send and receive electrical signals to and from these components, so some method of coupling must be used. The common method of doing this, and the method used in the original televiewer design, is through a slip ring assembly. This mechanism consists of wires attached to a set of conductive carbon brushes which are held in contact by springs to a set of silver rings which rotate with the rotating components. Wires attached to the silver rings connect to the rotating components.

A number of problems have been experienced with the use of slip rings in the televiewer. Sharp edges on the hard carbon brushes have been known to cut slivers of silver from the rings which float around in the oil until they lodge in some inconvenient place and cause shorts. The brushes wear down and must be replaced periodically, and they must be kept clean for good electrical contact; and contact bounce generates electrical noise that interferes with legitimate signals. The most serious problem is that at high temperature the springs lose their tension and fail to hold the brushes on the rings. Rather than attempt to design a better slip ring assembly, it was decided to try coupling signals to the rotating components magnetically across a gap.

A system of rotating transformers was designed and assembled into the acoustic sensor housing to perform this job of magnetically coupling across a gap. Each rotating transformer is made of two donut-shaped cores of magnetic material of rectangular cross section which fit together one inside the other with a very small gap between them (Figure 19). The outer core is the stator (stationary core) and the inner core is the rotor (rotating core). Grooves are machined in the adjacent faces of the cores for the transformer windings and because each groove contains the same number of turns the windings can be used interchangeably as primary or secondary. Applying a current to the primary winding induces magnetic lines of flux in the cores which close on themselves and follow the path of highest permeability. Since the permeability of the magnetic material is higher 
than the permeability of air this magnetic field is confined to, and shared by, the two cores except in the region of the gap. As long as the gap is kept small the magnetic flux lines will not move out of it. If the gap is made too large, efficiency is reduced and the flux lines may stray away from the gap and be sensed by adjacent transformers or the sensitive magnetometer. When the primary winding is driven by an AC signal, time varying flux lines are produced which induce a current in the secondary winding.

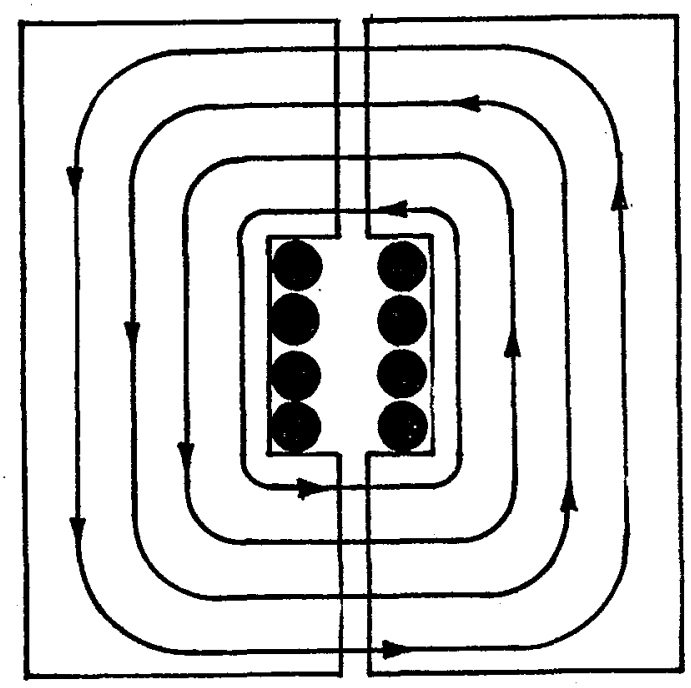

Figure 19. Rotating Transformer

Figure 20 is a cutaway drawing of the rotating transformer assembly containing three transformers. Two of these transformers are used for the magnetometer drive signal and the magnetometer output signal. The other one is used as a two-way coupling for the transducer excitation and receiver signals. Ceramic ferrites were chosen for use as the core material over silicon-iron and nickeliron alloys. The iron alloy materials typically have high magnetic permeabjlities and make good low frequency, high power transformers, but ferrites are easily machined to any desired shape and have very low losses at the high frequencies we use. The particular ferrite chosen was the nigh Curie temperature $\left(340^{\circ} \mathrm{C}\right)$ nickel-zinc ferrite (C2050) from Ceramic Magnetics of Fairfield, N.J. This rotary transformer assembly has worked well in all tests in the lab and in the 
field. It has eliminated the operational problems associated with slip ring assemblies with lower cost, simpler maintenance, and more reliable signal coupling.

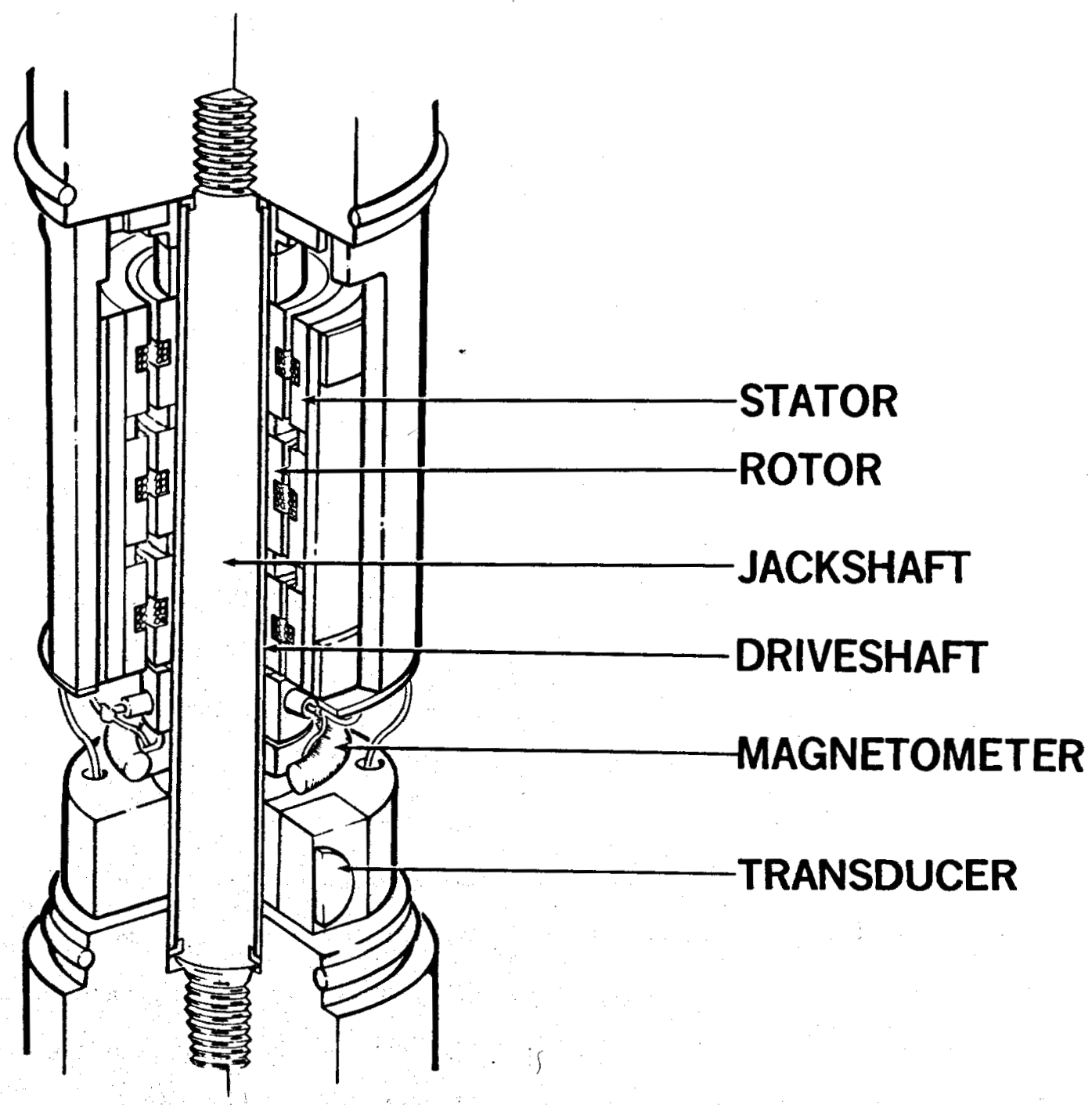

Figure 20. Rotating Transformer Assembly 


\section{FLUX GATE MAGNETOMETER}

Direction sensing in the televiewer system is accomplished through the use of a flux gate magnetometer which rotates with the transducer. The flux gate magnetometer consists of coils of wire wound on a core of saturating, high-permeability iron alloy. It detects the intensity of the component of the earth's magnetic field parallel to the axis of the core.

An iron alloy material of high permeability has a very low "resistance" to magnetic flux. It tends to attract lines of flux existing around it and locally bend and concentrate them inside the material. Once a certain density of flux lines in the material is obtained the material is said to "saturate" and will have a high resistance to any more flux (i.e., permeability is reduced).

When a bar or strip of this high permeability material is aligned parallel to the lines of flux of the earth's magnetic field, they will tend to concentrate in the iron alloy strip since it offers less "resistance" than the surrounding low permeability medium. If a coil is placed around the core and driven with a current to generate sufficient flux density, the iron alloy will saturate and permeability will be reduced, causing the flux lines due to the earth's field to be driven out of the core. The iron alloy core and coil arrangement act as a "flux gate" to the earth's magnetic flux lines. When current is absent from the drive winding, the gate is open and the flux lines tend to locally concentrate in the core. When a high current is applied to saturate the core, the gate is closed to the eartin's field flux lines and they resume their original patins unperturbed by the presence of the core. Figure 21 shows how the flux lines (due to the earth's field) alternately concentrate in the core and exit the core as the core is driven into and out of saturation.

If a sense winding is wound on the core, a voltage will be induced in it each time the magnetic flux lines cut or pass through it upon entering and exiting as the core is driven into and out of saturation. The magnitude of this voltage is proportional to the number of lines cutting the winding or the intensity of the component of the magnetic field which lies parallel to the core. The polarity of the voltage is determined by the direction of the parallel component of this field. 


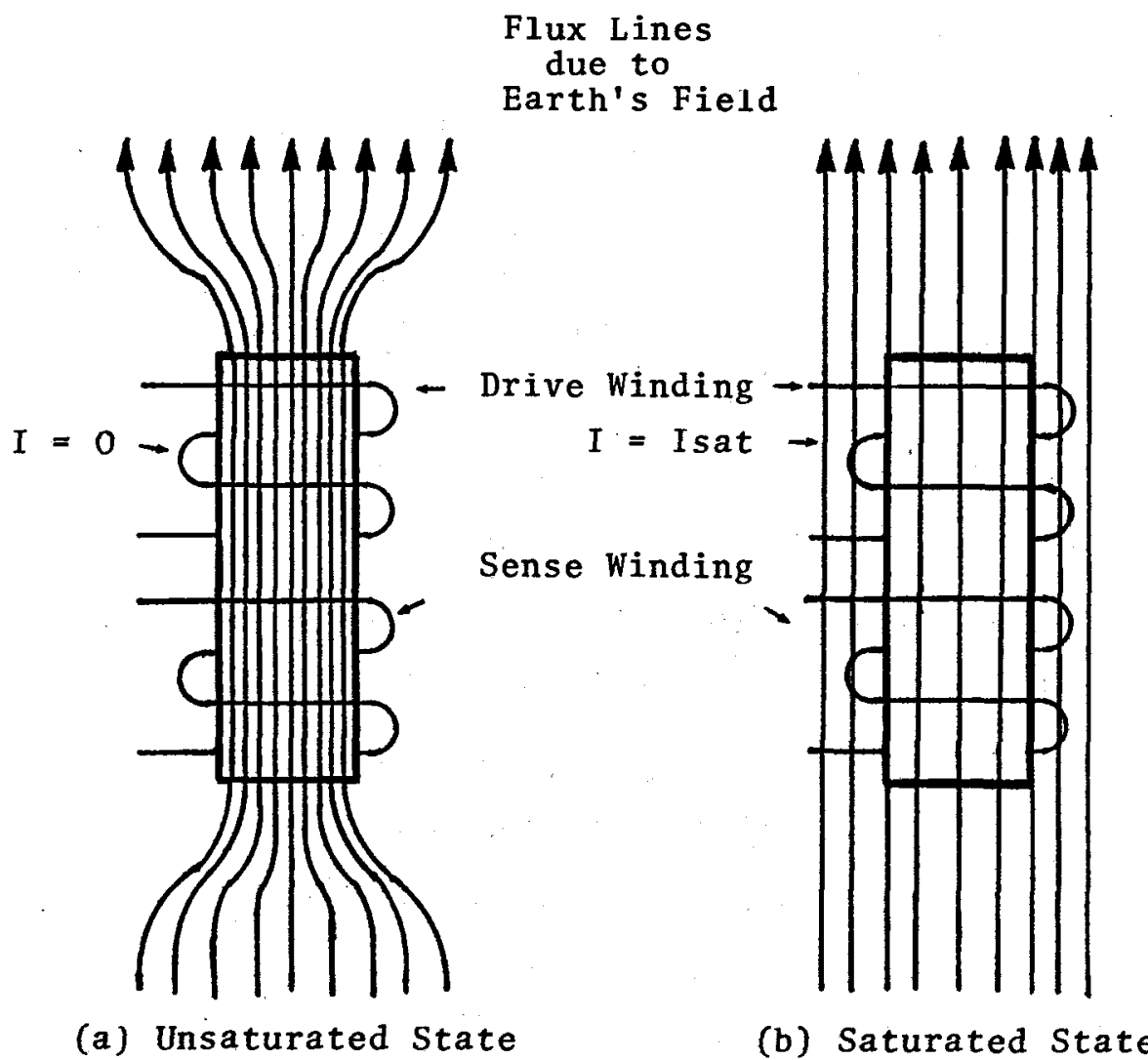

Figure 21. a) Flux Lines Due to Earth's Magnetic Field with Core in Unsaturated State

b) Flux Lines with Core in Saturated State

Note: Only flux lines due to the earth's magnetic field are shown

This iron alloy core with its drive and sense windings is called a "flux gate magnetometer." If the drive winding is driven with a saturating, alternating current the flux gate will open and close at twice the frequency of the drive current. The flux due to the earth's field will concentrate and then exit the core once for each half cycle of the drive current. This action will produce an $A C$ voltage on the sense winding at twice the frequency of the drive current. The peak-to-peak amplitude of the $A C$ voltage on the sense winding will be directly proportional to the amplitude of the component of the earth's field vector parallel to the axis of the flux gate magnetometer. When the flux gate magnetometer is oriented in a horizontal plane parallel to the horizontal component of the earth's magnetic field, the peak-to-peak amplitude of the $A C$ voltage on the sense 
winding due to the earth's magnetic field will be maximum. If the magnetometer is rotated 180 degrees in the horizontal plane (still parallel to the earth's field horizontal component) this peak-to-peak amplitude will also be maximum, but the voltage will be 180 degrees out of phase with the original voltage (i.e., polarity reversed). If the magnetometer is oriented in the horizontal plane perpendicular to the earth's field horizontal component, the peak-to-peak amplitude will be zero. Thus, sufficient information can be obtained from the sense winding to determine the direction of the earth's magnetic field.

In addition to the voltage induced in the sense winding by the earth's magnetic flux lines, there is a voltage induced by the saturating flux lines generated by the $A C$ drive signal. This voltage is of high amplitude and interferes with the desired voltage. It can be filtered out since its frequency is half that of the desired voltage induced by the earth's magnetic lines of flux. But, this requires a very sharp bandpass filter centered at twice the frequency of the drive signal. The stop band attenuation of this filter must be very good to detect a sense voltage caused by a field as weak as the earth's.

There are a number of schemes suggested in the literature $13,14,15,16$ to eliminate this interfering voltage in the sense winding. The method used by the televiewer incorporates a toroidal form with an iron alloy tape wound around it. Figure 22 illustrates this method with a rectangular configuration for geometric simplicity. The explanation of the operation given here also applies to the circular configuration actually used. Figure $22(\mathrm{a})$ shows a rectangular core with four windings on it. The standard transformer dot convention is used to indicate the direction of mutual coupling for each winding. Windings $W 1$ and $W 2$ are actually overlapping and bifilar wound, as are W3 and W4. The drive winding consists of the combination of $W 1$ and $W 3$ in a series aiding configuration. In Figure 22(b) the core is in the saturated state, the permeability is low, and the flux lines of the earth's magnetic field are undisturbed by the presence of the core. The saturating flux lines caused by the drive current form closed loops confined to the core material. Since the sense winding formed by windings $W 2$ and $W 4$ is connected series opposing, the voltage induced in W2 cancels the voltage induced in W4 so 


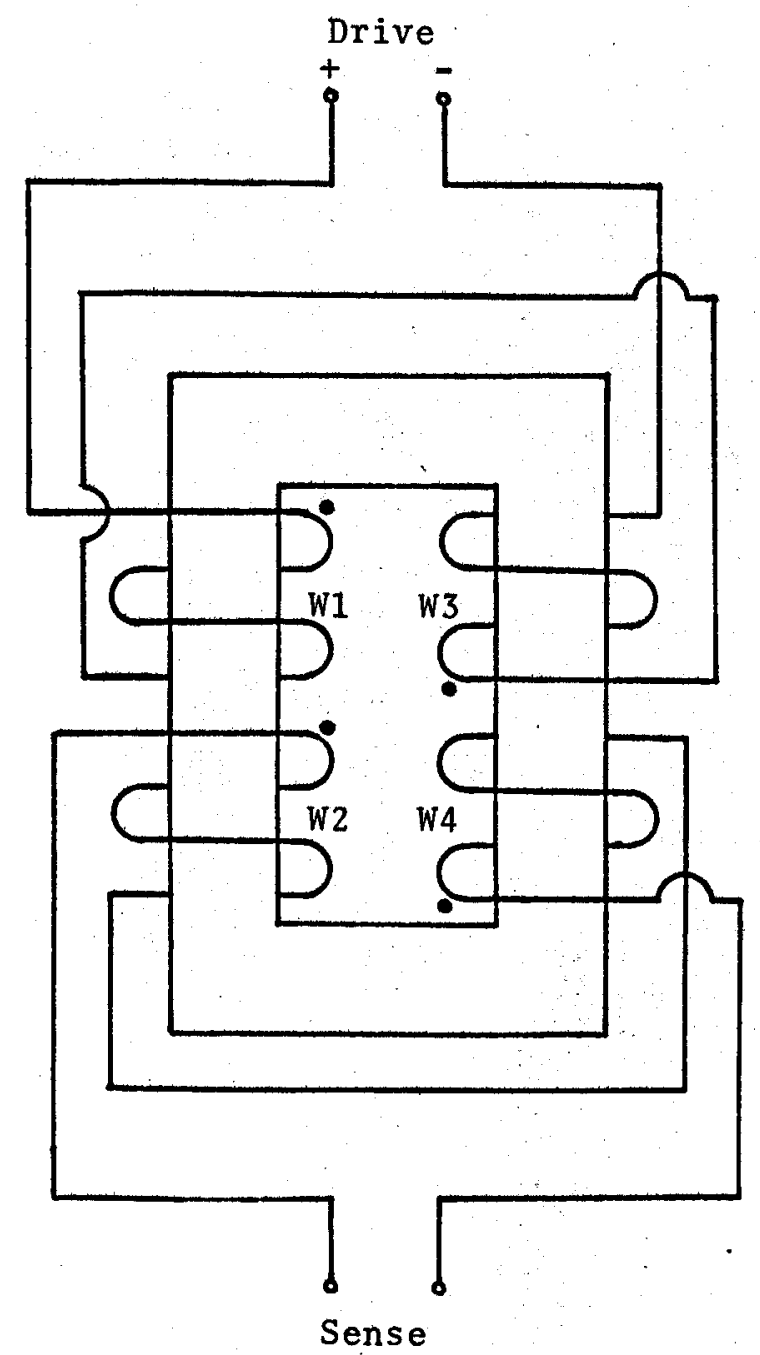

(a)

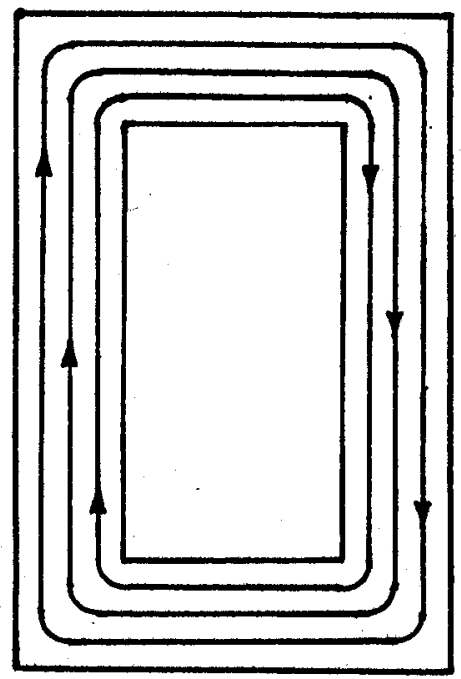

(b)
Flux Lines Due to Earth's Magnetic Field

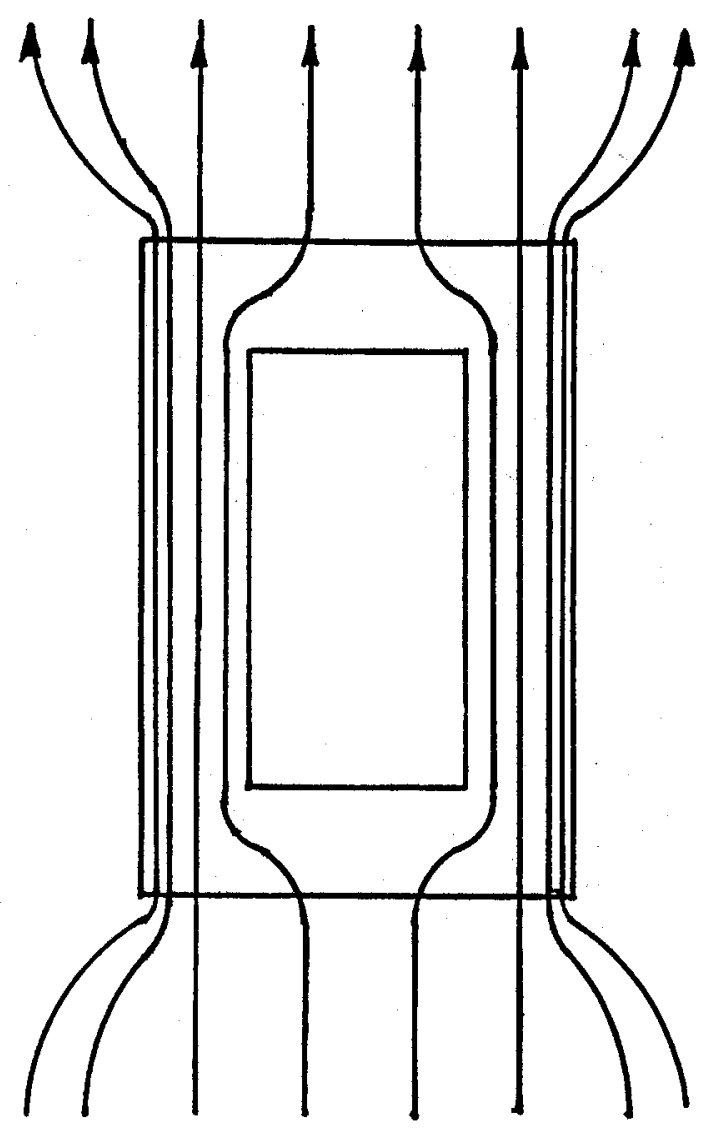

(c)

Figure 22. (a) Winding Configuration Due to Drive Current

(b) Flux Lines with Core Saturated

(c) Flux Lines with Core Unsaturated 
that the net effect of the saturation flux on the sense winding is zero. Figure 22(c) shows the flux lines inside the core when the flux gate is in the unsaturated state (i.e., drive current is zero). It can be seen here that this changing flux will tend to induce voltages in W2 and W4 so that the net effect on the sense winding is to double the voltage that would be induced in just one of these windings.

Figure 23 shows the actual magnetometer configuration used. The core material is a single wrap of 0.001 inch thick iron alloy tape held in a groove around the outside of a toroidal form by an 0-ring. The material used for the form is a high-temperature DuPont plastic called Vespel. The windings on each side of the toroidal form are composed of 130 turns of bifilar transformer wire. The transformer wire used is \#32 copper with a high-temperature polymide coating (HML) rated for operation at $220^{\circ} \mathrm{C}$ for thousands of hours (this wire can be derated for operation at $275^{\circ} \mathrm{C}$ to a useful life of hundreds of hours ${ }^{17}$.)
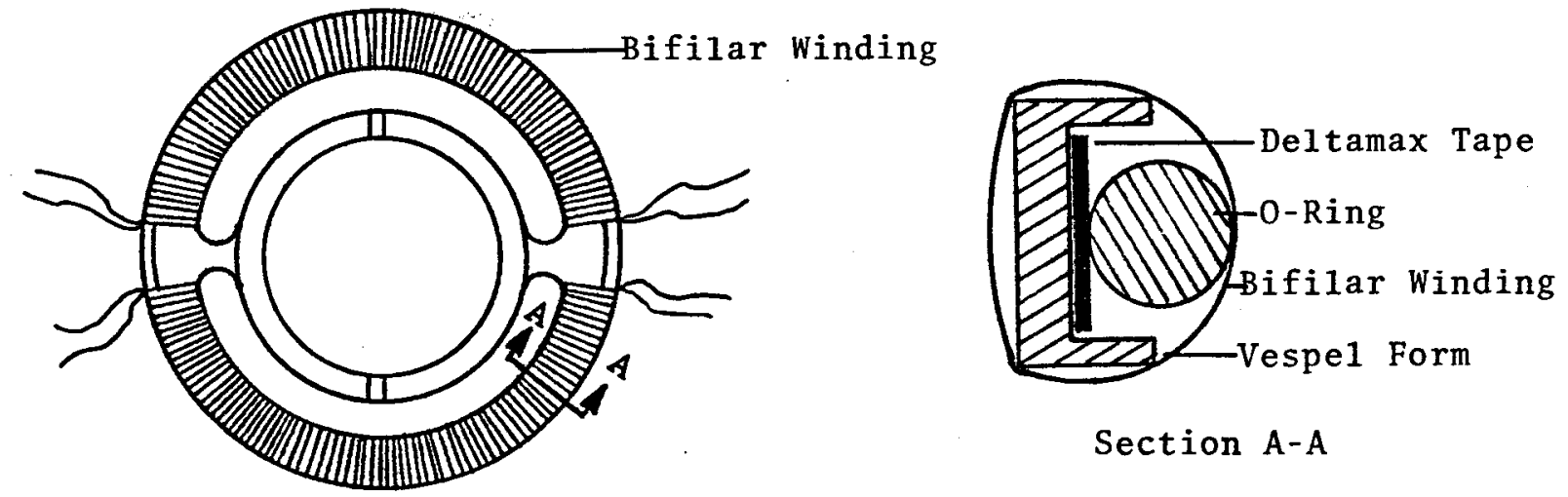

Section A-A

Figure 23. Magnetometer Configuration 
The flux gate magnetometer is mounted on the drive sleeve directly above the transducer assembly with its axis normal to the axis of the transducer. When the transducer axis is oriented north-south the magnetometer axis is oriented eastwest. This means that as the transducer rotates througn magnetic north there is a null of the peak-to-peak voltage and a 180 degree phase reversal on the sense winding of the magnetometer. This can be detected by the magnetometer processing circuitry to deliver the nortin reference synch signal.

The iron alloy tape core material used is a $50 \%$ nickel, 50\% iron material called Deltamax (Arnold Engineering). Deltamax works very well for this type application because its $B-H$ loop very closely approximates the ideal square loop characteristic upon which flux gate theory is based. It also has very low core loss at the hign frequency $(10 \mathrm{KHz})$ used for the orive current. Deltamax with its $480^{\circ} \mathrm{C}$ Curie temperature nas operated witnout problems at the design temperature of the Sandia televiewer. Figure 24 , generated from data in the literature ${ }^{18}$ snows a comparison of the $\mathrm{B}-\mathrm{H}$ curves of Deltamax at $22^{\circ} \mathrm{C}$ and $262^{\circ} \mathrm{C}$. The curves show that saturation flux density, remnant flux density $\left(B_{r}\right)$, coercivity $\left(H_{C}\right)$, and permeability change with temperature, but the relative squareness of the two curves is about the same. Flux gate theory requires that the squareness of the $\mathrm{B}-\mathrm{H}$ curve be maintained for operation over the temperature range. The variability of the other properties will affect the current drive necessary for saturation and the peak-to-peak amplitude of the voltage on the sense winding of the magnetometer in a given magnetic fiela. But, since the north synch signal is derived from the position of a voltage null and 180 degrees phase reversal of the magnetometer output, the absolute amplitude is unimportant. Increases in temperature which affect the magnetic properties do not affect the accuracy as long as the material still exnibits this square loop property. Sufficient drive current, however, must be provided to saturate the flux gate under all temperature conditions. For even nigner temperature operation (up to $450^{\circ} \mathrm{C}$ ) the literature ${ }^{18}$ suggests that an iron alloy material called $2 V$ Permendur (49\% cobalt, $49 \%$ iron, $2 \%$ vanadium) can be used. This material exnibits smaller changes in its magnetic properties over a broader temperature range than Deltamax. $2 \mathrm{~V}$ Permendur was not tested at Sandia in the flux gate magnetometer configuration since Deltamax was found to be sufficient. 


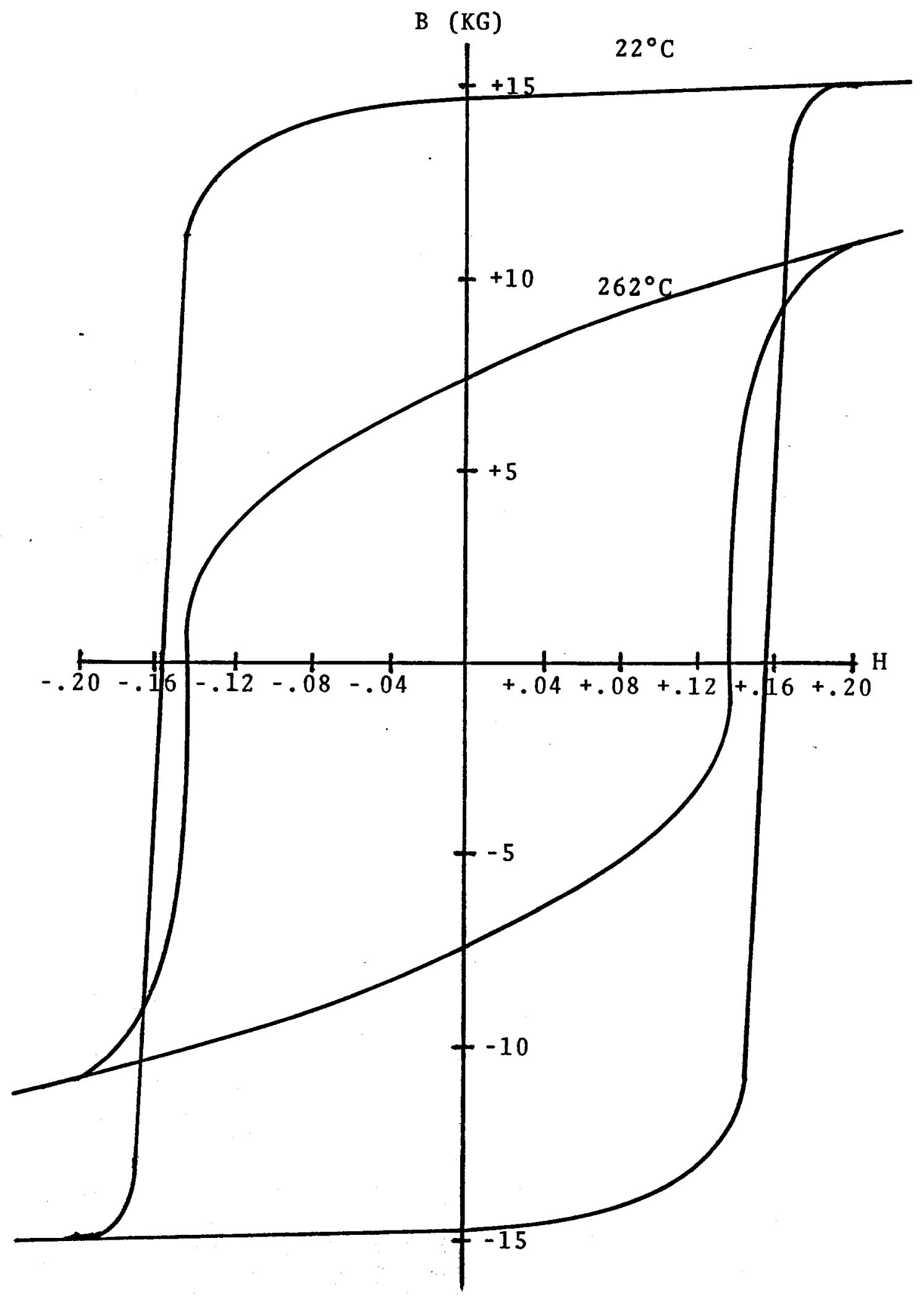

Figure 24. B-H Curves of Deltamax 


\section{DOWNHOLE ELECTRONICS}

Figure 25 is a block diagram of the downhole electronics of the televiewer. The transducer, flux gate magnetometer, rotating transformer assembly, AC synchronous motor and mark sensor are mounted in the acoustic sensor housing portion of the tool. These components are exposed to the temperature and pressure environment of the borehole and are designed to operate at the $275^{\circ} \mathrm{C} / 5000$ psi extremes. The remainder of the electronics is housed inside a dewar in the electronics pressure barrel. The dewar uses a eutectic phase changing metal to hold the temperature inside the dewar below $138^{\circ} \mathrm{C}$ for a time estimated by the manufacturer to be about 8 hours. Even though military grade electronics are only specified for operation to $125^{\circ} \mathrm{C}$, most military components can be used at $138^{\circ} \mathrm{C}$ if a slight degradation in the specifications can be tolerated.

All of the circuit designs used in the televiewer were tested in an oven for proper operation at $138^{\circ} \mathrm{C}$. All of the circuits inside the dewar were laid out on $1-3 / 4$ inch wide printed circuit boards. The printed circuit board realization was found to be much more reliable than the original point-to-point wiring technique used in the original televiewer. Circuits were redesigned to minimize power consumption, increase reliability over the temperature range, and reduce volume. Figure 26 shows the five P.C. boards which contain all of the circuitry in the dewar with the exception of the step attenuator and two large capacitors. This circuit realization represents a two to one reduction in size and volume occupied in the dewar.

The downhole electronics of the televiewer can be grouped into three major categories: 1) circuitry associated with the generation and conditioning of the acoustic signals, 2) circuitry for generating the horizontal synch signals, and 3) circuitry for converting power delivered from the surface to useable noise free voltage levels. Communication with the surface is performed with a seven conductor logging cable. Some of the wires in the cable perform double functions by carrying both $A C$ and $D C$ signals. 

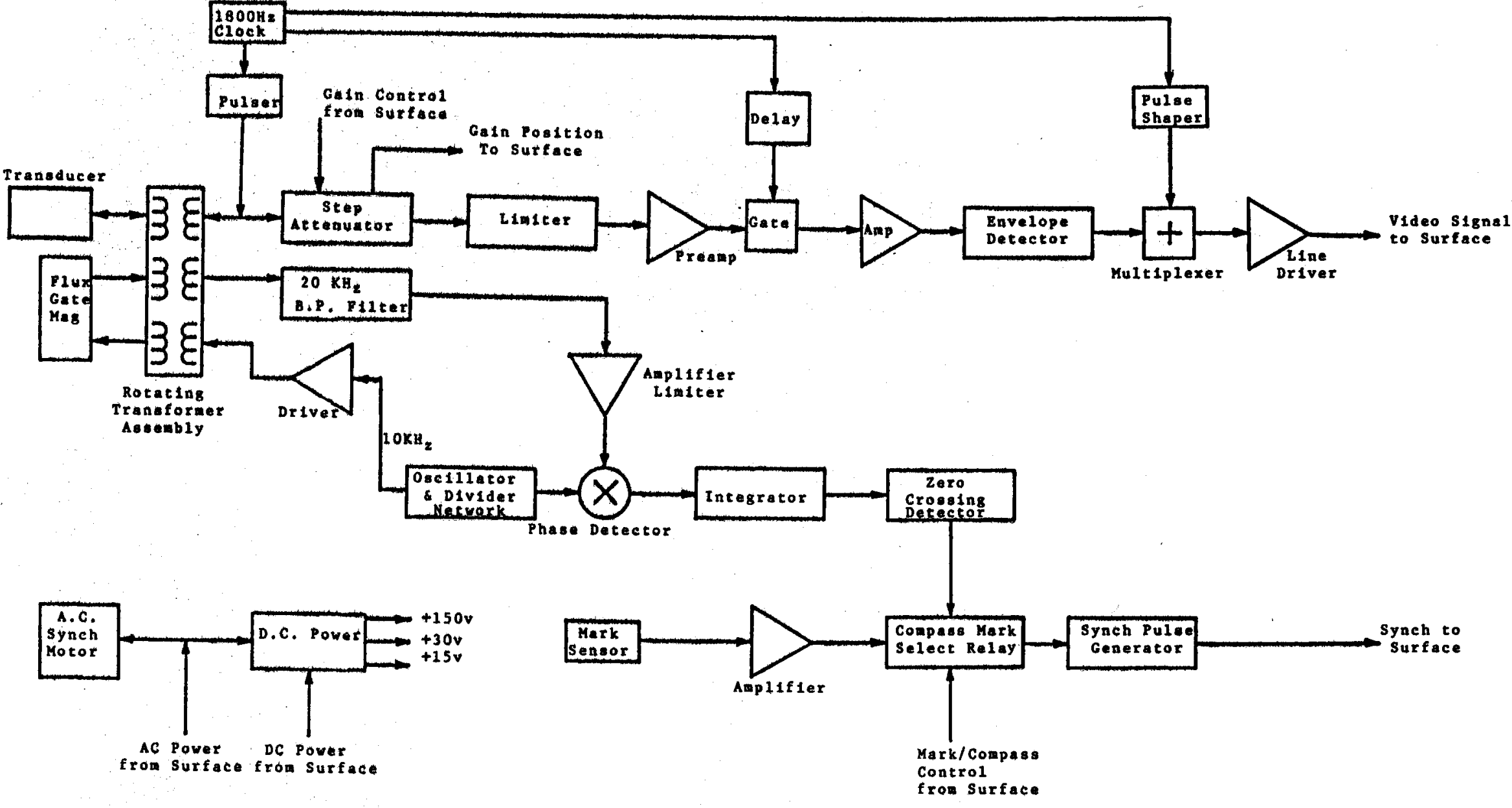

frov surface from Surface

from Surface

Figure 25, Block Diagram of Downhole Electronics 


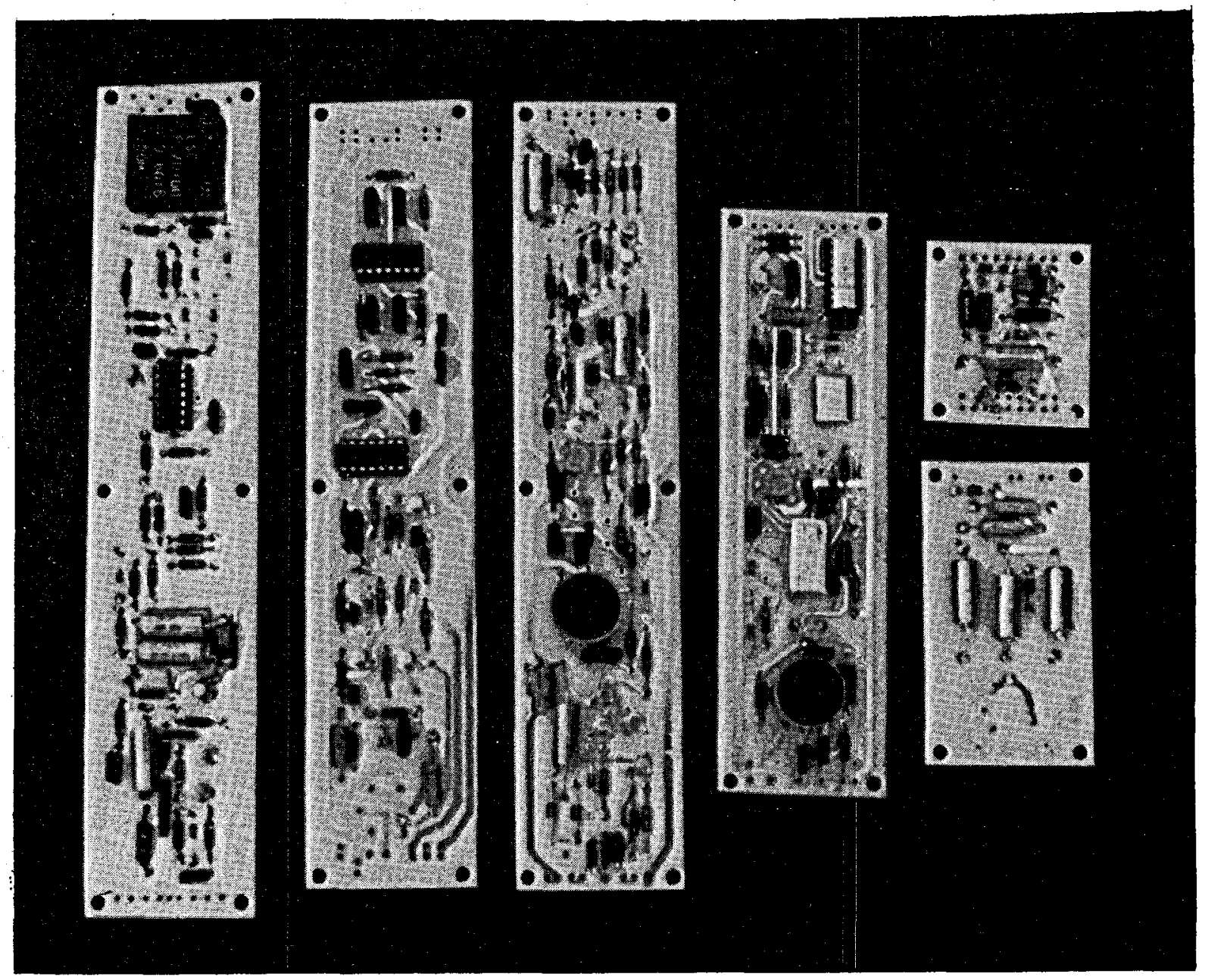

Figure 26. BHTV P.C. Boards

The acoustic pulse is generated by exciting a piezoelectric transducer at its resonance with a large amplitude $1.3 \mathrm{MHz}$ decaying sinusoid. This excitation is developed by an SCR-controlled capacitor discharge pulser circuit similar to the one shown schematically in figure 4. The pulser circuit is triggered at an 1800 $\mathrm{Hz}$ rate determined by the CMOS clock circuit. The energy from the pulser is coupled to the transqucer by one of the rotary transformers. When the acoustic pulse is reflected by the borehole wall and returned to the transducer, the low amplitude burst of $1.3 \mathrm{MHz}$ energy is coupled through the rotary transformer in the opposite direction to a step attenuator circuit made up of a 10 position stepping switch which is controlled from the surface. One of the two decks of this switch forms a resistive voltage divider to attenuate the transducer signal in $6 \mathrm{~dB}$ steps before it enters the limiter and preamp. The other deck divides a $D C$ voltage and sends it to the surface as an indication of switch position or downhole gain. 
Since the output to the step attenuator contains both the large amplitude pulsing signal and the low amplitude reflected signal, a limiter is used to keep the pulsing signal from saturating the preamp. The limiter is composed of two back-to-back parallel diodes to clip the pulsing voltage and allow the reflected signal, which is below the limit level, to pass unaltered. A gate is placed after the preamp to eliminate that portion of the pulsing voltage that gets through the limiter. The signal coming out of the gate should consist of only the reflected signal.

The reflected signal leaving the gate is amplified again and passed through an envelope detector. Since bandwidth of the logging cable is limited, it is not possible to send a $1.3 \mathrm{MHz}$ signal to the surface. The envelope detector is composed of diodes and a low-pass filter to strip the $1.3 \mathrm{MHz}$ carrier and pass a video signal whose amplitude corresponds to the envelope of the reflected $1.3 \mathrm{MHz}$ pulse.

A time reference is needed for surface panel caliper and gating circuitry. A pulse is derived from the $1800 \mathrm{~Hz}$ clock, which corresponds to the time the transducer is pulsed. This pulse is added to the video signal to form the composite video signal.

The composite video signal is applied to the cable for transmission to the surface by a line driver. Since the distributed capacitance of the cable may be on the order of tens of picofarads per foot and cable lengtins of up to 25,000 feet must be accommodated, a low output impedence push-pull amplifier is used as a driver.

As mentioned previously, two types of horizontal (rotational) synch pulses are generated by the tool. When the televiewer is operated in an open hole the norizontal syncin is derived from the magnetometer or compass pulse. When the tool is used in a cased section of borenole, the magnetic casing locally disturbs the earth's magnetic field and makes magnetometer operation erratic. When this happens, the horizontal synch is derived from a housing reference pulse called a mark pulse. The selection of compass or mark mode is made from the surface by toggling the latching compass/mark select relay with an electrical signal. This 
selects either the output of the magnetometer circuitry or the output of the mark sensor circuitry to trigger the synch pulse generator, which develops and transmits the horizontal synch pulse to the surface.

The mark sensor is a stationary magnetic pickup composed of a coil wound around a permanent magnet core. A disc with a magnet imbedded in it is coupled to the motor drive shaft. As the disc is rotated, the magnet passes by the pickup once for each revolution of the transducer, which generates a pulse each time the magnet passes it. This pulse is amplified and applied to the input of the compass/mark relay. When the compass/mark relay is in the mark position the leading edge of this pulse triggers the synci pulse generator, which generates the horizontal syncin.

The compass pulse is generated by the flux gate magnetometer and its associated drive and processing circuitry. An oscillator and CMOS divider network is used to generate $10 \mathrm{KHz}$ and $20 \mathrm{KHz}$ phase locked square waves. The $10 \mathrm{KHz}$ square wave feeds a driver circuit which provides the saturating drive current to the flux gate magnetometer tinrough a rotary transformer. The output voltage from the sense winding of the magnetometer is coupled through a rotary transformer to a 20 $\mathrm{KHz}$ band pass filter. This filter will block the higher narmonics of the sense voltage waveform so that a sine wave representation is obtained. The toroidal core flux gate magnetometer, with series opposing sense windings, eliminates most of the interferring $10 \mathrm{KHz}$ signal due to the saturating flux. However, any asymmetry in position and number of windings on each side causes a small amount of 10 $\mathrm{KHz}$ to appear on the sense winding winich is blocked by the $20 \mathrm{KHz}$ band pass filter. The $20 \mathrm{KHz}$ sine wave output of the filter is passed through a high gain amplifier and limiter, whose output is a $20 \mathrm{kHz}$ square wave. The peak-to-peak amplitude of the square wave goes to zero and the phase reverses $180^{\circ}$ when the transducer passes through magnetic north-south (magnetometer oriented east-west). Tnis signal ana a $20 \mathrm{KHz}$ reterence signal are multiplied in the phase detector and the output is passed through an integrator or low pass filter. The output of the integrator is a square wave whose frequency corresponds to the rotation rate of the transducer. The appropriate edge or voltage transition corresponding to north 
is detected by the zero crossing detector and applied to the compass mark select relay to trigger the synci pulse generator when the compass mode is selected.

All power for the electronics is supplied by the surface panel. The 55 volt, 60 cycle $A C$ powers a high-temperature, two-phase synchronous motor (American Electronics Model 15JG3). The second phase is generated with a 90 degree phase shifting capacitor in the electronics assembly. A voltage doubling circuit and a diode rectifier and filter in the $D C$ power block use the $A C$ current to generate the 150 volt $D C$ high voltage. The 30 volt $D C$ power from the surface is filtered and conditioned in the $D C$ power block to power the remainder of the electronics.

\section{SURFACE PANEL ELECTRONICS}

The surface panel allows the operator to control and monitor downhole conditions and convert televiewer signals into a form necessary to generate the log on a CRT display. The surface panel electronics is in a 9" high rack mountable chassis with front panel controls and meters to monitor voltage levels and currents. A block diagram of the surface panel is shown in Figure 27.

Power supply circuitry contained in the panel converts the line power $(120$ volt $A C, 60$ cycle) to a form useable by the panel electronics and the downinole electronics. Front panel controls and meters allow the operator to adjust the $A C$ and $D C$ voltages and manitor the currents. The compass/mark switch sends a momentary $D C$ positive or negative voltage down a control line to select the horizontal synch mode. The borenole gain step circuit sends a momentary DC voltage to the step attenuator to set the downinole gain.

The composite video signal from downinole is composed of two pulses: 1) a trigger pulse marking the time the transducer is pulsed, and 2) the lower amplitude video pulse derived from the $1.3 \mathrm{MHz}$ reflected acoustic signal. Many times, this composite video signal may contain video pulses derived from signals resulting from multiple reflections (i.e., transducer to wall to transducer to wall and back to transducer). The composite video signal feeds an amplifier, the gain of winich is controlled by the trigger sensitivity potentiometer on the front panel. This sets a level for triggering a monostable multivibrator (single shot) with the trigger pulse on the composite video signal. This single shot (trigger 

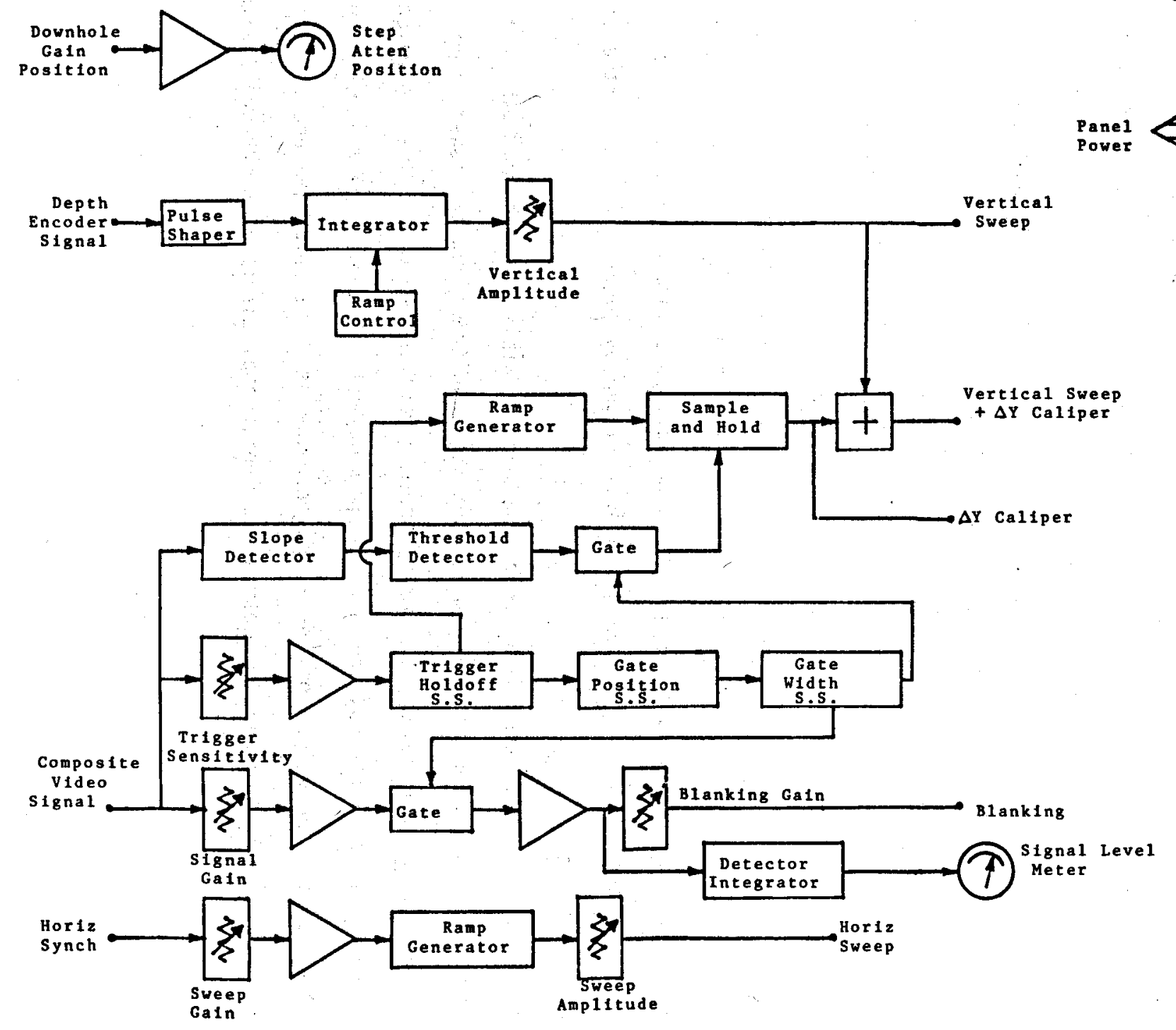

SI

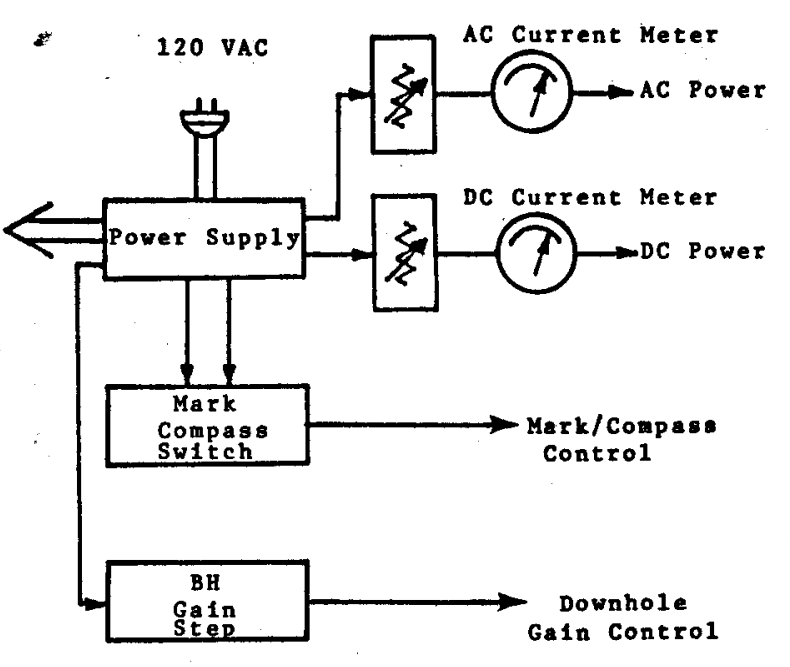

Figure 27. Block Diagram of Surface Panel Electronics 
holdoff single shot) is set for a delay slightly less than the period of the 1800 $\mathrm{Hz}$ pulse repetition rate, and is not retriggerable until this delay times out. Once triggered by the trigger pulse it cannot be retriggered by the reflected video pulse until the set delay times out. Soon after the set delay times out the next trigger pulse arrives to initiate another cycle. Two more single shots follow the trigger holdoff circuit to adjust the position and width of a gating pulse. These single shots have front panel controls so the operator may adjust the position of the gating pulse relative to that of the trigger pulse and control the gate width.

The composite video signal also feeds an amplifier with a front panel potens tiometer adjustment labeled "signal gain." The output of this amplifier feeds a gating circuit controlled by the gating pulse mentioned above. This gating pulse is positioned to overlap the reflected video pulse so the trigger pulse portion of the composite video signal is eliminated. The width of the gating pulse is adjusted to accommodate the entire reflected video pulse but eliminate video pulses due to multiple reflections. This video pulse is amplified again and output to a connector on the front panel through an attenuator labeled "blanking gain." The pulse is called the blanking signal at this point since its function is to control the intensity or blank the CRT beam. The output of the amplifier ahead of the blanking gain control is also appliea to a detector and integrator to drive a signal level meter for an indication of changes in the average amplitude of the reflected return signal.

The horizontal synch pulse from downhole is amplified and applied to the trigger input of a ramp generator which outputs a voltage that increases linearly with time until it is reset to zero by another horizontal synch pulse. A potentiometer front panel control labeled "sweep gain" sets the effective trigger level for the reset. The output of the ramp generator is a sawtooth voltage which is applied to the CRT to sweep the beam in the horizontal direction syncinronous with the transducer rotation. The sweep amplitude potentiometer allows the operator to adjust the width of this sweep. 
The downhole gain position signal is a $D C$ voltage sent to the surface for monitoring the position of the step attenuator. This voltage is amplified and applied to a front panel meter.

All logging trucks derive an indication of tool depth by different schemes of counting revolutions of a pulley wheel over which the cable passes. Most logging trucks use an optical system, where a clear glass disk with black lines on it is coupled to the pulley. The disk is placed between an optical source and detector so that as the disk rotates the lines interrupt a beam of light. This generates a certain number of pulses per foot as the cable passes over the pulley wheel. The depth encoder signal is the direct output of this optical depth measuring system. This signal is brought into the surface panel where it undergoes some conditioning in the pulse shaper before it is applied to the input of an integrator. Each pulse causes the integrator output voltage to increase a small amount in a ramping fashion to generate a vertical sweep. The block labeled "ramp control" contains circuitry for adjusting the rate of integration (volts/pulse), and a reset signal when a section of the $\log$ is complete on the CRT screen. When the televiewer log is recorded on film with a camera, the ramp is started when the shutter is opened and concluded when the shutter is closed. A contact closure in the camera is used by the ramp control circuitry to reset the integrator. The vertical amplitude front panel potentiometer allows the operator to set the vertical sweep height.

The Sandia surface panel originaliy contained circuitry for acoustic caliper measurement at four points, 90 degrees apart around the borehole. Sandia replaced this circuitry ana instead opted for a continuous acoustic caliper of 600 points (1800 pulses/sec at 3 revolutions/sec). The signal necessary for accomplishing this is a continuous voltage, proportional to the travel time of the ultrasonic pulse from the transaucer to the borehole wall and back as the transducer rotates. This signal is called the $\Delta Y$ caliper signal.

The $\Delta Y$ caliper signal is generated by starting a ramping voltage at a time corresponding to the time the transducer is pulsed and sampling this ramp voltage when the reflected signal return is detected. This sampled voltage is held until the reflected signal return arrives in the next cycle. The voltage out of the 
sample and hold will then vary as the depth of features on the borehole wall vary. The composite video signal feeds the block labeled "slope detector" which is a differentiator circuit which generates a signal proportional to the rate of rise of the voltage on its input. This signal is applied to a threshold detector which generates a pulse coincident with the leading edge of the reflected video pulse. This pulse is passed through a gate controlled by the same gating pulse used to generate the blanking signal. This gate eliminates unwanted pulses which are due to the presence of the trigger pulse and multiple reflection pulses on the composite video line. The output of the gate controls the sample and hold circuit so that the ramp is sampled and held once each cycle at the time of arrival of the reflected video pulse. The ramp generator is reset by the output of the trigger noldoff single shot.

The caliper $\log$ is formed by using the combination of the vertical sweep plus $\Delta Y$ caliper signals to drive the CRT vertical circuits. The blanking signal is removed from the CRT and the intensity is adjusted to make the beam visible. The result is a display similar to that of Figure $3(b)$.

\section{MECHANICAL DESCRIPTION}

Figure 28 is an artist's drawing of the Sandia borehole televiewer with a cutaway view of the rotary mechanism (above) and the electronics assembly (below). The tool has a nominal 00 of $3-1 / 2$ inches and is about 16 feet long including centralizers top and bottom. The logging cable is attacined to the tool at the top of the upper centralizer.

The electronics is mecnanically protectea by the 3-1/2 incies stainless stee 1 pressure housing. Inside the housing is a stainless steel dewar vessel to thermally shiela the electronics from the nign borenole temperature. The devar is made up of two concentric thin wall stainless steel tubes. End plates are welded to both the inner and outer tubes on one end. A ring is welded at the otner end to form the mouth of the dewar. The annulus betwieen the inner and outer wall is insulated witn layers of aluminum separated by glass fibers and high vacuum. Further details of dewar construction are available in the literature. 19 


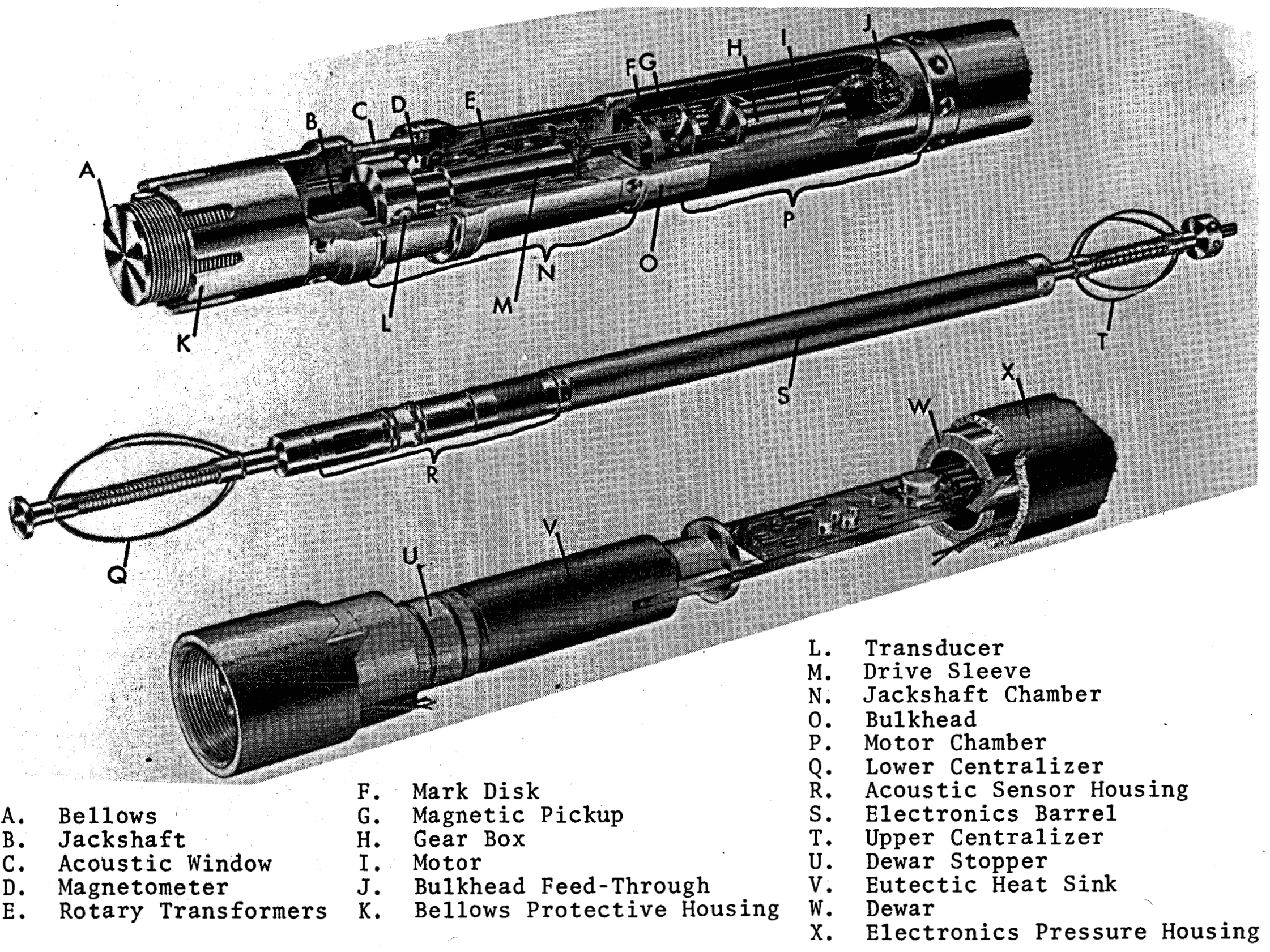


The stopper for the dewar is made of an insulation material called Marinite (Johns-Manville Construction Materials). Low thermal conductivity nickel wire is run through the center of the stopper to carry electrical signals with minimum neat loss.

A eutectic heat sink material called Cerrotru (Cerro Metal Products) is used to absorb the heat in the dewar. This eutectic alloy (58\% bismuth, $42 \%$ tin) which melts at $138^{\circ} \mathrm{C}$, absorbing a large amount of heat in the process, essentially acts as the "ice" in the dewar. About $40 \%$ to $50 \%$ of the heat gain is through the stopper and along the inner wall at the mouth of the dewar. ${ }^{20}$ for this reason, most of the eutectic is placed at the open end and an aluminum tube lining the inner wall is used to distribute the heat more evenly and eliminate hot spots.

The electronic printed circuit boards are attached to two aluminum rails winich run the length of the dewar between the heat sinks as shown in the figure.

The rotary mechanism housing portion of the tool is filled with a high temperature oil (Mobil jet 0il II) to lubricate the moving parts and efficiently couple energy from the transducer to the window. The heating of the Mobil Jet 0il II produces a discoloration which was originally thought to be a decomposition. Samples of the discolored oil were examined and compared to unexposed oil using an Infrared Spectrophotometer and were found to have identical IR spectrums, indicating no chemical breakdown of the oil. It was also considered that discoloration could be due to suspended carbon particles, but when the sample was centrifuged none could be found. Based on this testing, the Mobil Jet 0il was felt to be adequate for operation at $275^{\circ} \mathrm{C}$.

Since the acoustic window is not designed to operate with a pressure differential across it, a metal bellows is mounted at the bottom of the rotary mecinanism housing to equalize the pressure inside the housing with that of the borehole. To accommodate expansion of the $0 i 1$ up to a temperature of $275^{\circ} \mathrm{C}$, the protective housing covering the bellows was lengthened to allow more room for bellows extension.

The rotary mechanism housing contains two chambers. The upper chamber contains the motor and magnetic pickup. The lower chamber contains the rotary trans- 
formers, magnetometer, and transducer. The electronics housing is separated from the rotary mechanism housing by a pressure bulkhead with 10 electrical feedthroughs to carry electrical signals and motor current. The motor is mounted below the pressure bulkhead attached to a 10:1 gearbox which divides the 1800 RPM motor output down to the required 180 RPM ( 3 revolutions/sec). The gearbox output shaft has the mark disc attached to it below the magnetic pickup. This disc was originally made of a magnetic steel with a slot in it. As the slot is rotated by the magnetic pickup a puise is generated. It was found, however, that the sensitivity of the magnetic pickup could be improved by replacing the slotted disc with a non-magnetic bronze disc containing an imbedded permanent magnet.

The lower chamber of the rotary mechanism housing is supported by a threaded jackshaft running through the center. This keeps the weight of the lower centralizer and bellows housing off the fragile acoustic window. The jackshaft is screwed into the assembly below the window and anchored into a bulkhead above the rotary transformer assembly. Small noles are drilled in this bulkhead for electrical wires and to allow fluid and pressure communication between the two chambers. Motor rotational power is coupled through this bulkhead by an offset shaft and gear linkage to a drive sleeve which rides over the jackshaft. The transducer nolder, magnetometer, ana the rotors of the rotary transformer set are mounted on this drive sleeve. The stator assembly is bolted to the bulkhead and aligned with the jackshaft and drive sleeve.

Three types of bearings were tried between the drive sleeve and jackshaft surface: 1) Vespel, 2) Teflon, ana 3) 0ilite (oil impregnated bronze). The Vespel bearings supplied with the tool were discarded because of Vespel's limited mecnanical stability atter exposure to temperatures up to $275^{\circ} \mathrm{C}$. The Teflon bearings expanded quite a bit, tending to create excessive drag at high temperature. The expansion coefficients of the 0ilite bearings are close to that of the jacksnaft and drive sleeve, and by maintaining reasonable clearances the drag problem was eliminated.

It was also found that the higher lengthwise expansion of the aluminum drive sleeve caused it to wedge itself between the two surfaces at the ends of the jack- 
shaft and stall the motor. This problem was corrected by increasing the clearance between the drive sleeve and the bulkhead surface.

Almost all elastomeric 0-ring materials suffer thermochemical degradation in geothermal brine at high temperature. ${ }^{21}$ Metal seals, the alternative to elastomeric seals, require special surfaces and complicated assembly procedures. Since some users have reported some success ${ }^{22}$ with viton seals if they are replaced after each run into a geothermal well, Sandia chose to use Viton 0-rings (Parker Seals V-709-80) in the televiewer.

An 0-ring failure was experienced in a field test at the Los Alamos National Labs Fenton Hill site. This O-ring was on one of ten Alberox high pressure bulkhead electrical feedthroughs and had been temperature cycled several times without replacement. Figure $29(a)$ shows the feedthrough and its sealing configuration. Because of the difficulty involved in replacing each of the 0-rings on the ten feedthrougins, an alternative sealing configuration was devised (Figure 29b). The pressure bulkhead was redesigned to accept $1 / 16$ inch NPT pipe plugs with selfsealing tapered threads. The threads on the feedthrougins were machined off and holes were arilled in $1 / 16$ inch NPT pipe plugs to accept the modified feedthrougins. The feedtnrougins were then inserted into the holes in the plugs and silver soldered in place. This tapered tinread makes a good high-pressure seal as long as the feedtinrough assemblies are not removed and replaced often enough to wear down the threads. Once the feedtnroughs are in place there should be no reason to remove them.

Anotiner 0-ring seal failure occurrea during a laboratory test. This was an 0-ring at the upper eno of the electronics pressure barrel that failed after about seven hours of high temperature operation. This kind of failure can only be avoided by using a better 0-ring material than Viton. Recently an elastomeric compound developea by L'Garde Inc. called Y267 EPDM has been shown through laboratory and field testing to be a much superior 0 -ring material. ${ }^{23}$ It is recommended that this compound be used for the televiewer seals as soon as it becomes commercially available. 


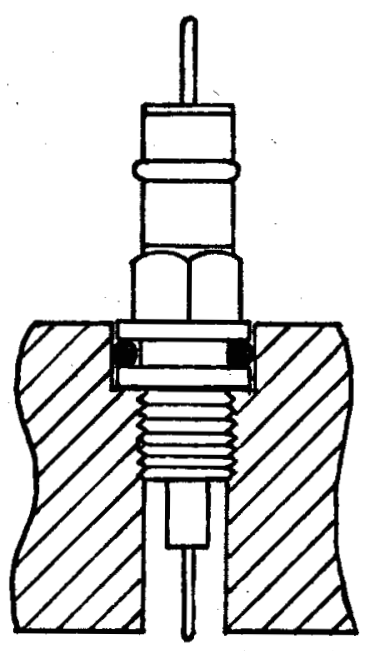

(a)

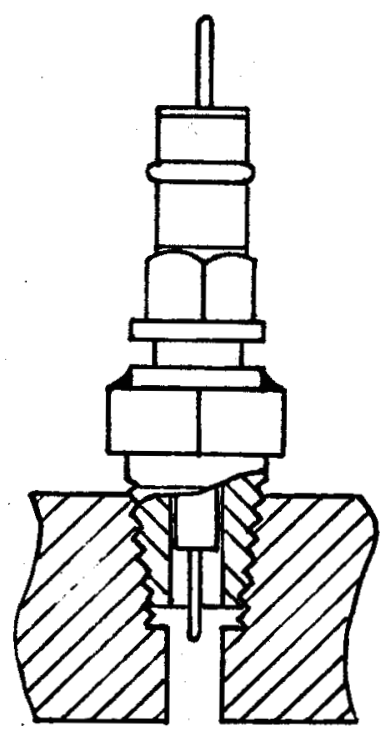

(b)

Figure 29. Alberox Bulkhead Feed-Throughs

(a) original sealing configuration

(b) redesigned sealing configuration 


\section{TESTING}

Three types of testing were performed in the Sandia high temperature televiewer development program: 1) component level, 2) subassembiy level, and 3) system leve1. Component level tests were performed very early to identify possible problem areas. Subassembly level tests were performed on the rotary mechanism and electronics subassembly. The component and subassembly tests were performed in small autoclaves and ovens. With each test, problems were identified and corrected. The tests were repeated until proper operation was obtained with high confidence. Once successful subassembly level tests were completed, system level tests were performed on the composite tool in the field in an actual geothermal environment and in the lab under controlled conditions of temperature and pressure. The results of these system level tests are described in the following text.

\section{Field Test LANL EE2, December 1980}

The first field test of the Sandia televiewer was conducted at the Los Alamos National Labs (LANL) Fenton Hill site in northern New Mexico. This was a joint field test in cooperation with the USGS, water Resources Division, and Los Alamos National Laboratories. The purpose of the test was to further identify problem areas associated with the operation of the televiewer in a geothermal environment.

On December 3, 1980 the televiever was run in the EE2 well for 4 hours reaching a maximum depth of 10,500 feet. The signals looked good and some pictures were taken of the inside surface of the casing. At a depth of 10,500 feet the synchronous motor stalled. Raising the tool 100 to 200 feet caused the motor to recover but lowering it back down caused it to stop again. The tool was pulled out of the hole still operating and was disassembled to determine the failure mechanism. Upon examination of the motor and gearbox assembly, an indication of rubbing of the mark sensor on the orientation disk was found. This appeared to have been caused by a loose bearing on the gearbox output shaft.

The gearbox with the loose bearing was replaced and the tool was run into the well again on December 15. Once again, the tool operated well on the way down until at 11,100 feet, at a temperature of about $225^{\circ} \mathrm{C}$ and pressure of $5500 \mathrm{psi}$, 
the motor stopped and could not be restarted. Soon afterward, the video signal was lost and some electrical lines appeared to be shorted. When the tool was brought to the surface it was found that an 0-ring seal on one of the high pressure bulknead feedthroughs had failed, allowing oil from the rotary mechanism to be forced under high pressure into the electronics housing. This caused the acoustic window to collapse around the transducer and stall the motor. When the pressure differential rose enough to puncture the window, water entered the tool and sinort-circuited the electronics. To eliminate this failure mode, the sealing configuration of the 10 bulkhead feedthroughs were redesigned as described in the previous section.

Field Test LANL GT2, May 1981

The televiewer was again taken to the LANL Fenton Hill site for testing, this time with a redesigned bulknead feedthrough configuration. Due to the unavailability of the EE2 well, the older GT2 well with a bottom-hole temperature between 180 and $200^{\circ} \mathrm{C}$ was chosen for the test. Several runs were made of the entire open nole section of the well without a single tool failure. A portion of the log obtained is reproduced in Figure 30.

This log was compared to a vertical spinner survey (Figure 31 ) run by LANL personnel in December 1980. Several of the fractured zones on the televiewer log were coincident with zones of fluid in-flow on the spinner survey.

Because of the reduced signal strength of the reflected return, the zone from 8670 to 8685 feet is believed to have a nignly irregular surface. Since the spinner survey shows this to be a heavily producing zone, this irregularity could be erosion caused by the in-rush of water. What appears to be the bottom of two fractures are noted at 8678 feet and 8684 feet dipping to the west. If these are fractures, the upper parts are masked by the erosion. Anotiner fracture dipping toward the west appears at 8750 , but, there is no indication on the spinner survey that this is a fluid producer. Fractures that show on the televiewer $\log$ at 8780 feet and 8795 teet must be producers since they coincide witn increases in fluid flow on tine spinner survey. 



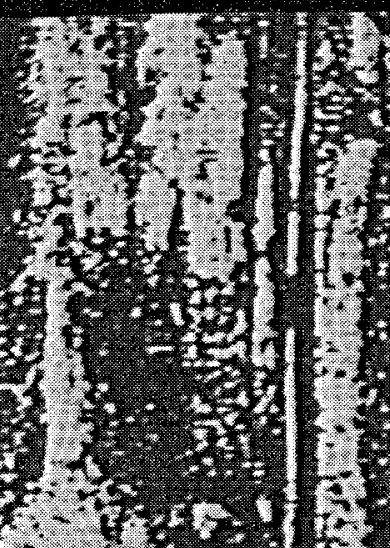

1. 351 is

- $x-1$.

$\left.86500^{5}\right)^{2}$

5.75

- 1 r

- 1 บ

ey.

唡了,

- 5 1)

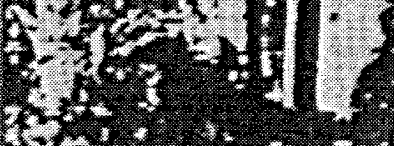

可.

Xis

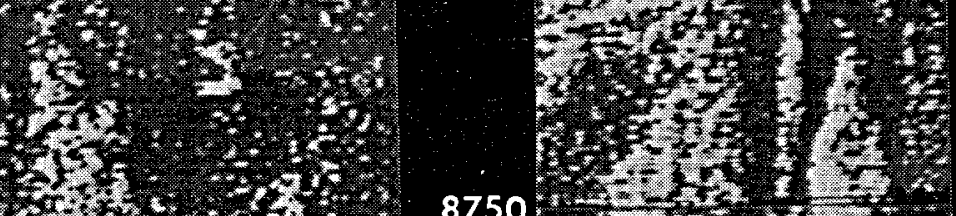

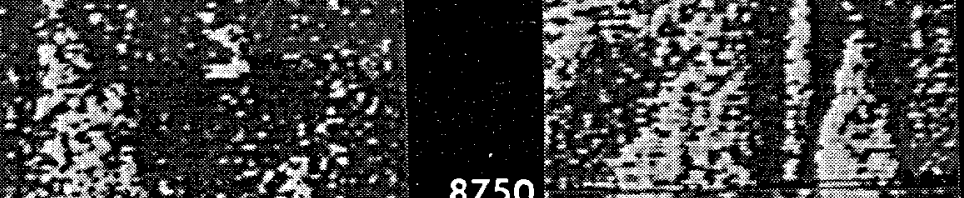

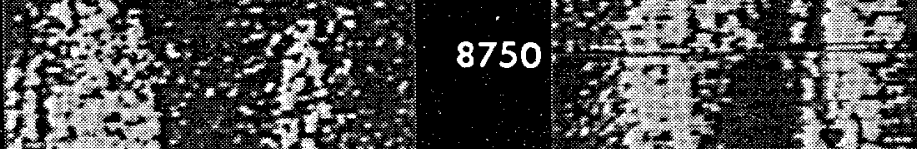

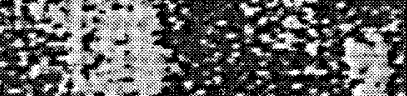

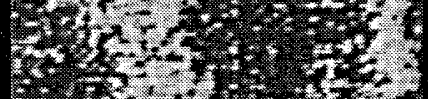

${ }_{8700}=2,5 x-5 x$

;

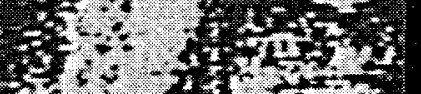

6. 5 , 57 n.t. on is 15

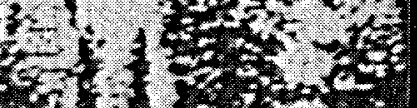
1)

(1) of

$x+5 x^{2}$

桨,

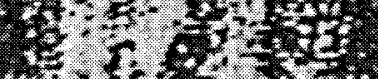

1. Hom 7. 10

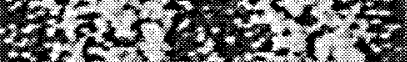

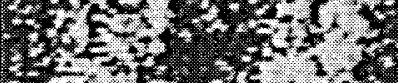

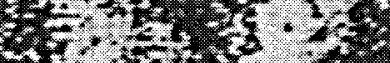
87100,1010 ; n, 30

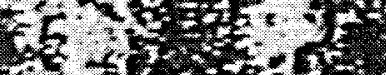
ot 3

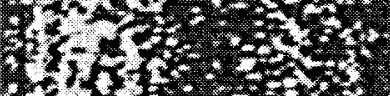
5 35

$4 x^{3}+x^{2}$

13 13:

$\left.y^{2}\right)$

$7,5=$

1 : 15

- 5 5 3)

4 , 310

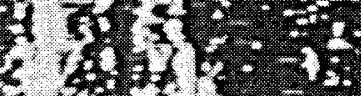

$4)^{2}+5:$

ic ${ }^{3}$, ?

स

\% 3 :

i,

if $x^{2}=$

7. $8,1 \%$

$-7=401 \div$ (4) 52,5

7. 3 : - :

$4+5$

$3 x^{2}, 4$

校

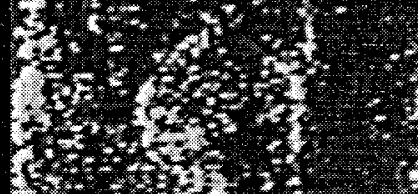

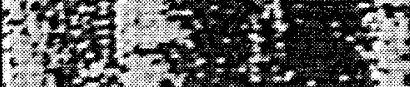

4.

87600753 ;

, b

5,15

20 3 .

7n

等

6)

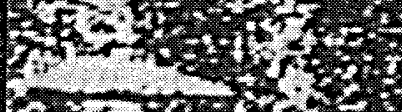

20730 8770



1.

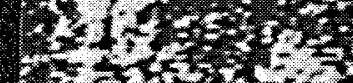

i intifiniti
1.

1, - 7 , at $5>1$

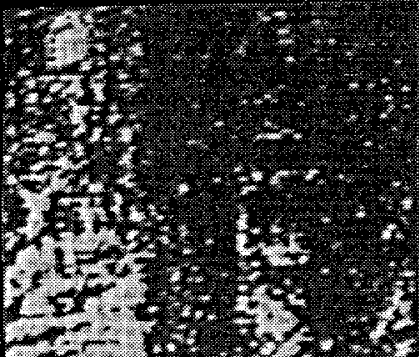

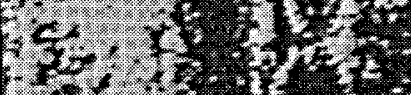

${ }^{8800}-10.450$

and , n

c. . . $35=$

(1) 15

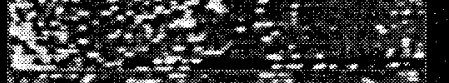

y.t.

at.

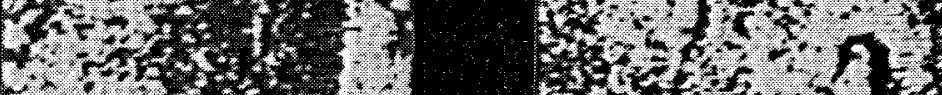

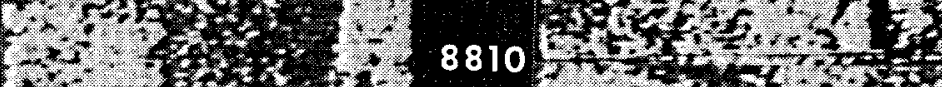

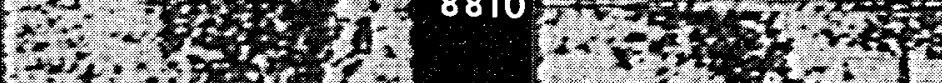

6ring

3. atis 7 .

$4>3,453$

7h, $x+4,5$

ats -1

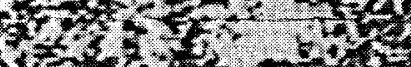

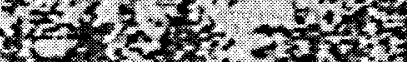

28.5.

- 3,5

4.

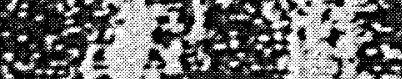

, 15,4

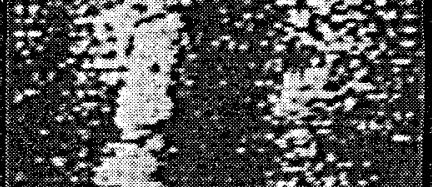

.

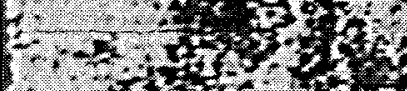
r. 365 sh

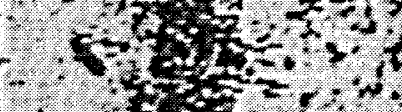

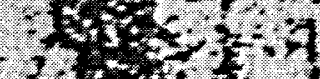
s. rin 3. (fis

a.

T, 35.

2. . . . n

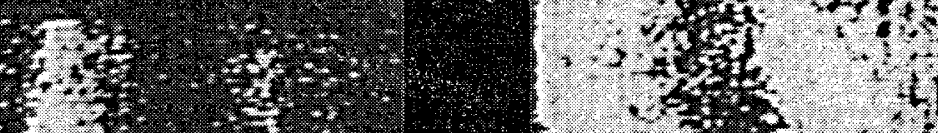

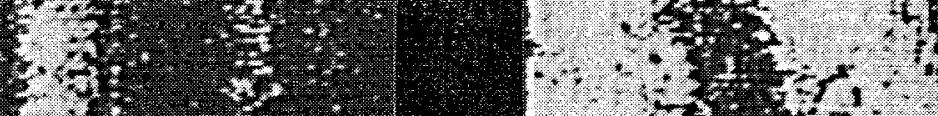

.

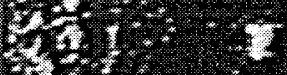

(1)

IX

t)

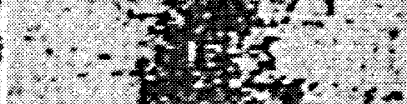

4. 956

$8820 \times x+7 x$

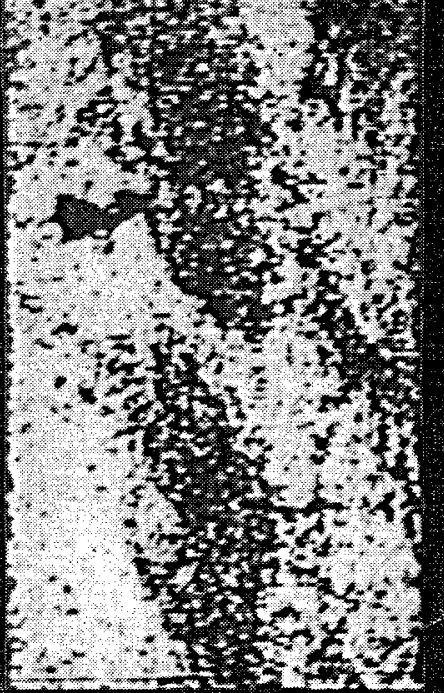



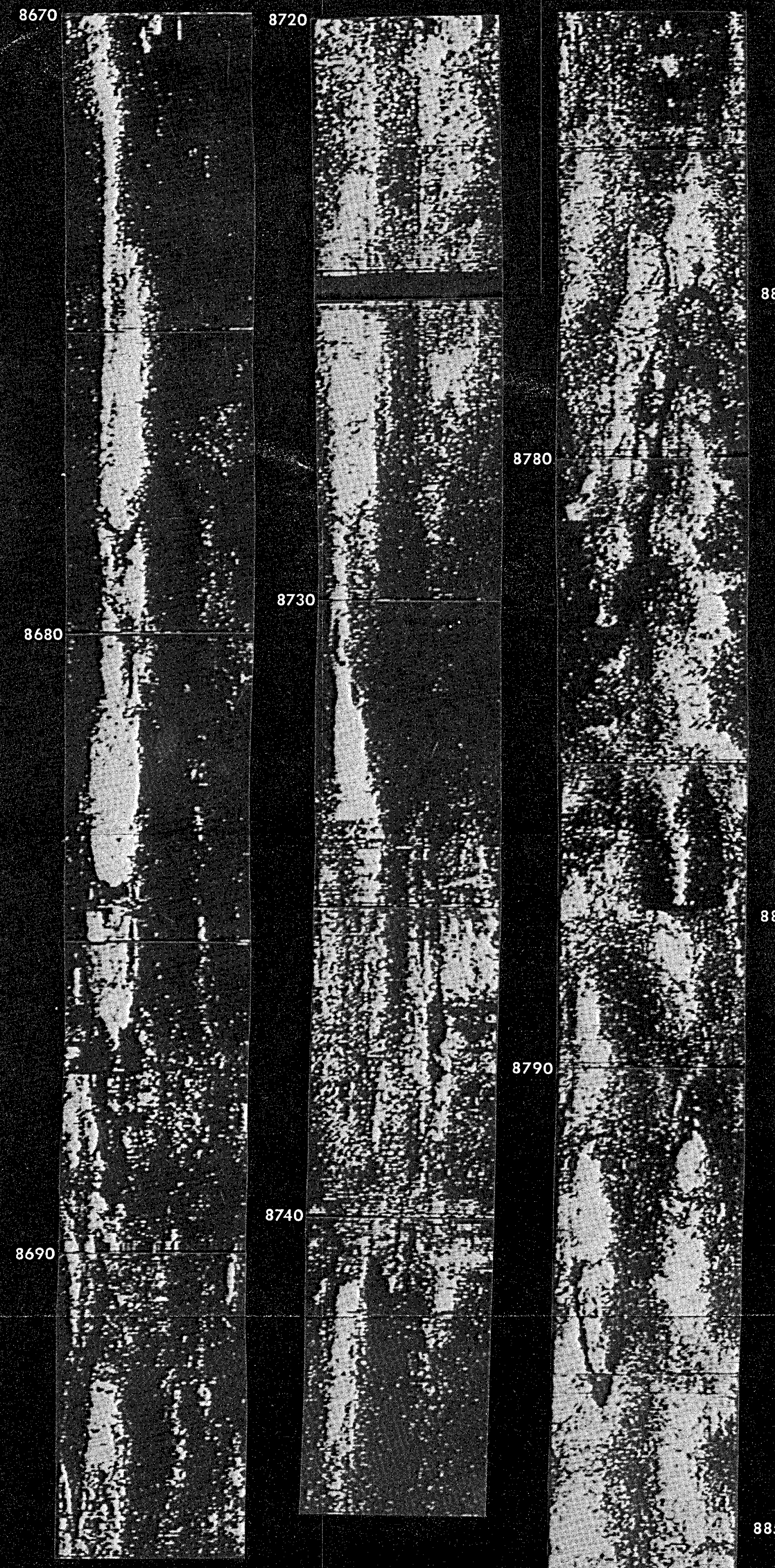

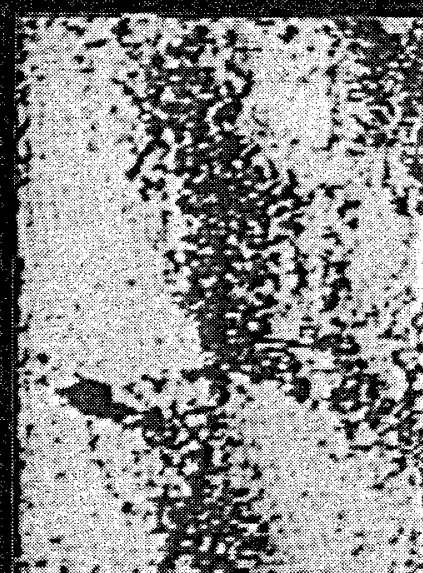

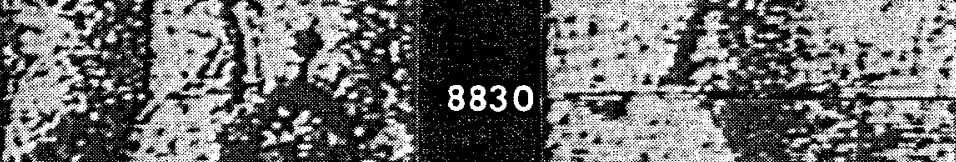

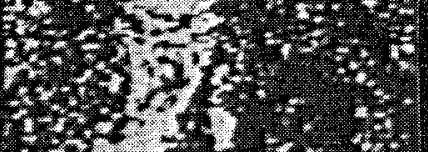

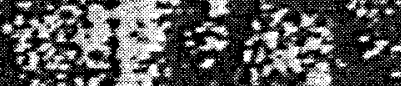
$8,5,3$ 8780 (4) Aly $5 b^{2}=0$

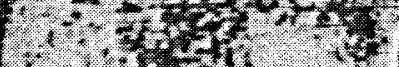
10.0.

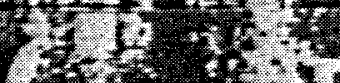

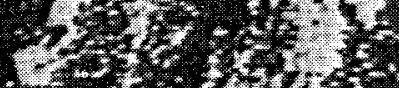
30 $3 y^{3}$ $4 .+3$ S . S

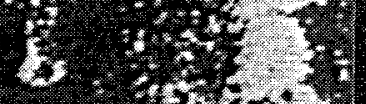
s.

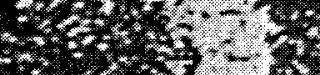

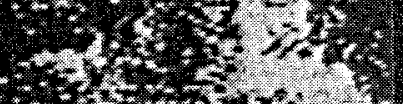
64:

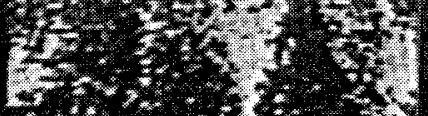

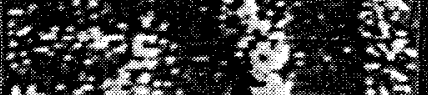

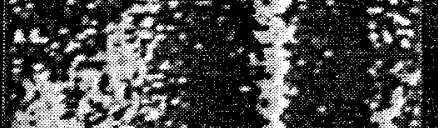
1. 1 . S. n. 175

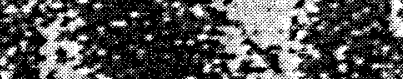
1 in: 1 ,

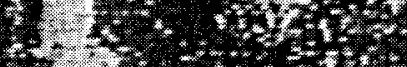
$\frac{y^{2}+1}{3}+5$ 1.20

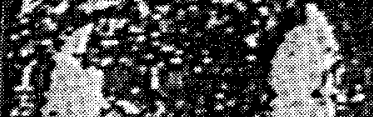
if

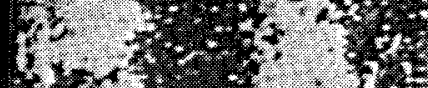
$4 y^{-1}+x^{2}$ 7for. 4 , n, L $12 x$ 1 35 ,

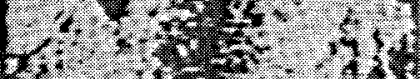
S. 0 (5) $4-3 x^{2}+5 \cdot \frac{1}{3}$

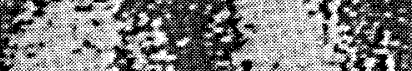
6. mistion 



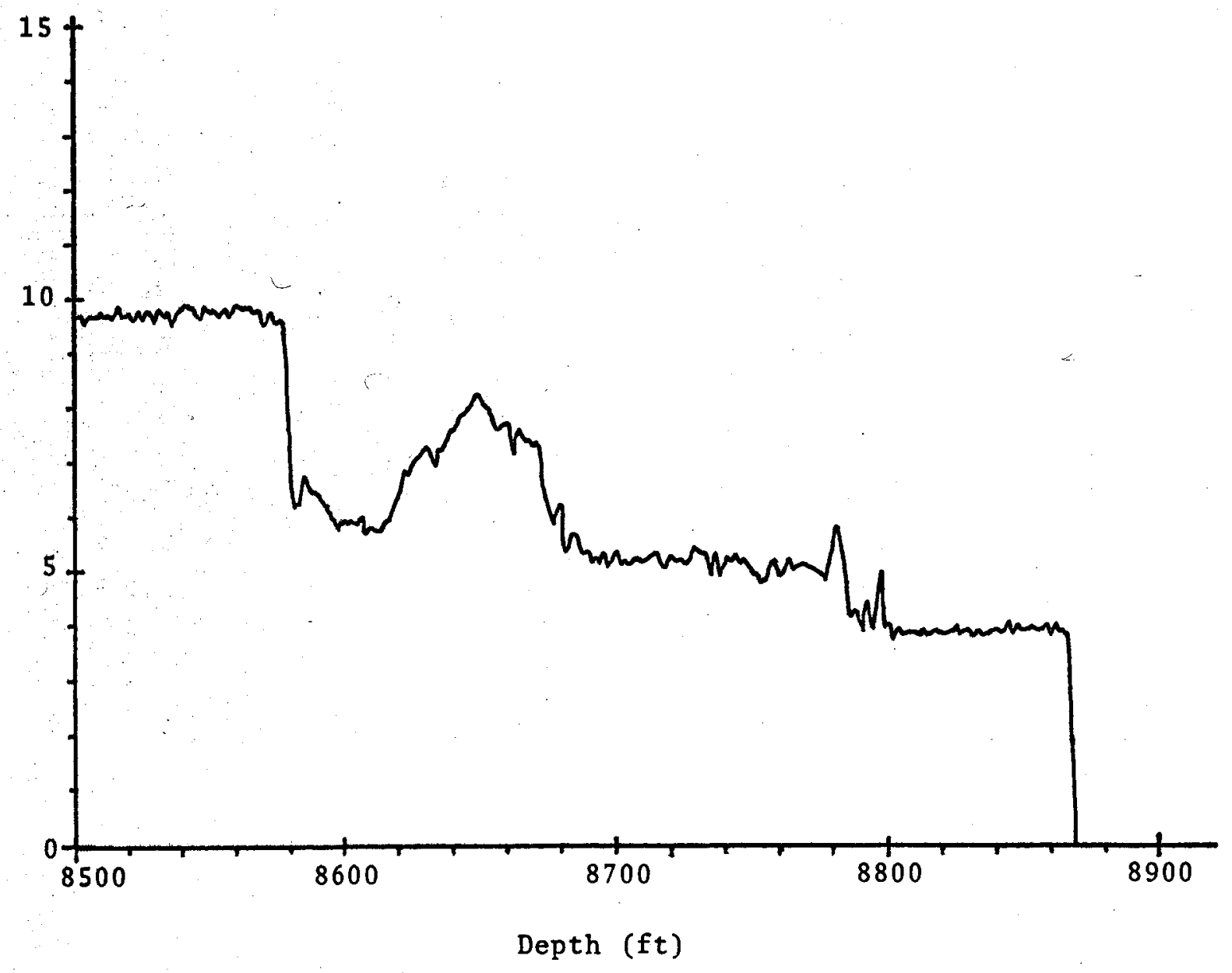

Figure 31. GT-2 Vertical Spinner Survey 12/15/80 
Since the deepest producing fracture is the one at 8795 feet, the zone below that is relatively erosion free, resulting in good reflected signal amplitude and unaltered surface features. There appears to be some sort of periodic pattern on the south side of the wall which is probably drill bit generated. There is a nonproducing fracture at 8840 feet dipping toward the east. Since one would expect naturally occurring fractures in a given formation to be parallel and dip in the same direction, this fracture could be drilling induced.

Field Test Baca 22, August 1981

A field test of the Sandia televiewer was conducted in August 1981 at the Union Geothermal Baca site in the Jemez Mountains of northern New Mexico. This test was performed in conjunction with a stimulation experiment organized by Republic Geothermal Inc. In preparing the well for stimulation, the open hole section was filled with sand while a liner was being cemented into place. After cementing was completed, a smaller bit was run into the open hole section to clean out the sand. This undersized bit apparently left an annulus of sand on the wall. Consequently, when the televiewer was pulled through this section of hole the centralizers would drag and jerk through the sand and the smooth vertical motion necessary to form a readable log could not be achieved. Even though an acceptable log could not be obtained, the televiewer operated without failure for more than 4 hours in a well where bottom-hole temperatures in excess of $260^{\circ} \mathrm{C}$ nad been reported.

Autoclave Test wyle Labs, October 1981

To facilitate the testing and identification of problem areas in a controlled environment, Sandia contracted with wyle Laboratories of El Segundo, California to build a nign temperature, nign pressure autoclave capable of testing tine composite tool in an operating mode viewing a target.

Figure 32 is a diagram of this autoclave. To simplify test vessel design, the cablenead and centralizers are not used by the televiewer during the test. The top end of the electronics barrel is attacied to the top flange througin an adapter assembly with a sealing configuration similar to that used in the centralizer assembly. The wires from the surface panel are fed througin the upper 


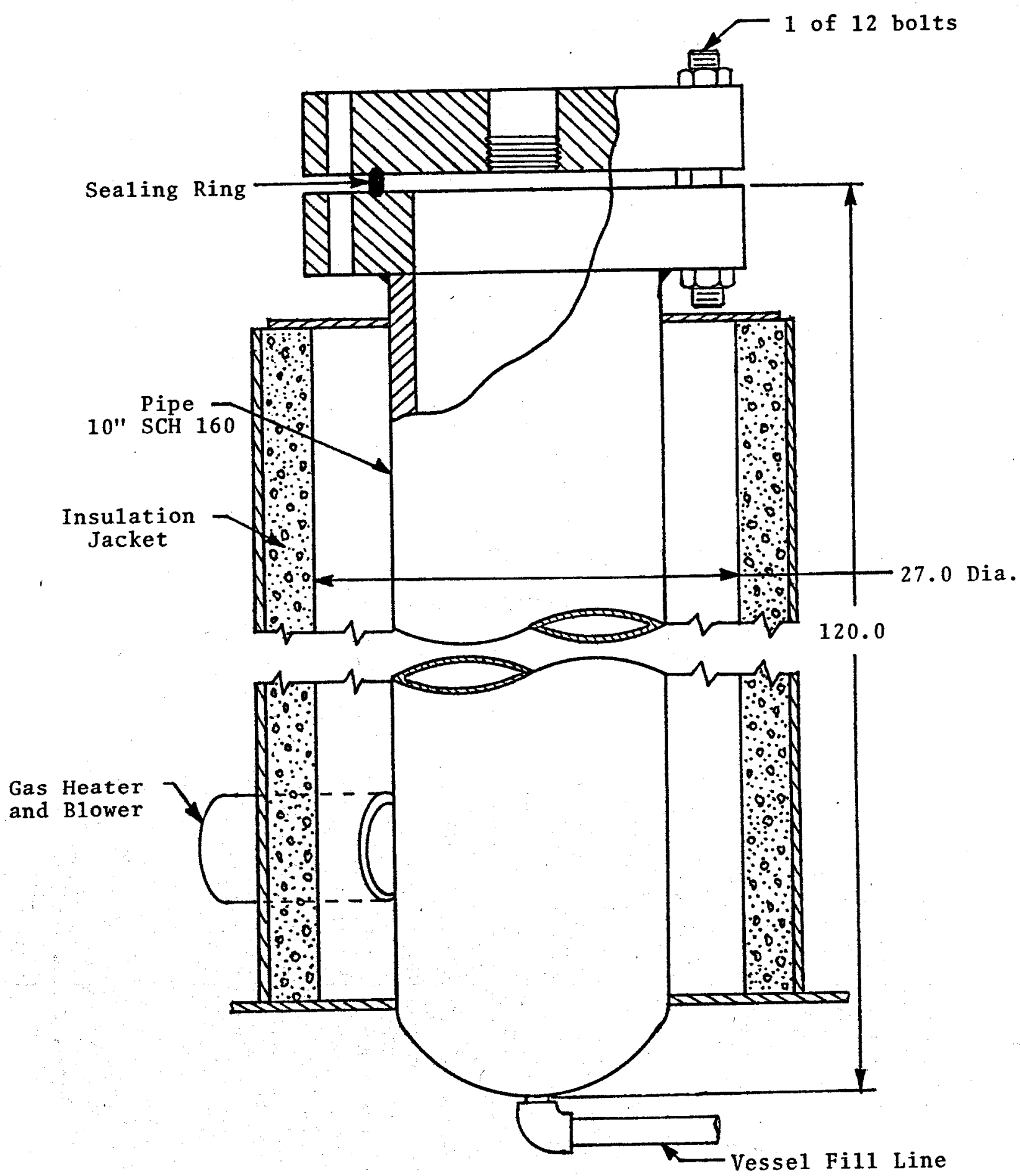

Figure 32. High Temperature/High Pressure Autoclave 
sealing flange and adapter assembly into the electronics barrel. The tool is attached to the top flange so that the axis of the tool is normal to the flange surface. Since the lower flange is normal to the autoclave wall, sealing the autoclave with the flange surfaces parallel would center the tool nicely. However, due to the irregularities in the sealing ring and the very high torques on the bolts needed for a good seal, the flange faces could not be made parallel. This caused very poor centering of the tool in the autoclave, especially near the bottom where the transducer is located.

The target is a 6 inch long stainless steel ring with its OD (outer diameter) in contact with the ID (inner diameter) of the autoclave wall in the vicinity of the acoustic window (Figure 33). It contains 7 groups of notches of varying widths. Notch groups 4 througn 7 each have three notches spaced $.125, .250, .375$, and .500 inch respectively for the purpose of resolution determination.

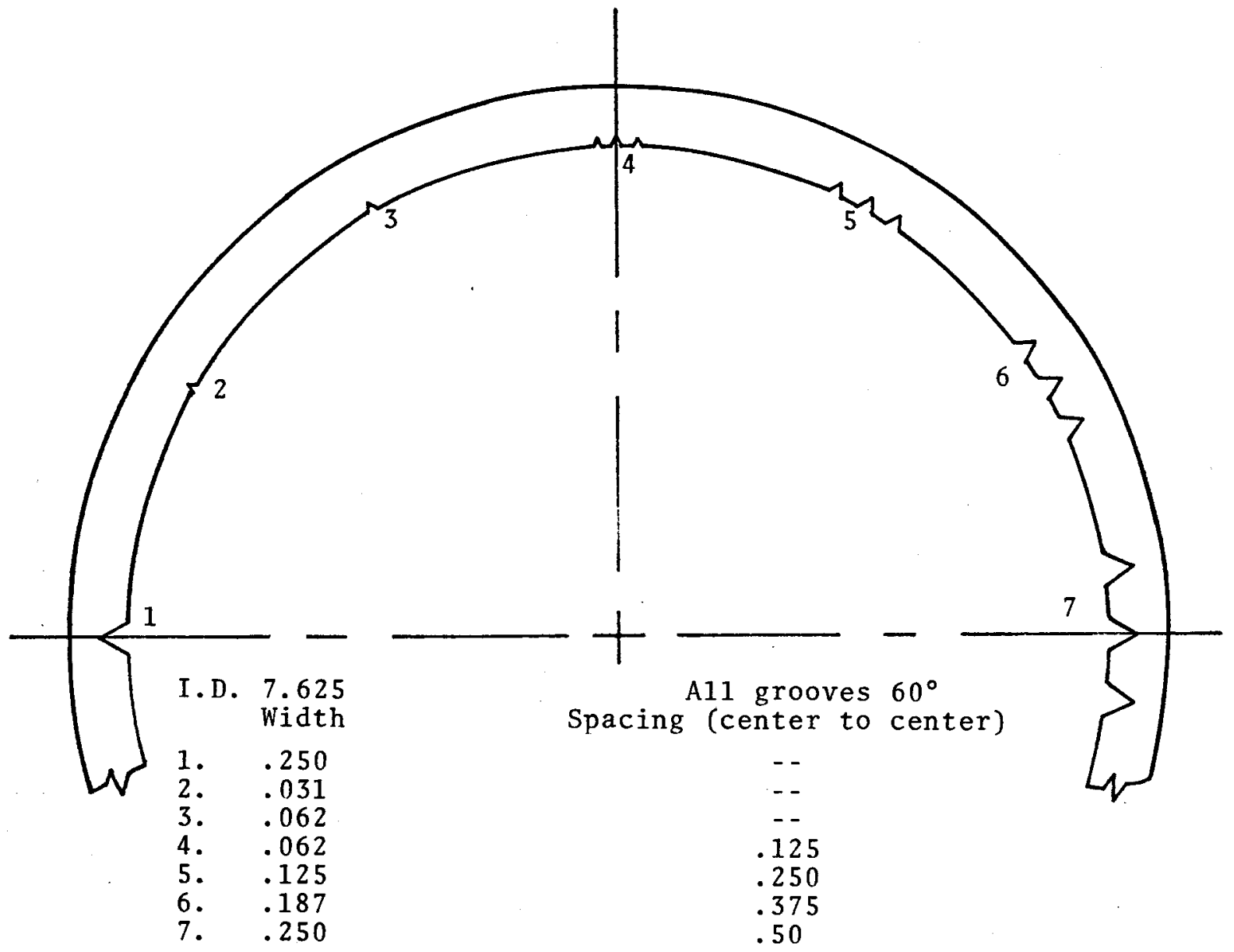

Figure 33. Wyle Autoclave Target 
When the tool is not centered with respect to the target ring, the amplitude of the signal reflected from the target ring and intercepted by the transducer varies with the angular position of the transducer. The oscilloscope pictures of Figure 34 illustrate how the amplitude of the signal received by the transducer varied over a complete revolution in this test. If the tool had been properly centered, the waveform would have been flat across the top with dips in amplitude only where the notches occur. Since the tool is not centered, the amplitude of the reflected pulses appear to be amplitude modulated by a sinusoid of twice the rotation frequency.

It can be seen in the pictures of Figure 34 that in areas where background reflected energy is high (notch groups 1, 2, and 7) the notches tend to scatter energy away from the transducer causing a reduction in amplitude, as is normally the case. However, in areas where background reflected energy is low (notch groups $3,4,5$, and 6) the notcines scatter energy in the direction of the transducer, causing an increase in amplitude.

There appears to be very little change in sensitivity and resolution of the televiewer over the temperature range. In both of these pictures, taken at temperatures of $38^{\circ} \mathrm{C}$ and $280^{\circ} \mathrm{C}$, the .031 inch wide notch can be picked out and the notches with the 0.250 inch spacing can be resolved.

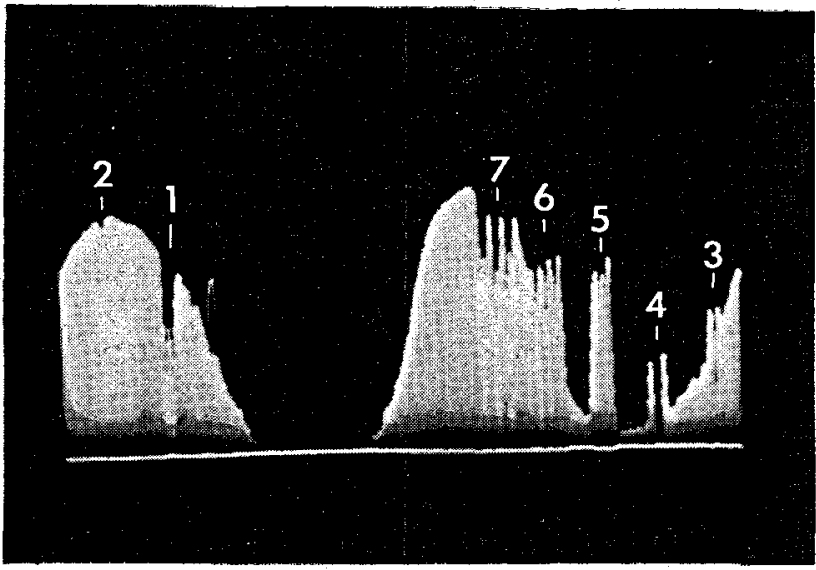

$38^{\circ} \mathrm{C}$

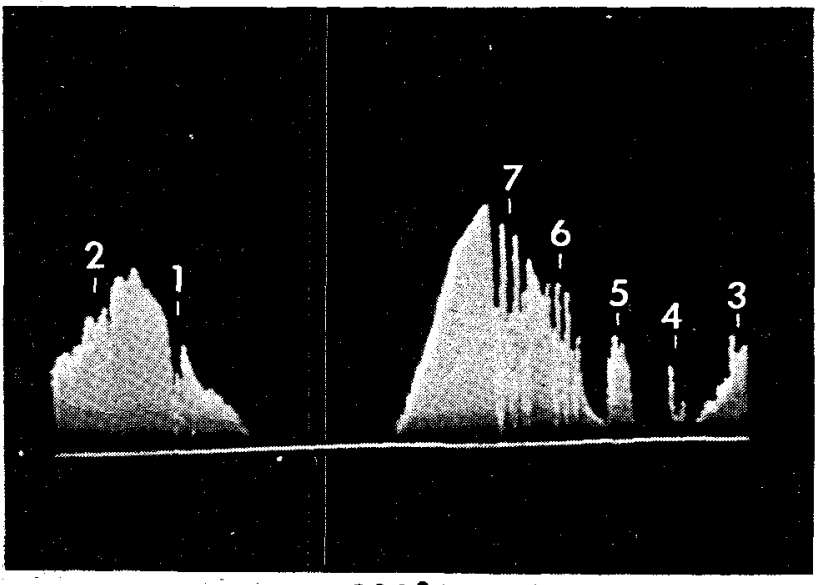

$280^{\circ} \mathrm{C}$

Figure 34. Reflected Amplitude Waveform for One Complete Rotation 
This test lasted about 7 hours with three hours coming up to the temperature of $280^{\circ} \mathrm{C}$ and four hours at temperature. The test was terminated at the end of the seven hours when a Viton 0-ring seal failed, letting moisture enter to short out electrical signals.

It is expected that the next version of the televiewer will use the soon to be available L'Garde EPOM hign temperature 0-ring compound.

Field Test LANL EE2, January 1982

A joint experiment with Los Alamos National Laboratories demonstrated the value of the televiewer as a casing inspection tool. Deep grooving of the inner wall of the casing in the LANL Fenton Hill EE2 well was indicated by a Dialog 64-arm caliper log run previously. The grooves were detected in two zones in the well at depths of 660 to 700 feet and at 6500 feet. This damage raised concern about the ability of the casing to survive the high pressure fracturing operations soon to be initiated. Since the Dialog caliper could only measure maximum deptn of the grooves as a function of hole deptin, additional information about width, lengtin, and orientation was required in order to predict the pressure limits of the damaged casing.

On January 15, 1982, the LANL logging truck and cable were used with the Sandia televiewer to $\log$ the two damages zones in the well. The televiewer data was used to generate both caliper and reflectivity mode logs, which showed two parallel vertical grooves in the upper damaged zone running from about 650 to 690 feet. A 15 toot section of the $\log$ of this zone is reproduced in Figure 35 . The grooves are as wide as 2.5 incines and as deep as .15 inches in places. In the lower damaged zone a five foot vertical groove was found with maximum dimensions similar to those of the grooves in the upper zone. Figure 36 shows this groove running from 6500 feet to 6505 feet.

The televiewer log clearly showed the vertical and circumferential dimensions of the damage winich when coupled with the precision caliper data of the Dialog tool, allowed LANL to properly access the damage and take the necessary action. 

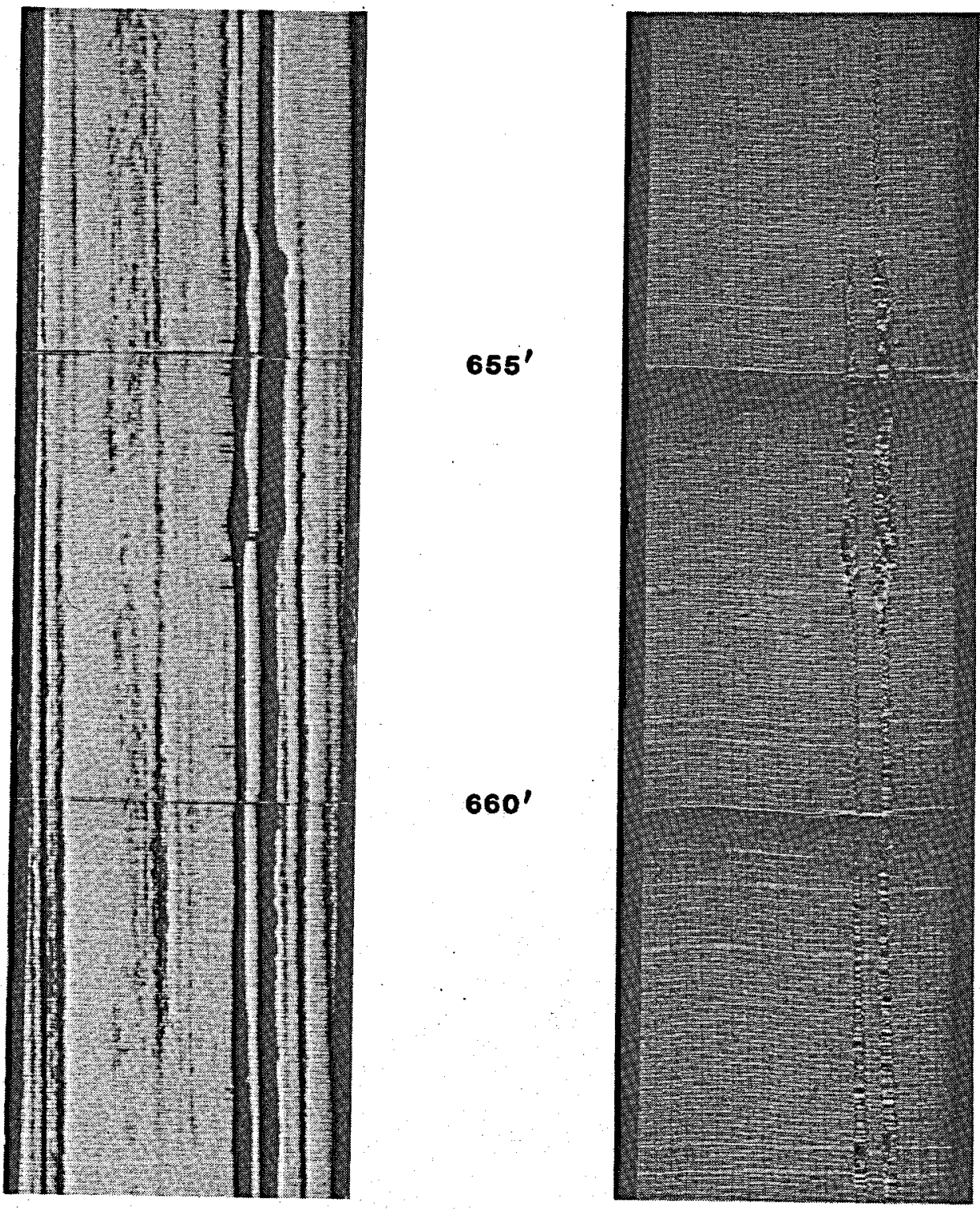

REFLECTIVITY

CALIPER

Figure 35. BHTV Log

LANL EE2 Casing 

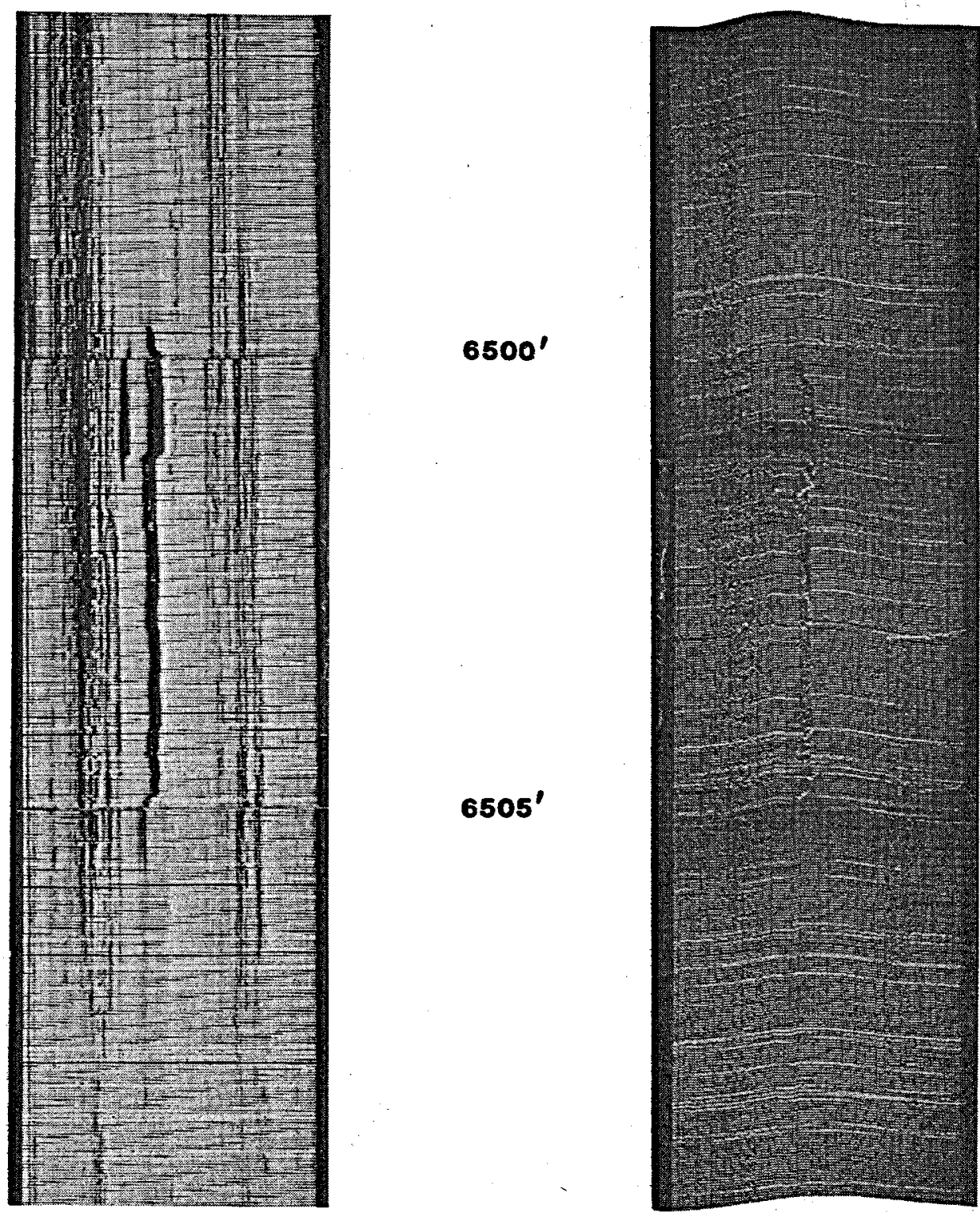

CALIPER

REFLECTIVITY

Figure 36. BHTV Log

LANL EE2 Casing 
SUMMARY AND RECOMMENDATIONS

The goals of this development program have been met, through the development and incorporation of the necessary technology and testing in the lab and in the field, to demonstrate that the acoustic borehole televiewer can be successfully used as a tool for geothermal well exploration and completion. The modified Sandia televiewer has been tested at temperatures as high as $280^{\circ} \mathrm{C}$ and pressures up to 5000 psi and has been used successfully to locate and view fractures and casing damage in geothermal wells.

Many key components and subassemblies have been developed, modified or upgraded for extended temperature operation. The troublesome slip ring assembly has been replaced by the more reliable rotating transformer assembly. The ceramic lead metaniobate transducer, which suffers from dielectric degradation at ingh temperature, has been replaced by a more stable single crystalline litnium niobate transducer. The rubber acoustic absorption material has been replaced with an alumina cement filled with tungsten particles wich not only survive the temperature and dissipates misdirected acoustic energy, but simplifies the mounting of the transducer and mechanically loads it. A satisfactory acoustic window configuration has been developed which is capable of excluding the hot and corrosive borenole fluid from the tool interior while remaining transparent to the acoustic energy. Much of the downho le circuitry has been redesigned for more efficient and reliable operation and the volume occupied by the electronics has been reduced by using printed circuit techniques. Many other changes and modjfications were made to the tool including the incorporation of inign temperature magnetic tape core material for improved flux gate magnetometer operation, mecianical changes which eliminate galling and jamming in the rotating mechanism causea by differing expansion coefficients of the metals used, and the development and incorporation of a useful method of displaying caliper mode data.

Much of the technology developed in this program is being used by the televiewer manufacturer and manufacturers of other logging instruments, to not only extend operational temperature range, but to improve overall operation and reliability. In particular, manufacturers of acoustic tools winicn must operate in 
deeper and hotter oil and gas wells are beginning to look at replacing the lead metaniobate transducers with lithium niobate and the lead titanate formulation tested. Slip ring assemblies in at least two commercial tool designs have been replaced with rotating transformers and the advantages of Teflon as an acoustically transparent, self-sealing window material are being appreciated in the logging industry.

It is recommended that new designs of high temperature televiewer logging systems be aimed at increased ease of use and ennanced data representation. The mechanical design should be a physically shorter tool that is easier to assemble, disassemble, and maintain. Since several o-ring failures have been observed during testing, it is recommended that this new design use better sealing techniques. The superior Y267 EPDM 0-ring compound, mentioned previously, should be used in place of Viton.

It is apparent in observing typical televiewer data that much information is lost due to the limited dynamic range of the system. It is recommended that some attempt be made to extend the dynamic range by using eitiner a nonlinear compression amplifier, or a pulse-to-pulse downinole AGC (automatic gain control) with AGC voltage monitoring, or some other method. It is also recommended that some improvements be made to overcome the severe acoustic attenuation of the signal imposed by neavy drilling muds. This has not been of concern in this program because most geothermal wells are water filled. However, there are some geothermal applications where a televiewer with a nigner loop gain (i.e., increased receiver sensitivity, increased pulsing voltage, and lower acoustic frequency) would be useful for viewing tinrougin neavy drilling mud.

The field operation procedures for using the televiewer could be greatly simplified it the operator could be relieved of the job of exposing, cutting, and taping togetiner the Polaroid pictures to form the finisined record. It is recommended that the surface panel be intertaced to a hard copy recorder capable of recording a log on a continuous sneet of paper. The operator would be more easily and quickly able to evaluate and compensate for changing borenole conditions if other methods of display were available to nim. The time delay associated with 
the exposure and developing of the hard copy media could be eliminated by converting the slow scan ( 3 sweeps/sec) televiewer output to a raster scan (television type) display using some form of digital storage. Also, a polar display using the caliper data to show the borehole surface in cross-section would be a useful aid to data interpretation. 


\section{REFERENCES}

1. J. Zemanek, "The Borehole Televiewer--A New Logging Concept for Fracture Location and Other Types of Borenole Inspection," Journal of Petroleum Technology, June 1969.

2. R. Wiley, "Borenole Televiewer-Revisited," SPWLA Twenty-First Annual Logging Symposium, July 1980, pp. HHl-16.

3. A. H. Jagelar, "New well Logging Too is Improve Formation Evaluation," World 0i], Marci 1980, pp. 89-103.

4. R. A. Broding, "Volumetric Scanning Well Logging," SPWLA Twenty-Second Annual Logging Symposium, June 1981, pp. Bl-17.

5. W. Scott Keys, "Borehole Geophysics In Igneous and Metamorphic Rocks," SPWLA Twentietn Annual Logging Symposium, June 1979, pp. 001-26.

6. W. Scott Keys, "The Application of the Acoustic Televiewer to the Characterization of Hydraulic Fractures in Geothermal Wells, "Proceedings of the Geothermal Reservoir well Stimulation Symposium, February 1980, pp. 176-202.

7. J. Zemanek, "Beam Benavior within the Nearfield of a Vibrating Piston," Journal of the Acoustical Society of America, vo 1. 49, no. 1, 1971.

8. H. Jaffe, "Piezoelectric Transducer Materials," Proceedings of the IEEE, vol. 53, no. 10, Oct. 1965, pp. 1372-1386.

9. A. W. Warner, "Determination of Elastic and Piezoelectric Constants for Crystals in Class $(3 \mathrm{~m}), "$ Journal of Acoustical Society of America, vo 1. 42, no. $6,1967$.

10. J. W. Wonn, "Development of an Acoustic Sensor for a Geothermal Borenole Televiewer;" Marcin 1979, Westinghouse Report under Contract OE-AC04-76-ET15391.

11. A. Hess, United States Geological Survey, Denver Federal Center, Denver, Colorado, private communication.

12. C. A. Arnold, "brine Resistance of window Materials for a Borenole Televiewer Tool," Sandia Report No. SAND81-2174, February 1982, available througin NTIS.

13. W. A. Geyger, Nonl inear-Magnetic Control Devices, McGraw-Hill, 1964.

14. W. A. Geyger, "Flux Gate Magnetometer Uses Toroidal Core," Electronics, June 1962 .

15. W. A. Geyger, "Selt balancing Flux Gate Magnetometer," AIEE Transactions, Vo 1. 77, pt. 1, page 213, May 1958.

16. D. Garner, "A Magnetic Heading Keference for Electro-Fluidic Auto Pilot," EAA15611, MS494, NASA Langley.

17. M. Nagao, G. Sawa, and M. Ieda, "Vielectric Breakdown of Polymide Film in Hign-Temperature Region," Electrical Engineering in Japan, vol. 97, no. 3, 1977

18. K. K. Pandy, "Final Keport on Higin Temperature Magnetic Materials Research," Texas A\&M Researci Foundation, Project No. 3842, SNL Project №. $3-0321,1980$. 
19. L. B. Thompson, "Thermal Protection-Vacuum Insulated Flasks," High Temperature Electronics and Instrumentation Proceedings, Sandia Report No. SAND80-0834, Dec. 1979.

20. R. Blanton, Vacuum Barrier Corp., private communication, Oct. 1981.

21. C. Arnold, K. Bieg, and J. Coquat, "Degradation of Elastomers in Geothermal Environments," American Society for Testing and Materials, Special Technical Publication 717, pp. 155-163, 1981.

22. A. Hess, United States Geological Survey, Denver Federal Center, Denver, Colorado, private communication.

23. A. Hirasuna, "High Temperature Y267 EPDM Elastomer--Field and Laboratory Experiences, August 1981," Geothermal Resources Council Bulletin, vol. 11, no. 3, Marci 1982. 
DISTRIBUTION :

TID-4500-R66-UC-66C (474)

Tom Anderson

Venture Innovations

P.0. Box 35845

Houston, Texas 77035

Ed Bingman

Shell Oil Company

Two She11 Plaza

P.0. Box 2099

Houston, Texas 77001

Larry Diamond

Dyna-Dri11

P.0. Box C-19576

Irvine, California 92713

Tom Turner

Phillips Petroleum Company

Geotherma1 Operations

655 East 4500 South

Sa1t Lake City, Utah 84107

Jim Kingsolver

Geotherma1 Operations

Smith Tool

P.0. Box C-19511

Irvine, California 92713

John C. Row1ey

Los Alamos National Labs

Mail Stop 570

Los Alamos, New Mexico 87545

Ed Martin

Superior 0i1

Eastern Division

P.0. Box 51108 OCS

Lafayette, Louisiana 70505

B. J. Livesay

129 Liverpoo1

Cardiff, California 92007

Ben Bradford

Dowe 11

P.0. Box 2710

Tulsa, Oklahoma 74102

Gerald Summers

Simplec Manufacturing Co., Inc. 4230 Shilling Way

Dallas, Texas 75237
Gene Polk

NL Baroid

6400 Uptown B1vd., N.E., $365 \mathrm{~W}$

Albuquerque, New Mexico 87110

James W. Langford

Security Division

Dresser Industries, Inc.

P.0. Box 24647

Da11as, Texas 75224

John E. Fontenot

NL, MWD

P.O. Box 60087

Houston, Texas 77205

De1 E. Pyle

Union Geothermal Division

Union 0il Co. of Ca1ifornia

Union Oil Center

Los Angeles, California 90017

William D. Rumbaugh

Research \& Development

otis

P.0. Box 34380

Dallas, Texas 75234

Dwight Smith

Hal1iburton

Drawer 1431

Duncan, Oklahoma 73533

Tom Warren

Amoco Production Company

Research Center

P.0. Box 591

Tulsa; Oklahoma 74102

H. E. Ma11ory

P.0. Box 54696

Tulsa, Oklahoma 74155

Bert R. Dennis

Los Alamos National Labs

Mail Stop 980

Los Alamos, New Mexico 87545

A. H. Jageler

Amoco Production Company

P.0. Box 591

Tu1sa, Oklahoma 74102 
DISTRIBUTION cont.

W. Scott Keys

U.S. Department of Interior

Geological Survey

P.0. Box 25046

Denver Federa1 Center, B1dg. 25

Denver, Colorado 80225

\section{J. Zemanek}

Mobil RED

P. O. Box 900

Da11as, Texas 75221

Dr. Melvin Friedman

Professor of Geology

Center for Tectonophysics

and Dept. of Geology

Texas AGM University

College Station, Texas 77843
R. A. Broding

Amoco Production Research

P.0. Box 591

Tulsa, Oklahoma 74102

Tony Veneruso

Gearhart Industries

P.0. Box 1936

Ft. Worth, Texas 76101

U.S. Department of Energy

(4)

Geothermal Hydropower

Technologies Division

Forrestal B1dg., CE 324

1000 Independence Ave. S.W.

Washington, D.C. 20585

Attn: J. Bresee

D. Clements

R. Toms

D. A11en

W. P. Grace, DOE/ALO

Nuclear \& Geosciences Division

0320 R. E. Spalding

0322 P. B. Herrington

0322 F. E. Heard (10)

3141 L. J. Erickson (5)

3151 W. L. Garner

6000 E. H. Beckner

6230 W. D. Weart

6240 R. K. Traeger

6241 J. R. Kelsey

6246 B. Granoff

6247 P. J. Hommert

6250 V. L. Dugan

6260 R. W. Lynch

8214 M. A. Pound 